Eduardo Umaras

\title{
Tolerâncias Dimensionais em Conjuntos Mecânicos: Estudo e Proposta para Otimização
}

\author{
Dissertação apresentada à Escola Poli- \\ técnica da Universidade de São Paulo \\ para obtenção do Título de Mestre em \\ Engenharia.
}


Eduardo Umaras

\title{
Tolerâncias Dimensionais em Conjuntos Mecânicos: Estudo e Proposta para Otimização
}

\author{
Dissertação apresentada à Escola Poli- \\ técnica da Universidade de São Paulo \\ para obtenção do Título de Mestre em \\ Engenharia. \\ Área de concentração: \\ Engenharia Mecânica \\ Orientador: \\ Prof. Dr. Marcos de Sales Guerra \\ Tsuzuki
}


Este exemplar foi revisado e alterado em relação à versão original, sob responsabilidade única do autor e com a anuência de seu orientador.

São Paulo, 11 de Setembro de 2010.

Assinatura do autor.

Assinatura do orientador.

FICHA CATALOGRÁFICA

Umaras, Eduardo

Tolerâncias dimensionais em conjuntos mecânicos: estudo e proposta para otimização / E. Umaras. -- ed.rev. -- São Paulo, 2010.

p.

Dissertação (Mestrado) - Escola Politécnica da Universidade de São Paulo. Departamento de Engenharia Mecatrônica e de Sistemas Mecânicos.

1. Tolerância e ajustagem de peças 2 . Projeto mecânico 3. Algoritmo (Otimização) 4. Custo Industrial 5. Qualidade do produto I. Universidade de São Paulo. Escola Politécnica. Departamento de Engenharia Mecatrônica e de Sistemas Mecânicos II. t. 
à memória

de meus pais e de meu irmão 


\section{Agradecimentos}

Agradeço

à Regina, minha esposa, pelo apoio e compreensão,

a Marcos de Sales Guerra Tsuzuki, por toda a dedicação. 


\section{Resumo}

Este trabalho aborda os conceitos necessários para o estudo de tolerâncias dimensionais de um conjunto mecânico e propõe um método eficaz para a especificação de tolerâncias na fase de detalhamento do projeto de um produto, através de um algoritmo de otimização baseado em custos de produção. Conceitos do custo da perda de qualidade desenvolvidos por Genichi Taguchi são também aplicados para a especificação de restrições funcionais, que visam garantir um determinado nível de qualidade em função de valores especificados para critérios funcionais. Comentários e comparações com outros trabalhos de otimização de tolerâncias dimensionais são também realizados, através dos quais podem ser observadas características específicas no método proposto. Um exemplo de aplicação é apresentado através do estudo de caso baseado em um projeto de sistema de transmissão de potência por correias a equipamentos periféricos de um motor de combustão interna. Os resultados da aplicação do algoritmo de otimização são comparados aos de métodos convencionais de síntese de tolerâncias, mostrando sua eficácia.

Palavras-chave: Tolerância dimensional. Otimização de tolerâncias. 


\section{Abstract}

This work approaches the concepts needed to the study of dimensional tolerances of a mechanical assembly and proposes an effective method for specifying tolerances in the detailing phase of product design, by means of an optimization algorithm based on manufacturing costs. Concepts of quality loss developed by Genichi Taguchi are also applied for specifying functional constraints, which aim to assure an adequate quality level regarding specified values of functional criteria. Comments and comparisons with other dimensional tolerances optimization works are also made, through which specific features of the proposed method can be observed. An application example of the method is presented through a case study based on a belt power transmission system to ancillary equipment of an internal combustion engine. Results of application of the optimization algorithm are compared with the ones of conventional tolerance synthesis methods, showing their effectiveness.

Keywords: Dimensional tolerances. Optimization of tolerances. 


\title{
Conteúdo
}

\section{Lista de Figuras}

\author{
Lista de Tabelas
}

\section{Lista de Símbolos}

$\begin{array}{llr}1 & \text { Introdução } & 18\end{array}$

2 Conceitos básicos $\quad 21$

2.1 Tolerância dimensional . . . . . . . . . . . . . . . . . . . . . . 21

2.2 Encadeamento de tolerâncias dimensionais . . . . . . . . . . . . 23

2.3 Restrições dimensionais de um conjunto de componentes . . . . . 24

2.4 Tolerâncias dimensionais no projeto do produto . . . . . . . . 25

2.5 Especificação de tolerâncias . . . . . . . . . . . . . . . . 28

2.6 O conceito de intercambiabilidade . . . . . . . . . . . . . 30

2.6.1 Intercambiabilidade total . . . . . . . . . . . . . 31

2.6.2 Intercambiabilidade limitada . . . . . . . . . . . . . . 32

2.6 .3 Usinagem para montar . . . . . . . . . . . . . . . . 34

3 Métodos para análise e síntese de tolerâncias dimensionais $\quad 35$

3.1 Análise e síntese de tolerâncias . . . . . . . . . . . . . . 35

3.2 Considerações sobre características das tolerâncias dos componentes 36

3.3 Análise de tolerâncias dimensionais . . . . . . . . . . . . . . . 37

3.3.1 Método para o pior caso . . . . . . . . . . . . . 38

3.3.2 Método da raiz da soma dos quadrados . . . . . . . . . . . 39

3.3.3 Método dos momentos . . . . . . . . . . . . . . . . 40 
3.3.4 Método de monte carlo . . . . . . . . . . . . . . . . 43

3.4 Síntese de tolerâncias . . . . . . . . . . . . . . . . . . . . 46

3.4.1 Alocação por tolerâncias iguais . . . . . . . . . . . . 47

3.4.2 Alocação por fator de proporcionalidade . . . . . . . . . 47

3.4 .3 Alocação por fator de precisão . . . . . . . . . . . . . . 48

3.4.4 Alocação por fatores de peso . . . . . . . . . . . . . . . . . 49

3.4.5 Outros tipos de alocação . . . . . . . . . . . . . 50

3.4.6 Alocação por otimização de custos de fabricação . . . . . . 51

3.4.7 Métodos para otimização simultânea de custos de fabricação e custos da não qualidade . . . . . . . . . . . . . 56

3.5 Considerações sobre desvios da média das distribuições . . . . . . 58

4 Considerações sobre custos de fabricação $\quad 60$

4.1 Relações tolerância-custo . . . . . . . . . . . . . . . . 60

4.2 Algoritmo para o cálculo do custo relativo da tolerância . . . . . . 65

5 Custo da não-qualidade $\quad 69$

5.1 A função perda de qualidade (Loss function $)$. . . . . . . . . . . 70

5.2 O fator de segurança econômico . . . . . . . . . . . . . . . 72

5.3 Relação entre a função perda de qualidade e o fator de segurança econômico . . . . . . . . . . . . . . . . . . . 73

6 Proposta para um novo método de síntese de tolerâncias $\quad 76$

6.1 Considerações para o desenvolvimento do método . . . . . . . 76

6.2 Requisitos do sistema . . . . . . . . . . . . . . . 78

6.3 Algoritmo para a otimização . . . . . . . . . . . . . . . . . 79

$\begin{array}{lll}7 & \text { Exemplo de aplicação } & 83\end{array}$

7.1 Descrição do sistema . . . . . . . . . . . . . . . . . 83

7.2 Cálculo das restrições funcionais . . . . . . . . . . . . . . . 84

7.2 .1 Limites funcionais . . . . . . . . . . . . . . . . 84 
7.2 .2 O fator de segurança econômico . . . . . . . . . . 85

7.2.3 Cálculo das restrições funcionais . . . . . . . . . . . . . 87

7.3 Considerações sobre restrições de projeto . . . . . . . . . . . 87

7.4 Racionalização de projeto . . . . . . . . . . . . . 88

7.4.1 Referências de cotação . . . . . . . . . . . . . . 88

7.4 .2 Integração de componentes . . . . . . . . . . . . . . 88

7.5 Desenvolvimento do programa de otimização . . . . . . . . . . . . 91

$\begin{array}{llr}8 & \text { Resultados } & 92\end{array}$

8.1 Processo de análise de tolerâncias . . . . . . . . . . . . . . . . 92

8.2 Processo de síntese de tolerâncias . . . . . . . . . . . . . . . . . 94

8.3 Discussões . . . . . . . . . . . . . . . . . . . . . . . . . . . 94

$\begin{array}{llr}9 & \text { Conclusões } & 99\end{array}$

$\begin{array}{ll}\text { Referências } & 101\end{array}$

Apêndice A - Conceitos de estatística aplicados a processos de fa$\begin{array}{ll}\text { bricação } & 107\end{array}$

A.1 O conceito de variação . . . . . . . . . . . . . . . . 107

A.2 Variáveis aleatórias . . . . . . . . . . . . . . . . 108

A.3 Gráficos de controle . . . . . . . . . . . . . . . . . . . . . . 110

A.4 O comportamento estatístico de um processo . . . . . . . . . . 111

A.5 Considerações sobre amostragem nos processos de produção . . 115

A.5.1 Tipos de amostragem probabilística . . . . . . . . . 115

A.5.2 Considerações especiais na amostragem de processos de produção . . . . . . . . . . . . . . . . . . . . 117

A.6 Medidas descritivas de uma distribuição . . . . . . . . . . . 118

A.6.1 Medidas de posição . . . . . . . . . . . . . . . . . . . . . . 119

A.6.2 Medidas de dispersão . . . . . . . . . . . . . . . . . . . . . 121

A.6.3 Momentos de uma distribuição . . . . . . . . . . . . . . . 124 
A.6.4 Medidas de assimetria . . . . . . . . . . . . . 125

A.6.5 Medidas de achatamento . . . . . . . . . . . 125

A.7 Índice de capacidade do processo f . . . . . . . . . . . . . . 126

A.8 Tipos de distribuições de frequências . . . . . . . . . . . . . . . . 128

A.8.1 Distribuição retangular ou uniforme . . . . . . . . . . . . . 128

A.8.2 Distribuição normal . . . . . . . . . . . . . . . . . . . . . . 128

A.8.3 Distribuição normal padronizada . . . . . . . . . . . . . . 129

A.8.4 Distribuição t de student . . . . . . . . . . . . . . . . 130

A.8.5 Outras distribuições . . . . . . . . . . . . . . . . . . 131

Apêndice B - Exemplo prático de aplicação do método de monte carlo

Apêndice C - Representações geométrica e vetorial

C.1 Representação geométrica . . . . . . . . . . . . . . . 135

C.2 Representação vetorial . . . . . . . . . . . . . . . . . . . . . 138

Apêndice D - Análise de modos e efeitos de falha

Apêndice E - Memorial de cálculo para alocação não otimizada de tolerâncias

E.1 Alocação por tolerâncias iguais . . . . . . . . . . . . . . 147

E.2 Alocação por fator de proporcionalidade . . . . . . . . . . . 148

E.2.1 Alocação por fator de precisão . . . . . . . . . . . . . . . 149

E.3 Alocação por fatores de peso . . . . . . . . . . . . . . . . . . 150 


\section{Lista de Figuras}

2.1 Elementos básicos de tolerância dimensional. Fonte: Bjorke ${ }^{[1]} \ldots 22$

2.2 Diagramas de encadeamento de tolerâncias. Fonte: Bjorke ${ }^{[1]}$. . . . . 25

2.3 Conjunto mecânico identificando uma restrição funcional. Fonte: Bjorke ${ }^{[1]} .26$

2.4 Relação entre tolerância e rugosidade superficial. Fonte: Trucks ${ }^{[2]}$. . . 30

3.1 Ilustração do conceito de análise e síntese de tolerâncias. Fonte: Chase ${ }^{[3]}$. 36

3.2 Esquema do processo de análise de tolerâncias dimensionais. . . . . . . 37

3.3 Esquema do método de simulação de Monte Carlo. Fonte: Hahn e

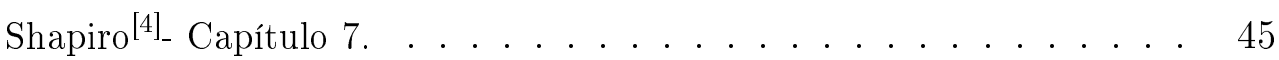

3.4 Representação gráfica da soma dos custos de fabricação $C(t)$ e da não qualidade $L(t)$. Fonte: Choi et al. ${ }^{[5]}$. . . . . . . . . . . . . . . 57

4.1 Coeficientes de tolerância e de acabamento superficial para processos de usinagem. Fonte: Swift ${ }^{[6]}$. . . . . . . . . . . . . . . . 62

4.2 Custos relativos em função da tolerância de usinagem. Fonte: Trucks ${ }^{[2]}$. 63

4.3 Custo de fabricação e seus componentes em função da tolerância para um processo isolado. Fonte: Bjorke ${ }^{[1]} \ldots \ldots$. . . . . . . . . 64

4.4 Comparação de modelos tolerância x custo com dados experimentais. Fonte: Chase e Greenwood ${ }^{[7]} \ldots$. . . . . . . . . . . . . . 65

4.5 Gráfico Custo x Tolerância. . . . . . . . . . . . . . . . 67

4.6 Algoritmo para cálculo da função custo relativo. . . . . . . . . . . . . 68

5.1 Relação entre perda de qualidade e desvio a partir de valor objetivo $(m)$. Fonte: Taguchi et al. ${ }^{[8]} \ldots \ldots \ldots$. . . . . . . . 71

5.2 Relação entre perda de qualidade e desvio a partir de valor objetivo $(m)$ para condição assimétrica. Fonte: Taguchi et al ${ }^{[8]}$. . . . . . . . . . 72

6.1 Encadeamento elementar de componentes em um conjunto mecânico. . $\quad 77$

6.2 Algoritmo de otimização. . . . . . . . . . . . . . . . . . . . . . . . 82 
7.1 Vista frontal do sistema de transmissão de potência por correia de um motor de combustão interna. . . . . . . . . . . . . . . . . . . . 84

7.2 Vista lateral do sistema estudado. . . . . . . . . . . . . . . . 85

7.3 Relação entre ângulo, deslocamento axial das polias e comprimento em balanço da correia. . . . . . . . . . . . . . . . . . 86

7.4 Configuração definitiva para o sistema. . . . . . . . . . . . . . . . 89

7.5 Representação esquemática dos encadeamentos inter-dependentes: Encadeamento principal: itens 1-2-3-4-5-6-7-8-9-10; Encadeamento secundário: itens 8-9-10-11-12-13. . . . . . . . . . . . . . . . . 89

8.1 Variação do custo relativo entre alternativas de especificação que atendam às restrições funcionais do sistema. . . . . . . . . . . . . . . . . 97

A.1 Gráfico de controle. Fonte: Kume ${ }^{[9]}$. . . . . . . . . . . . . . . . . . 110

A.2 Processo fora de controle por pontos fora da especificação. Fonte: Kume ${ }^{[9]} .111$

A.3 Folha de verificação de processo. Fonte: Kume ${ }^{[9]}$ - Capítulo 2. . . . . . 111

A.4 Histograma e polígono de frequências gerados a partir dos dados da Tabela 4.2. Fonte: Costa Neto ${ }^{[10]} \ldots$. . . . . . . . . . . . . . . . . . 114

A.5 Polígono de freqüências relativas acumuladas gerados a partir dos dados da Tabela 4.2. Fonte: Costa Neto[10] . . . . . . . . . . . . . . . . . . 114

A.6 Gráfico de medições individuais mostrando como o processo de usinagem é afetado por ajustes no sistema máquina-fixação-ferramenta-peça. Fonte: Balakshin ${ }^{[11]} \ldots$. . . . . . . . . . . . . . . . . 117

A.7 Relação entre Média (Me), Mediana (Md) e Moda (Mo) para três funções densidade e probabilidade. Fonte: Hahn e Shapiro ${ }^{[4]}$. . . . . . . . 121

A.8 Área sob a curva normal em função do desvio padrão. Fonte Kume ${ }^{[9]}$. 124

A.9 Distribuições platicúrtica, mesocúrtica e leptocúrtica. Fonte: Costa Neto $^{[10]} \ldots \ldots \ldots \ldots \ldots \ldots$

A.10 Distribuições para $C p=1$ e $C p=2$. Fonte: Creveling ${ }^{[12]} \ldots \ldots$. . . 127 A.11 Distribuição retangular. Fonte: Haugen ${ }^{[13]} \ldots$. . . . . . . . . . . . . . 128

A.12 Distribuição normal padronizada. Fonte: Costa Neto ${ }^{[10]}$. . . . . . . . 130

A.13 Distribuição t de student. Fonte: Creveling ${ }^{[12]} \ldots$. . . . . . . . . . . 130 
B.1 Distribuições de dimensões de três componentes montados em conjunto sequencial. Fonte: Spotts ${ }^{[14]} \ldots$. . . . . . . . . . . . . . 132

B.2 Determinação de dimensões de 50 conjuntos de três componentes pelo Método de Monte Carlo. Fonte: Spotts ${ }^{[14]}$. . . . . . . . . . . . . . 134

B.3 Determinação da distribuição de frequências do conjunto: a) Classes de frequência da soma dos componentes; b) Distribuição das dimensões dos 50 conjuntos conforme item (a); c) Distribuição a longo prazo para o conjunto. Fonte: Spotts ${ }^{[14]} \ldots$. . . . . . . . . . . . . . . . 134

C.1 Equivalência entre representação geométrica e por coordenadas ortogonais. Fonte: Foster ${ }^{[15]}$. . . . . . . . . . . . . . . . . . 136

C.2 Tolerância de planeza. . . . . . . . . . . . . . . . . . 137

C.3 Símbolos da representação geométrica de tolerâncias. Fonte: NBR $6049: 1997^{[16]} \ldots \ldots \ldots \ldots \ldots \ldots$

C.4 Representação dos três vetores básicos e de suas tolerâncias na representação vetorial. Fonte: Wirtz ${ }^{[17]}$. . . . . . . . . . . . . . . . . 139

C.5 Comparação da representação geométrica de tolerâncias de paralelismo e planeza especificadas por norma e caso real por representação vetorial. Fonte: Martinsen ${ }^{[18]}$. . . . . . . . . . . . . . . . . . . . . . . 140

C.6 Avaliação da retitude de uma superfície cilíndrica. Fonte: ASME ${ }^{[19]}$. . 141 


\section{Lista de Tabelas}

2.1 Campos de tolerância usuais para processos de usinagem. Fonte: ISO $286-1^{[20]} \ldots \ldots \ldots \ldots \ldots \ldots \ldots \ldots$

2.2 Classes de tolerâncias IT em função de processos de fabricação convencionais . Fonte: ASME B4.2 ${ }^{[21]}$. . . . . . . . . . . . . . . . 29

4.1 Propostas de modelos custo-tolerância. Fonte: Chase et al. ${ }^{[7]}$. . . . 64

4.2 Valores de tolerância calculados por interpolação linear a partir de gráficos custo relativo-tolerância de três fontes bibliográficas . . . . . . . 67

7.1 Identificação dos componentes do sistema conforme Figura 7.2 . . . . . 86

7.2 Identificação dos componentes do sistema e respectivas médias de distribuições conforme Figura 7.4 . . . . . . . . . . . . . . . . . . . . 90

8.1 Valores opcionais para especificação - os valores das classes IT (ISO 2861) referem-se às respectivas semi-tolerâncias; valores em itálico referemse a itens com tolerâncias pré-determinadas . . . . . . . . . . .

8.2 Resultados do processo de síntese de tolerâncias: Otimiz. Classe IT14= Otimização relativa à Classe IT14; Esp.: Especificação adicional; Otimiz. Esp.= Otimização relativa à especificação adicional; Tol. Iguais= Alocação por tolerâncias iguais; Fat. Prop.= Alocação por fator de proporcionalidade; Fat. Prec.= Alocação por fator de precisão; Fat. Peso= Alocação proporcional ao fator de peso . . . . . . . . . . . . . . . 95

A.1 Valores de diâmetro de uma peça produzidas por processo de torneamento. Fonte: Costa Neto[10] . . . . . . . . . . . . . . . . 112

A.2 Distribuição de freqüências e freqüências acumuladas a partir dos dados da Tabela A.1. Fonte: Costa Neto ${ }^{[10]}$. . . . . . . . . . . . . . . 113 


\section{Lista de Símbolos}

c Constante genérica

$C(t) \quad$ Custo relativo da tolerância $t$

$C r(t) \quad$ Custo real da tolerância $t$

$C T \quad$ Custo total

$c v(x) \quad$ Coeficiente de variação de $x$

$C p, C p k$ índices de capacidade de processo

$d_{i} \quad$ Dimensão do componente $i$

$D X \quad$ Dimensão do conjunto $X$

$E(x) \quad$ Expectância ou média de $x$

$f \quad$ Frequência de ocorrência; função genérica

F $\quad$ Frequência acumulada

$k \quad$ Número de classes

LIE $\quad$ Limite inferior de especificação

$L S E \quad$ Limite superior de especificação

$m_{i} \quad$ Momento de ordem $i$ de uma distribuição

$m s_{i} \quad$ Fator de correção para desvio estimado da média

Md Mediana de uma distribuição

Mo Moda de uma distribuição

$n \quad$ Número de elementos

nd Número de componentes com tolerâncias determináveis

np Número de componentes com tolerâncias pré-determinadas 
$p \quad$ Probabilidade de ocorrência

$P \quad$ Probabilidade de ocorrência acumulada

$R \quad$ Amplitude de variação

$R f \quad$ Restrição funcional

$s(x) \quad$ Variância da amostra $x$

$t_{i} \quad$ Tolerância do componente $i$

$t p_{i} \quad$ Tolerância pré-determinada do componente $i$

$t d_{j} \quad$ Tolerância determinável do componente $j$

T Tolerância de conjunto

$T X \quad$ Tolerância do encadeamento $X$

$\operatorname{Var}(x) \quad$ Variância de $x$

$x \quad$ Variável genérica

$\mu(x) \quad$ Média de $x$

$\mu_{k}(x) \quad$ Momento de ordem $k$ de $x$

$\phi \quad$ Fator de segurança econômico de Taguchi

$\lambda \quad$ Multiplicador de Lagrange

$\Delta_{i} \quad$ Tolerância do componente $i$ (Taguchi)

$\triangle_{0} \quad$ Limite funcional da especificação (Taguchi)

$\beta_{3} \quad$ Coeficiente de assimetria de uma distribuição

$\beta_{4} \quad$ Coeficiente de curtose de uma distribuição

$\sigma^{2}(x) \quad$ Variância de $x$

$\sigma(x) \quad$ Desvio padrão de $x$ 


\section{Introdução}

O conceito primitivo do estudo de tolerâncias dimensionais decorre da observação de que é impossível a fabricação de qualquer peça nas suas dimensões exatas, ou seja, a característica de variação é inerente a qualquer processo produtivo.

Em princípio, a especificação de tolerâncias dimensionais em componentes mecânicos somente faz sentido quando estes são montados junto a outros, formando conjuntos. Conjuntos mecânicos, por sua vez, estão sujeitos a restrições, tais como as dimensionais de montagem com outros conjuntos, funcionais como alinhamentos radiais e axiais, requisitos de lubrificação e vedação, de fluxo de fluidos e transmissão de calor e até de requisitos visuais e estéticos como, por exemplo, os do preciso alinhamento entre partes de carrocerias dos veículos modernos estão sujeitos a elas. Observa-se também que as tolerâncias dimensionais apresentam significativa influência no custo de produção de componentes. Assim, existe um problema recorrente na especificação das tolerâncias dimensionais, que é o do equilíbrio entre as necessidades funcionais do projeto, a viabilidade de fabricação e o custo envolvido:

\section{$\begin{array}{lllll}\text { desempenho } & \mathrm{x} & \text { viabilidade do processo } & \mathrm{x} & \text { custo }\end{array}$}

A especificação de tolerâncias dimensionais originou-se de requisitos de funcionalidade básica do projeto, independentemente da quantidade de itens fabricados. Este conceito permaneceu até o século XIX, quando o contexto da produção industrial gerou a necessidade do enfoque de projeto voltado à intercambiabilidade para reposição de peças e à produção em massa ${ }^{[12]}$. O estudo metódico das tolerâncias dimensionais teve início no período pós Segunda Guerra Mundial. O advento da corrida espacial, que exigiu maior desempenho e maior precisão dimensional nos projetos, também trouxe grande impulso no estudo de tolerâncias a partir da década de 1960 com a publicação das primeiras obras importantes sobre o assunto. Este período coincide com o início de transformações na Indústria Automotiva, com a exigência de maior robustez e qualidade em seus produtos. Atualmente, a especificação de tolerâncias dimensionais se apresenta como fator 
fundamental para o desempenho funcional e para a competitividade econômica de produtos em diversos ramos de atividade. O fator custo evidenciou-se, pois os altos volumes de produção exigidos pela demanda do mercado, cujo panorama alterou-se radicalmente nos últimos cinquenta anos, fazem com que diferenciais mínimos de custo em unidades produzidas signifiquem grandes somas que podem afetar o retorno financeiro do produto.

A evolução do mercado fez também, nas últimas décadas, com que o conceito de custo fosse ampliado além da área de produção, atingindo a de pós venda: os problemas funcionais originados por inadequação de tolerâncias dimensionais do conjunto mecânico podem gerar custos ao usuário devido a problemas de qualidade. Estes custos podem variar desde perdas devidas à indisponibilidade do produto durante o período de reparo a perdas maiores envolvendo, inclusive, riscos de segurança. Como pode então ser observado, o problema da especificação de tolerâncias dimensionais, inicialmente restrito a questões meramente funcionais, tornou-se amplo e exige uma abordagem sistêmica para que possa ser adequadamente considerado.

A motivação para a elaboração deste trabalho foi a constatação pelo autor, durante sua atividade profissional, de que o problema da especificação de tolerâncias dimensionais não é adequadamente tratado na fase de projeto do produto pela maioria das empresas, inexistindo um sistema específico que o considere. Este fato pode ser atribuído à falta de conhecimento do assunto pelos responsáveis pela atividade de projeto e também à complexidade das propostas existentes na literatura, que as inviabiliza para uma efetiva aplicação prática. Assim, o objetivo geral do trabalho é o de apresentar um estudo que considere os principais fatores que afetam a especificação de tolerâncias dimensionais de conjuntos mecânicos. O objetivo específico é o de apresentar um método de otimização de tolerâncias dimensionais em função dos custos de produção dos componentes, com a devida consideração aos conceitos atuais de qualidade e que possa ser implementado com menor dificuldade na fase projeto do produto.

Devido à abrangência do assunto, este é delimitado pela atividade de projeto e utilização do conceito de intercambiabilidade total. Para a obtenção do resultado objetivado, o trabalho é organizado na seguinte sequência:

- Apresentação de conceitos básicos necessários ao estudo de tolerâncias dimensionais;

- Apresentação dos métodos usuais para análise e síntese de tolerâncias;

- Considerações sobre custos de fabricação e proposição de uma rotina de 
cálculo de uma função custo, utilizada posteriormente no processo de otimização;

- Considerações sobre custos da não qualidade;

- Proposta para um método de síntese otimizada de tolerâncias;

- Aplicação do método proposto em um estudo de caso;

- Apresentação e discussão dos resultados;

- Conclusões do trabalho

Conceitos que podem servir de suporte ao texto, assim como o detalhamento de conceitos específicos utilizados no texto são abordados através dos apêndices. 


\section{Conceitos básicos}

A especificação de tolerâncias dimensionais e de forma somente tem significado e importância quando as características toleradas de um elemento mecânico apresentam contato ou outro tipo de interação com outras características de elementos mecânicos correspondentes de sua vizinhança. Por exemplo, a tolerância de um diâmetro de um eixo somente será importante quando este componente for montado em um alojamento em condição de ajuste adequada à função requerida para o conjunto. O conceito de tolerância, de modo geral, está relacionado a desvios no valor nominal de uma grandeza física e esta variação deve ser proporcionalmente pequena em relação a este valor. Bjorke ${ }^{[1]}$ - Capítulo 2 - define: " a tecnologia de tolerâncias objetiva o estudo de pequenos desvios em variáveis ". Para processos de fabricação convencionais, o valor das tolerâncias varia em relação direta com os valores nominais das respectivas grandezas, ou seja, quanto maior for o valor de uma dimensão, maior será o valor da tolerância correspondente. A preocupação com a especificação de tolerâncias dimensionais apropriadas no projeto de elementos mecânicos está sendo reconhecida pela indústria como fator chave nos esforços para o aumento da produtividade. Pequenos esforços nesta área podem significar reduções de custo significativas com pequeno investimento de capital ${ }^{[7]}$. Assim, o tratamento adequado do problema, desde o início do projeto, torna-se fundamental para a obtenção de resultados que afetam diretamente a competitividade do produto. Neste capítulo são apresentados alguns conceitos fundamentais para estudo do assunto, que serão referidos no decorrer do trabalho.

\subsection{Tolerância dimensional}

O conceito básico de tolerância dimensional pode ser entendido como a variação admitida, no projeto de um componente, para uma dimensão. Esta variação é intrínseca e resultante dos processos de fabricação planejados para cada caso.

Apesar do conceito ser único, tipos diferentes de representação são utilizados na especificação de tolerâncias dimensionais em desenhos, dependendo de requisitos 
específicos de cada projeto. Um mesmo desenho pode, inclusive, considerar tipos diferentes de representação.

A representação de tolerâncias por coordenadas cartesianas é a forma primitiva e também mais simples. Outras formas de representação, a geométrica e a vetorial são descritas no Apêndice C. Na representação por coordenadas cartesianas, duas formas principais são utilizadas:

1. Através do limite inferior e do limite superior da especificação como, por exemplo:

50,200

50,300

2. Através de uma medida básica e de um desvio admissível desta medida:

$$
\begin{aligned}
50,000 & +0.200 \text { ou } \quad 50.250 \pm 0.050 \\
& +0.300
\end{aligned}
$$

O sistema de coordenadas polares, com menor frequência para casos específicos, também é utilizado a partir destes mesmos princípios. A Figura 2.1 ilustra graficamente os elementos básicos relevantes:

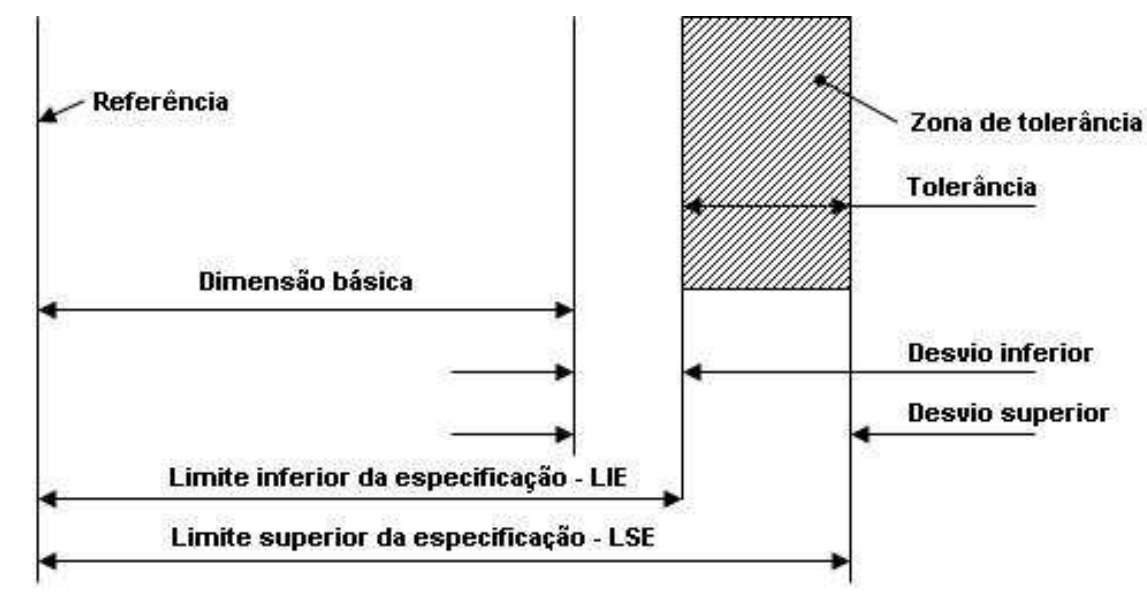

Figura 2.1: Elementos básicos de tolerância dimensional. Fonte: Bjorke ${ }^{[1]}$

As seguintes definições aplicam-se:

- a referência (datum) é o ponto de partida para o posicionamento da dimensão e da tolerância no componente;

- os limites, superior e inferior, da especificação são os valores máximos e mínimos da dimensão aceitáveis pela especificação, respectivamente; 
- a dimensão básica é o valor a partir do qual os cálculos dos limites são realizados;

- o desvio superior é a diferença entre o limite superior da especificação e a dimensão básica;

- o desvio inferior é a diferença entre o limite inferior da especificação e a dimensão básica;

- a tolerância é a diferença entre os limites superior e inferior da especificação; consequentemente é também a diferença entre os desvios superior e inferior. Sempre é um valor absoluto.

Os desvios podem ser positivos, nulos ou negativos individualmente se os limites correspondentes da especificação forem maiores, iguais ou menores que a dimensão básica, respectivamente.

Quando a dimensão básica coincide com um dos limites da especificação, diz-se que este é um caso de tolerância unilateral. Quando a zona de tolerância é dividida igualmente a partir da dimensão nominal, diz-se que este é um caso de tolerância bilateral e seus componentes são denominados semi-tolerâncias. Este é o caso adotado para os estudos de análise e síntese de tolerâncias estatísticas, pois a dimensão nominal é representada pela média da distribuição do processo e as semi-tolerâncias pelas variações simetricamente distribuídas em relação à média. Neste caso, as semi-tolerâncias são chamadas indistintamente na literatura também como tolerâncias. Esta variante de nomenclatura é utilizada como simplificação e geralmente não traz prejuízo para a interpretação.

\subsection{Encadeamento de tolerâncias dimensionais}

As dimensões toleradas de um conjunto mecânico são resultantes do encadeamento de dimensões toleradas dos componentes que o integram. Bjorke ${ }^{[1]}$ - Capítulo 2 - define um encadeamento (chain) como " uma sequência de elementos na qual cada elemento tem um ponto inicial em comum com seu predecessor na sequência e outro ponto final com seu sucessor nesta sequência". O ponto inicial com o elemento predecessor no encadeamento está localizado em superfície acabada de contato, denominada referência característica (datum feature) ${ }^{[22]}$. Portanto, o projeto de cada componente deve considerar estas referências como pontos de partida para o dimensionamento, caso contrário o encadeamento estará comprometido e qualquer trabalho de análise não apresentará resultados 
corretos. Umaras e Tsuzuki ${ }^{[23]}$ identificam o problema em trabalho específico. Estas superfícies acabadas são geralmente obtidas por processos de usinagem ou estampagem $^{[24]}$. O encadeamento de tolerâncias pode ser classificado em função de suas características representando as condições de montagem dos componentes de um conjunto ${ }^{[1]}$ :

- elementar: aquele que não utiliza o mesmo ponto final por duas vezes;

- simples: aquele que não utiliza o mesmo elemento por duas vezes;

- inter-relacionado: aquele que não é elementar ou simples.

A Figura 2.2 ilustra os três tipos de encadeamentos citados, onde os arcos representam as ligações e os vértices, as conexões entre os elementos. Os elementos identificados por $T$ conectam os vértices de um encadeamento de tolerâncias de um conjunto. A interconexão entre ligações de um encadeamento é regida por equações fundamentais, definidas na proxima seção. Caso as equações fundamentais sejam independentes, como a Equação 2.2, o encadeamento é simples; se forem dependentes, o encadeamento é inter-relacionado. Os encadeamentos elementares não apresentam utilidade prática no estudo de tolerâncias por serem abertos, ou seja, não estão sujeitos a restrições funcionais, descritas em seguida. Os encadeamentos inter-relacionados podem exigir a solução de duas ou mais equações simultaneamente e apresentam maior complexidade.

\subsection{Restrições dimensionais de um conjunto de componentes}

Nos conjuntos mecânicos, algumas dimensões apresentam maior importância em relação às demais, pois definem requisitos dimensionais de montagem ou funcionais. Estas dimensões são chamadas de restrições dimensionais ou restrições funcionais de um conjunto e podem também ser denominadas dimensões resultantes (sum dimensions/ functional dimensions ${ }^{[1]}$, concluding member dimensions $\left.^{[11]}\right)$. A Figura 2.3 ilustra um exemplo prático de um conjunto mecânico de transmissão por engrenagens. A dimensão da folga $D$ tem importância funcional, pois se for muito reduzida pode provocar o engripamento do eixo e se for muito grande pode permitir um deslocamento axial excessivo no engrenamento, portanto, seu valor deve ser especificado entre valores restritos. Como pode ser observado, o valor de $D$ é função de outras dimensões:

$$
D=f\left(d_{i}\right)
$$



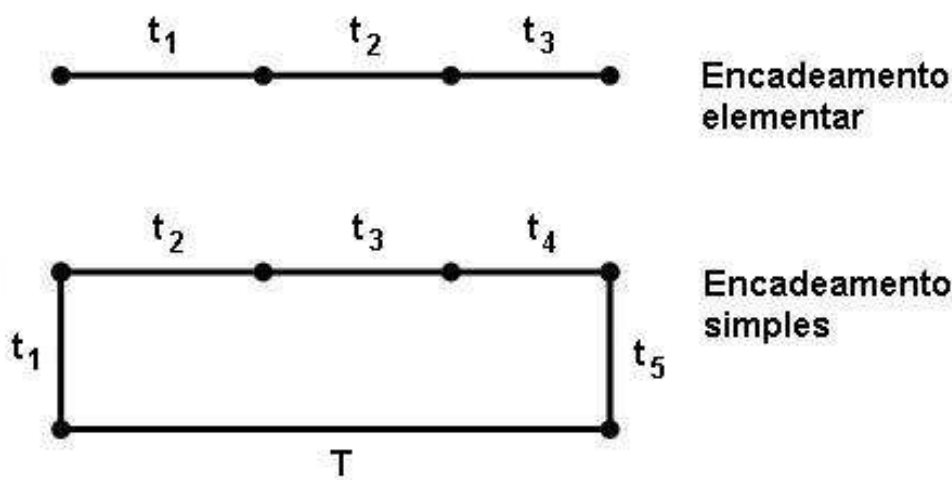

\section{Encadeamento simples}

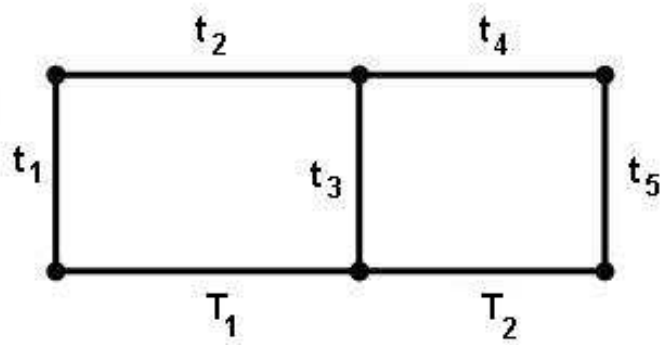

\section{Encadeamento} inter-relacionado

Figura 2.2: Diagramas de encadeamento de tolerâncias. Fonte: Bjorke ${ }^{[1]}$.

Para o exemplo, pode-se observar facilmente que a dimensão resultante da folga D é função da soma e diferença de dimensões dos componentes, conforme Equação 2.2:

$$
D=d_{1}+d_{2}-d_{4}-d_{3}-d_{5}
$$

A Equação 2.2 expressa a relação entre a dimensão resultante e as dimensões individuais dos componentes do conjunto e é denominada equação fundamental do encadeamento. No caso de tolerâncias estatísticas que serão tratadas adiante neste texto, a equação fundamental é utilizada para o relacionamento das médias das distribuições de tolerâncias dos componentes. Para cada restrição dimensional deverá ser identificada a equação fundamental de encadeamento para que o estudo das tolerâncias individuais dos componentes possa ser realizado.

\subsection{Tolerâncias dimensionais no projeto do pro- duto}

Para o correto entendimento da proposta para análise de tolerâncias dimensionais contida neste trabalho, é importante a localização cronológica das atividades de especificação de tolerâncias durante as fases de desenvolvimento de um produto. A literatura sobre o assunto é vasta e refere métodos de alocação, análise e otimi- 


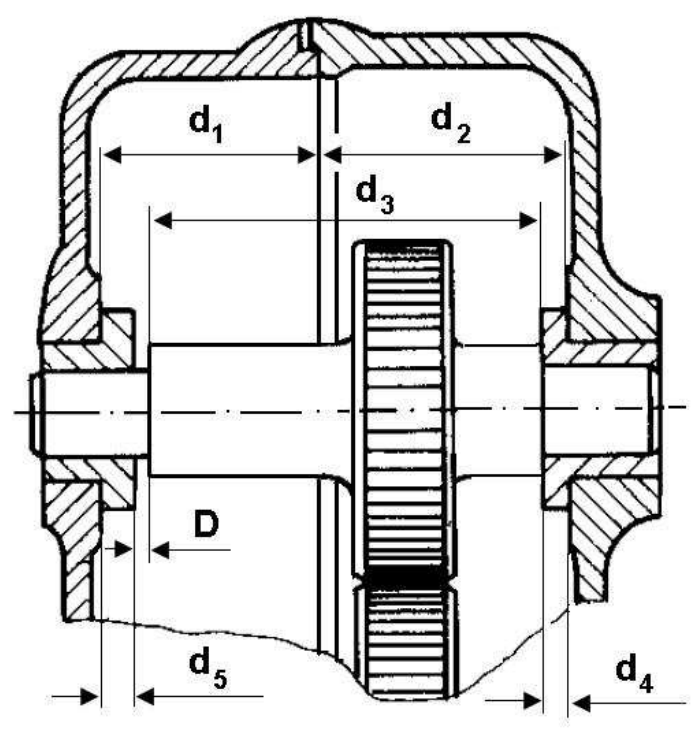

Figura 2.3: Conjunto mecânico identificando uma restrição funcional. Fonte: Bjorke $^{[1]}$.

zação, porém não trata devidamente, em sua maioria, da origem, da ordem e da forma verificadas na prática industrial, nas quais as tolerâncias dimensionais são especificadas. Ullman ${ }^{[25]}$ - Capítulo 6, Bjorke ${ }^{[1]}$ - Capítulo 1 e Dieter ${ }^{[26]}$ - Capítulo 2 , identificam as seguintes fases no desenvolvimento de um produto. As terminologias apresentam diferenças, porém os conceitos envolvidos são os mesmos; Pahl e outros $^{[27]}$, de forma mais abrangente, identificam conceitualmente o processo de desenvolvimento do produto de forma semelhante:

1. Desenvolvimento da especificação do produto

2. Projeto conceitual

3. Projeto do produto

4. Projeto do processo

5. Produção

6. Serviços

Taguchi $^{[28]}$ - Capítulo 1 - identifica as fases de projeto especificamente sob a visão da qualidade, descrita no Capítulo 5 deste trabalho. A especificação do produto consiste basicamente na definição dos seguintes elementos ${ }^{[1]}$ que apresentam individualmente uma especificação nominal e uma tolerância:

- material 
- forma

- dimensões

- requisitos de superfície

O objetivo deste trabalho é essencialmente o tratamento das dimensões do produto, embora estas estejam vinculadas, de alguma maneira, aos requisitos de superfície, como será referido na próxima seção. Segundo Ullman ${ }^{[25]}$ - Capítulo 10, a geração do produto inicia-se na fase do projeto conceitual, com a elaboração de esboços ou desenhos esquemáticos, sem compromisso de detalhes formais ou dimensionais e termina na fase de projeto do produto. Em alguns casos, tais como os de itens reprojetados a partir de outros já existentes, a geração do novo produto inicia-se diretamente na fase de projeto do produto. Nesta fase, mais especificamente no processo de documentação, podem ser identificados três elementos principais:

\section{Layout do produto}

2. Desenhos de detalhe

3. Desenho de conjunto

O layout é um documento de trabalho que objetiva o desenvolvimento dos principais componentes e suas interações e é elaborado em escala real. Somente as principais dimensões e as tolerâncias de restrições funcionais são mostradas - as tolerâncias dimensionais de componentes não o são. Assim que cumpre a função de definir os componentes de detalhe, geralmente é tornado obsoleto. As atualizações posteriores são realizadas nos desenhos de detalhe. Atualmente os layouts são elaborados e modelados em CAD em três dimensões, o que facilita muito a criação dos modelos de componentes, também tridimensionais.

Os desenhos de detalhe, em vistas bidimensionais para impressão em papel, são gerados a partir dos respectivos modelos tridimensionais. Neles, todas as dimensões e tolerâncias, assim como todas as informações para a fabricação, tais como materiais e proteção superficial, devem ser informadas. Ainda conforme Ullman $^{[25]}$ - Capítulo 12, estudos mostram que somente $20 \%$ das tolerâncias de um desenho afetam a função do componente. Geralmente as tolerâncias de forma e posição são especificadas através de simbologia própria, referida através de normas específicas, como ASME Y14.5M ${ }^{[22]}$ e ISO $1101^{[29]}$. Os desenhos de detalhe impressos são distribuídos para utilização por outros setores da empresa, fornecedores e clientes e devem ser aprovados física ou eletronicamente por pessoas 
responsáveis pelo projeto.

Os desenhos de conjunto consistem em vistas ortográficas do produto relacionando e identificando todos os componentes envolvidos através de listas de peças. Apesar de conterem as mesmas informações dos layouts, seu objetivo e sua forma de apresentação são diferentes; vistas isométricas e informações para a montagem são consideradas conforme necessidade. Apenas dimensões e tolerâncias importantes afetando o conjunto e suas restrições de projeto são especificadas. Os desenhos de conjunto também são elaborados em duas dimensões e aprovados como os desenhos de detalhe. Listas de peças separadas são geradas no sistema de dados da organização para fins de aquisição, administração e logística de materiais.

\subsection{Especificação de tolerâncias}

A especificação de tolerâncias na fase de detalhamento do produto é talvez uma das principais atividades de projeto, pois afeta diretamente a qualidade e o custo do produto. Uma tolerância mal especificada pode afetar a qualidade de um produto, gerando ao cliente custos relativos a falhas em sua função principal ou por gerar problemas secundários. De outra forma, uma má especificação não corrigida pode acarretar um diferencial de custo desnecessário embutido por toda a vida útil de um produto. Embora a especificação de tolerâncias possa ser realizada através de experiência de projetos anteriores, para que haja um direcionamento nesta especificação, ela pode ser realizada por recorrência a:

- Normas internacionais e nacionais, tais como ISO 286-1 ${ }^{[20]}$, ASME B4.2 ${ }^{[21]}$ e NBR $6158^{[30]}$. Estas normas apresentam classes de tolerâncias em função de campos de dimensões nominais, cujos valores são coincidentes para dimensões até $500 \mathrm{~mm}$. A Tabela 2.1 foi extraída da norma ISO citada para classes de tolerâncias relativas a processos de usinagem e campos de dimensões utilizados na fabricação de produtos convencionais. A Tabela 2.2 refere capacidades de processos convencionais para classes de tolerâncias dimensionais;

- Normas internas, geralmente disponibilizadas nas empresas de maior porte e baseadas em dados resultantes de desenvolvimentos de processos;

- Literatura específica como, por exemplo, as obras de Trucks ${ }^{[2]}$ - Capítulo 2, Bralla $^{[31]}$ - capítulo 4, Yankee ${ }^{[32]}$ - Capítulo 1 e Bjorke ${ }^{[1]}$ - Apêndice. 
Tabela 2.1: Campos de tolerância usuais para processos de usinagem. Fonte: ISO $286-1^{[20]}$.

\begin{tabular}{|l|l|l|l|l|l|l|l|l|l|l|}
\hline \multicolumn{2}{|l|}{ Dimensões [mm] } & \multicolumn{8}{l|}{ Campos de tolerâncias conforme classes IT $[\mu \mathrm{m}]$} \\
\hline De & até (incl.) & IT6 & IT7 & IT8 & IT9 & IT10 & IT11 & IT12 & IT13 & IT14 \\
\hline 0 & 3 & 6 & 10 & 14 & 25 & 40 & 60 & 100 & 140 & 250 \\
3 & 6 & 8 & 12 & 18 & 30 & 48 & 75 & 120 & 180 & 300 \\
6 & 10 & 9 & 15 & 22 & 36 & 58 & 90 & 150 & 220 & 360 \\
10 & 18 & 11 & 18 & 27 & 43 & 70 & 110 & 180 & 270 & 430 \\
18 & 30 & 13 & 21 & 33 & 52 & 84 & 130 & 210 & 330 & 520 \\
30 & 50 & 16 & 25 & 39 & 62 & 100 & 160 & 250 & 390 & 620 \\
50 & 80 & 19 & 30 & 46 & 74 & 120 & 190 & 300 & 460 & 740 \\
80 & 120 & 22 & 35 & 54 & 87 & 140 & 220 & 350 & 540 & 870 \\
120 & 180 & 25 & 40 & 63 & 100 & 160 & 250 & 400 & 630 & 1000 \\
180 & 250 & 29 & 46 & 72 & 115 & 185 & 290 & 460 & 720 & 1150 \\
250 & 315 & 32 & 52 & 81 & 130 & 210 & 320 & 520 & 810 & 1300 \\
315 & 400 & 36 & 57 & 89 & 140 & 230 & 360 & 570 & 890 & 1400 \\
400 & 500 & 40 & 63 & 97 & 155 & 250 & 400 & 630 & 970 & 1550 \\
\hline
\end{tabular}

Tabela 2.2: Classes de tolerâncias IT em função de processos de fabricação convencionais . Fonte: ASME B4.2 ${ }^{[21]}$.

\begin{tabular}{|l|l|l|l|l|l|l|l|l|}
\hline & IT4 & IT5 & IT6 & IT7 & IT8 & IT9 & IT10 & IT11 \\
\hline 1 & $\mathrm{X}$ & $\mathrm{X}$ & & & & & & \\
\hline 2 & & $\mathrm{X}$ & $\mathrm{X}$ & $\mathrm{X}$ & & & & \\
\hline 3 & & $\mathrm{X}$ & $\mathrm{X}$ & $\mathrm{X}$ & $\mathrm{X}$ & & & \\
\hline 4 & & $\mathrm{X}$ & $\mathrm{X}$ & $\mathrm{X}$ & & & & \\
\hline 5 & & $\mathrm{X}$ & $\mathrm{X}$ & $\mathrm{X}$ & & & & \\
\hline 6 & & $\mathrm{X}$ & $\mathrm{X}$ & $\mathrm{X}$ & $\mathrm{X}$ & & & \\
\hline 7 & & & $\mathrm{X}$ & $\mathrm{X}$ & $\mathrm{X}$ & & & \\
\hline 8 & & & $\mathrm{X}$ & $\mathrm{X}$ & $\mathrm{X}$ & $\mathrm{X}$ & $\mathrm{X}$ & \\
\hline 9 & & & & $\mathrm{X}$ & $\mathrm{X}$ & $\mathrm{X}$ & $\mathrm{X}$ & $\mathrm{X}$ \\
\hline 10 & & & $\mathrm{X}$ & $\mathrm{X}$ & $\mathrm{X}$ & $\mathrm{X}$ & \\
\hline 11 & & & $\mathrm{X}$ & $\mathrm{X}$ & $\mathrm{X}$ & $\mathrm{X}$ & $\mathrm{X}$ \\
\hline 12 & & & & & & $\mathrm{X}$ & $\mathrm{X}$ \\
\hline 13 & & & & & $\mathrm{X}$ & $\mathrm{X}$ \\
\hline 14 & & & & & $\mathrm{X}$ & $\mathrm{X}$ \\
\hline 15 & & & & & $\mathrm{X}$ & $\mathrm{X}$ \\
\hline 16 & & & & & & $\mathrm{X}$ \\
\hline 1-Lapidação, brunimento \\
2-Retificação cilíndrica \\
3-Retificação plana \\
4-Toneamento com diamante \\
5-Alargamento com diamante \\
6-Brochamento \\
7-Metalurgia do pó \\
8-Alargamento \\
9-Torneamento \\
10-Sinterização \\
11-Mandrilamento \\
12-Fresamento \\
13-Aplainamento \\
14-Furação com broca \\
15-Corte com punção \\
16-Fundição sob pressão \\
\hline
\end{tabular}


A Figura $2.4^{[2]}$ ilustra as rugosidades superficiais mínimas em função do campo de tolerâncias correspondente para processos normais. O custo relativo é também mostrado, sugerindo a especificação de rugosidades e campos de tolerâncias maiores sempre que possível.

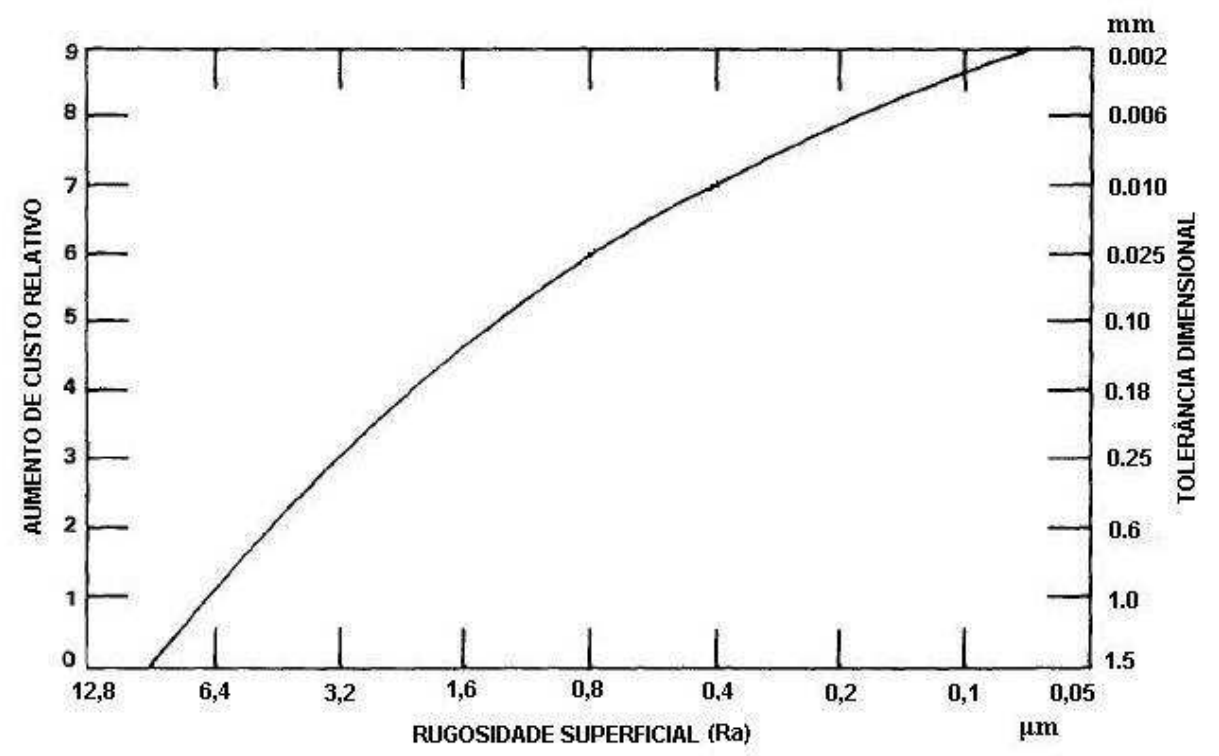

Figura 2.4: Relação entre tolerância e rugosidade superficial. Fonte: Trucks ${ }^{[2]}$

As normas ISO 286-2 ${ }^{[33]}$ e ASME B4.2 ${ }^{[21]}$ e especificam campos de tolerâncias para ajustes entre eixos e furos, a partir das classes IT já mencionadas.

\subsection{O conceito de intercambiabilidade}

A especificação de tolerâncias dimensionais está intimamente relacionada ao conceito de intercambiabilidade. Segundo Bjorke ${ }^{[1]}$ se, em um grupo de peças conformes às mesmas especificações, qualquer uma possa ser selecionada aleatoriamente para ser utilizada no lugar de qualquer outra, com igual probabilidade de que possa ser montada e funcione satisfatoriamente, então esta peça é definida como intercambiável. A qualificação de intercambiabilidade não faz restrição a que tal peça seja originária de um mesmo lote ou a quando e a que condições ela seja capaz de substituir qualquer outra. Deve-se observar também que, embora uma peça seja intercambiável, não existe a certeza de que, em determinado caso, ela possa substituir qualquer outra, já que a definição acima expressa somente que as peças apresentam a mesma probabilidade de satisfazer a função no conjunto e nada é dito sobre quão provável isso possa ser. Assim, pode-se também definir o conceito de grau de intercambiabilidade que expressa o quão provável a fun- 
ção da peça no conjunto seja mantida quando esta seja substituída. O grau de intercambiabilidade pode variar caso a caso num espectro de zero a $100 \%$ e, na prática de manufatura, podem ser identificados três casos:

- intercambiabilidade total: o grau de intercambiabilidade é de $100 \%$;

- intercambiabilidade limitada: o grau de intercambiabilidade é maior que zero, mas menor que $100 \%$;

- usinagem para montar: o grau de intercambiabilidade é de $0 \%$.

A abordagem geral, descrita acima, refere-se à intercambiabilidade universal. O termo universal é utilizado para distingui-lo do conceito de intercambiabilidade restrita, ou intercambiabilidade local, utilizada somente entre peças de um mesmo lote e empregada em certos casos como auxiliar de manufatura para o aproveitamento de itens em montagens de conjuntos de produção e não aplicáveis a peças de reposição. O conceito de variância é o mesmo para as intercambiabilidades universal e local, mas o posicionamento da distribuição é menos rigoroso no caso da local: a flexibilização de requisitos do valor absoluto de dimensões é possibilitada através da seleção de dimensões reais de peças fabricadas em lotes. Isto é possível uma vez que os lotes sejam feitos em sequência e o ajuste de máquinas e ferramentas possa ser feito em função de peças previamente fabricadas. Bjorke ${ }^{[1]}$ fornece ainda as características dos três tipos principais de intercambiabilidade descritos a seguir, com o objetivo de oferecer fundamentação teórica sobre o assunto.

Neste trabalho será apenas considerado o caso de intercambiabilidade total, pois as características dos outros tipos restringem seu uso, devido a fatores econômicos, em processos produtivos de larga escala.

\subsubsection{Intercambiabilidade total}

$\mathrm{Na}$ intercambiabilidade total, os limites da especificação de tolerâncias no projeto devem ser maiores ou iguais aos limites da capacidade do processo; caso contrário, operações adicionais seriam necessárias para a obtenção de ajustes e o princípio de intercambiabilidade total seria violado. Balakshin ${ }^{[11]}$ descreve como o exemplo mais simples de intercambiabilidade total ou ilimitada, a montagem de qualquer lâmpada na rosca do respectivo soquete; outro exemplo seria a de uma transmissão veicular, onde todos os componentes podem ser substituídos e a dimensão crítica, a folga entre os dentes das engrenagens deve permanecer restrita a um 
valor especificado. A desvantagem em relação à intercambiabilidade limitada é seu maior custo; as vantagens são:

- não há necessidade de operações adicionais durante a montagem;

- podem ser utilizadas linhas de montagem;

- pode ser utilizada montagem automatizada;

- podem ser utilizadas peças padronizadas;

- podem ser utilizadas peças fabricadas em locais diferentes;

- pode ser empregada mão de obra de baixa habilidade;

- o fornecimento de peças de reposição é simplificado.

Como o conceito de intercambiabilidade total vincula sua validade à capacidade de um processo, sua aplicação apresenta as limitações resultantes desta característica. Por exemplo, a montagem de duas contra-peças unidas precisamente por dois pinos cônicos não poderia se utilizar do princípio de intercambiabilidade total, pois a precisão necessária à furação e alargamento dos furos é maior que a disponibilizada pela capacidade dos processos convencionais. Assim, este tipo de montagem deve prever a usinagem das peças montadas na posição e, portanto, sem intercambiabilidade.

\subsubsection{Intercambiabilidade limitada}

Na intercambiabilidade limitada, os limites da especificação de tolerâncias no projeto podem ser menores que os limites da capacidade do processo e ela apresenta as seguintes vantagens:

- operações adicionais durante a montagem podem ser removidas até um nível de confiança determinado:

- linhas de montagem podem ser utilizadas com certo grau de risco;

- peças padronizadas podem ser utilizadas;

- o fornecimento de peças de reposição é simplificado;

- tolerâncias significativamente maiores podem ser utilizadas. 
As desvantagens deste princípio estão principalmente relacionadas à rejeição de peças e com as operações adicionais necessárias durante a montagem. Estas desvantagens podem ser contrabalançadas, em alguns casos, pelas vantagens mencionadas, porém a limitação inerente ao conceito requer a consideração de restrições importantes descritas a seguir, pois impedem seu uso em processos altamente produtivos.

\subsubsection{Seleção direta}

No processo de seleção direta, os grupos de peças que serão submetidos à montagem são disponibilizados a um montador que seleciona pares de contra-peças que desempenhem a função do produto adequadamente. Esta verificação funcional por pares pode consumir maior ou menor tempo e pode ser realizada através de inspeção $100 \%$ ou por amostragem. A vantagem do método é a simplicidade e a grande desvantagem é que a qualidade das montagens depende inteiramente da habilidade e da experiência do montador.

\subsubsection{Montagem seletiva}

A montagem seletiva é um método no qual as peças são classificadas em grupos de acordo com seu tamanho, assim como suas contra-peças. Os conjuntos correspondentes montam e funcionam corretamente. A verificação individual dos requisitos funcionais de cada conjunto não é necessária, já que as peças são previamente medidas e classificadas para permitirem a montagem desejada. Devido à seleção, a precisão de montagem neste método é maior e mais estável do que a conseguida através da usinagem das peças individualmente.

A grande desvantagem deste método, além do custo intrínseco da seleção, é o acúmulo de peças não utilizadas em diferentes grupos pois, na seleção, nem o número de peças é igual em cada grupo, nem as distribuições dos conjuntos são as mesmas. Esta não utilização gera perdas devido a não possibilidade de utilização e aumenta o volume de peças em processo. Alguns artigos ${ }^{[34-37]}$ contemplam o problema através da proposição de algoritmos otimizadores para a minimização de itens excedentes no processo de montagem seletiva, mas seus conteúdos não serão tratados neste texto, pois fogem do objetivo do trabalho.

Um exemplo de montagem seletiva, se observadas as diferenças, é o processo de seleção de bielas de motores de combustão interna em relação à sua faixa de peso, pois todas as bielas do motor devem pertencer à mesma faixa para que um maior nível de vibração do produto seja evitado. Embora as bielas rejeitadas pela não 
utilização possam ser retrabalhadas para mudança de classe de peso, uma maior quantidade de peças em processo não pode ser evitada.

\subsubsection{Compensação}

A essência deste método consiste no uso de campos de tolerâncias largos para todos os componentes do conjunto, com exceção do último da cadeia de montagem, cuja dimensão é utilizada para compensar toda a variação dos outros componentes. Os elementos de compensação podem ser de dois tipos:

- Ajustáveis, através de características do projeto.

- Fixos, usinados com diversas dimensões e aplicados conforme necessidade da montagem específica.

As vantagens deste tipo são:

- possibilidade de usinagem dos componentes do conjunto com maiores campos de tolerância, facilitando os processos e reduzindo custos;

- simplicidade de montagem de conjuntos sujeitos a restrições de alta precisão;

- possibilidade de ajustes tanto na montagem quanto em serviço.

\subsubsection{Usinagem para montar}

Este é o método mais primitivo utilizado para assegurar a condição de montagem. Consiste na usinagem de todos os componentes, exceto um, nas dimensões próximas às nominais e a dimensão do último componente é então usinada sob medida para garantir a montagem. A precisão da usinagem limita o grau de intercambiabilidade do método para processos de produção e seu uso é restrito a trabalhos de reparação ou à fabricação de um único conjunto. 


\section{Métodos para análise e síntese de tolerâncias dimensionais}

\subsection{Análise e síntese de tolerâncias}

Um conceito fundamental no estudo das tolerâncias dimensionais é a diferenciação entre os procedimentos de análise e síntese de tolerâncias:

- na análise $\left(\right.$ analysis $\left.^{[7]}\right)$, também conhecida por controle $\left(\right.$ control $\left.^{[1]}\right)$, as tolerâncias individuais dos componentes são conhecidas e a tolerância resultante do conjunto pode ser calculada por processo de encadeamento;

- na síntese, também denominada alocação (allocation ${ }^{[7]}$ ) ou distribuição (distribution $\left.{ }^{[1]}\right)$, a tolerância dimensional do conjunto, na forma de restrição de projeto, é conhecida, mas as tolerâncias individuais dos componentes não são. A síntese de tolerâncias consiste na distribuição da tolerância disponível do conjunto entre os componentes, através de um processo racional.

Outra diferença entre os dois procedimentos refere-se à fração de rejeição do processo de montagem, que é a indicação do nível de qualidade do produto e pode ser também entendido como o porcentual de conjuntos que não atendem aos requisitos de tolerância especificados ${ }^{[1]}$. Para níveis de alta qualidade, este índice é de algumas partes por milhão (PPM). Na análise de tolerâncias, o porcentual de rejeição do conjunto é desconhecido, mas pode ser determinado através da soma das tolerâncias dos componentes e do conhecimento dos limites da especificação. $\mathrm{Na}$ alocação de tolerâncias, o porcentual de rejeição do conjunto é especificado como requisito de projeto e as tolerâncias dos componentes devem ser ajustadas para que a tolerância resultante do conjunto atenda à especificação. A Figura 3.1 ilustra esquematicamente a diferença fundamental entre os dois procedimentos. Os métodos para análise e síntese de tolerâncias dimensionais estão descritos em detalhe neste capítulo. A próxima seção coloca conceitos importantes quanto à forma de participação de tolerâncias nos processos de análise e síntese em função de suas características. 

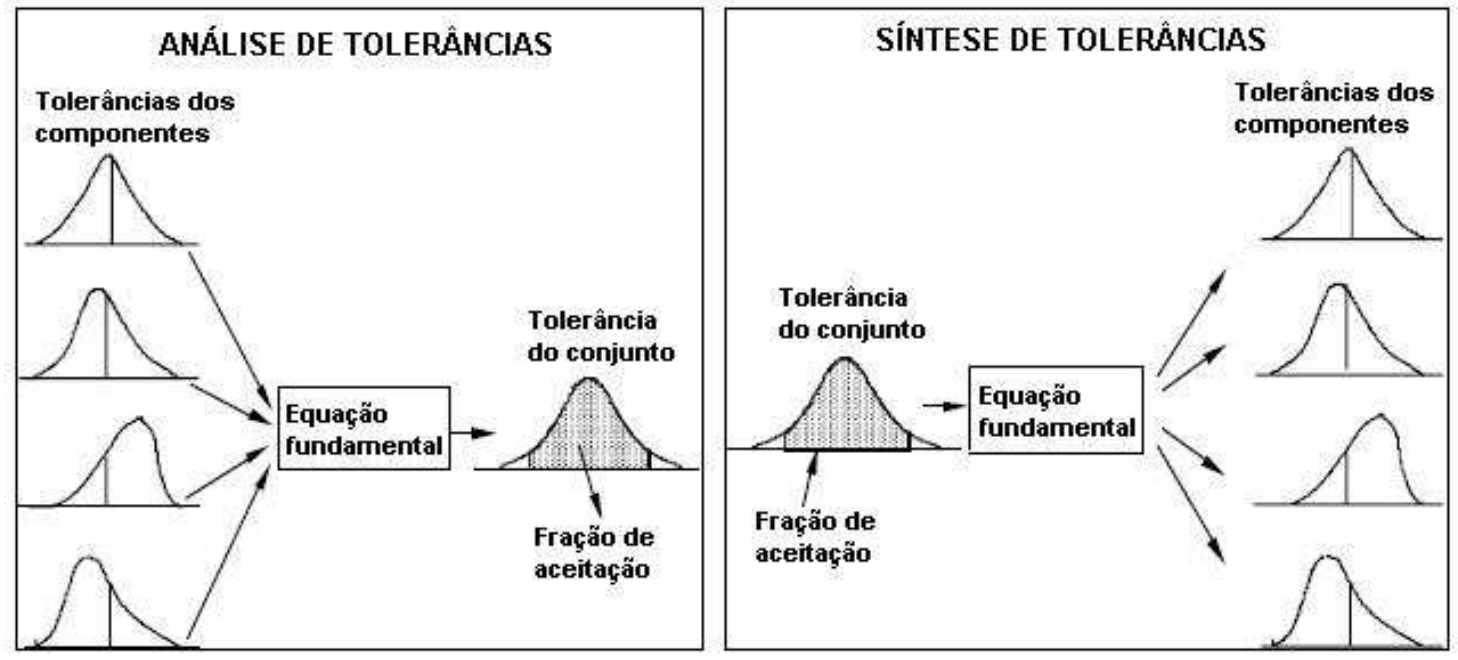

Figura 3.1: Ilustração do conceito de análise e síntese de tolerâncias. Fonte: Chase $^{[3]}$.

\subsection{Considerações sobre características das tole- râncias dos componentes}

Dois tipos de considerações podem ser feitas quanto a características das tolerâncias dos componentes:

1. Se as tolerâncias são pré-determinadas ou determináveis;

2. Tipo de distribuição de frequências.

As tolerâncias dos componentes são pré-determinadas quando os componentes forem padronizados, tais como rolamentos, chavetas ou correias. Podem também ser pré-determinadas se forem sujeitas a algum outro tipo de restrição, tal como estarem envolvidas em outros encadeamentos; caso contrário, serão determináveis $^{[1]}$. O número total de componentes do encadeamento é a soma dos componentes com tolerâncias determináveis $(n d)$ e dos componentes com tolerâncias pré-determinadas $(n p)$.

$$
N=n d+n p
$$

Para as tolerâncias determináveis, deve ser definido o tipo de distribuição de frequências. Os tipos geralmente observados nos processos de produção são a distribuição retangular e a normal ${ }^{[1]}$, referidas no Apêndice A. A aplicação da distribuição retangular, utilizada quando o comportamento do processo não é conhecido, gera a síntese ou análise para o "pior caso" (worst case), extremamente conservadora, pois considera a soma dos limites da especificação e uma condição 
de igual probabilidade para o resultado das dimensões obtidas pelo processo, o que normalmente não se observa na prática.

\subsection{Análise de tolerâncias dimensionais}

O processo de análise de um sistema, de modo geral, objetiva a obtenção de uma característica de desempenho em função de determinadas variáveis desse sistema, através de uma relação funcional. A Figura 3.2 ilustra as fases do processo de análise de tolerâncias. Nesta seção estão incluídos os principais métodos de análise

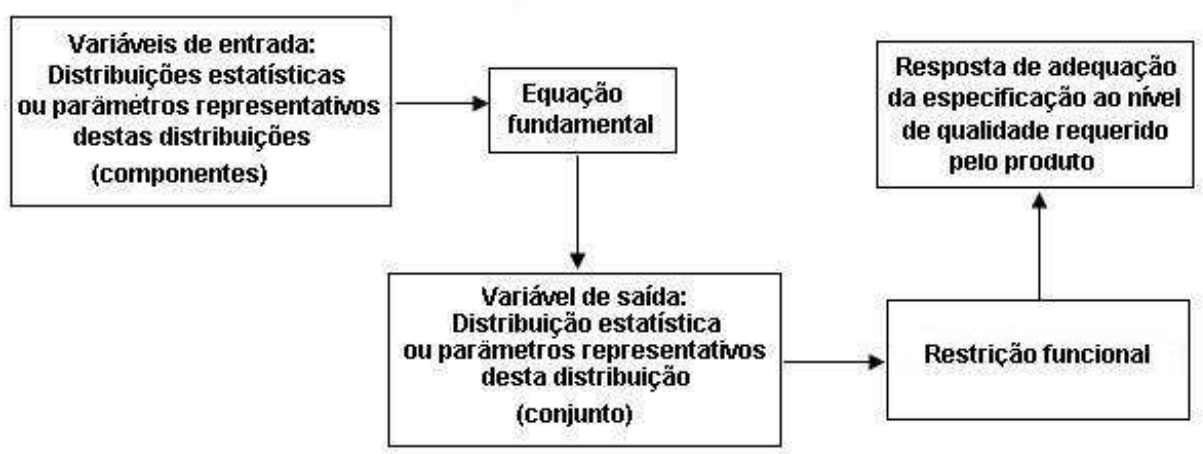

Figura 3.2: Esquema do processo de análise de tolerâncias dimensionais.

de tolerâncias dimensionais. Os métodos dos Momentos e de Monte Carlo estão descritos por Cox ${ }^{[38]}$, Hahn e Shapiro ${ }^{[4]}$, Haugen ${ }^{[13]}$ e Shapiro e Gross ${ }^{[39]}$ como métodos matemáticos para análise de sistemas em geral. Os métodos para o pior caso e o da raiz da soma dos quadrados, descritos por Bjorke ${ }^{[1]}$, Creveling ${ }^{[12]}$, Nigam e Turner ${ }^{[40]}$ e Chase ${ }^{[41]}$, podem ser definidos como casos particulares do método dos momentos. Cronologicamente, a primeira referência importante encontrada referente à análise de tolerâncias é a de Spotts ${ }^{[2]}$ - Capítulo 13, que a descreve como problema de dimensionamento em conjuntos mecânicos e introduz os conceitos estatísticos. Outro dos primeiros trabalhos importantes a ser mencionado e referência obrigatória no assunto é o de Fortini ${ }^{[43]}$, citado na quase totalidade das publicações pesquisadas. Na mesma década, Wade ${ }^{[44]}$ apresenta um método interessante de análise de tolerâncias através de "Cartas de Tolerâncias", elaboradas manualmente, que se assemelham às atuais folhas de processo. 


\subsubsection{Método para o pior caso}

Também conhecido como empilhamento de tolerâncias (stack-up), o método para o pior caso (worst case) é utilizado quando:

1. não há informações sobre os processos de fabricação dos componentes;

2. o conjunto é formado por poucos componentes sujeitos a restrições dimensionais críticas devidas à função do produto, isto é, não são permitidos quaisquer índices de rejeição. Este método deve ser considerado nos casos em que as restrições funcionais envolvam condições de segurança ou estejam relacionadas à legislação.

Como as informações dos processos não são conhecidas, nenhuma análise estatística pode ser feita. Porém, como na realidade a tendência dos processos usuais mantém os valores próximos ao valor médio da especificação, seu resultado é geralmente muito conservador. Nos casos em que a escolha do método deve-se ao item 2, ou seja, em projetos nos casos de restrições funcionais que envolvam condições de segurança, por exemplo, as dimensões características que formam o conjunto devem ser submetidas à inspeção total. Isto pode ser feito na linha de produção através da medição de $100 \%$ dos itens através de calibradores do tipo passa-não-passa ${ }^{[1]}$ o que, na prática, significa que a distribuição estatística gerada pelo processo está sendo truncada na região das caudas nos valores determinados pela especificação. O estudo de caso deste trabalho fornece um exemplo de aplicação para este método.

O modelo geral para o caso linear considera a soma das dimensões dos componentes nos valores máximos e mínimos para o pior caso ${ }^{[12]}$. Para o cálculo nos dois casos deve ser observada a equação fundamental do encadeamento que refere os sinais das tolerâncias dos componentes. Por exemplo, para o encadeamento ilustrado na Figura 2.3 e calculado pela Equação 2.2:

O valor da folga será máximo para:

$$
D_{M A X}=d_{1 M A X}+d_{2 M A X}-d_{3 M I N}-d_{4 M I N}-d_{5 M I N}
$$

O valor da folga será mínimo para:

$$
D_{M I N}=d_{1 M I N}+d_{2 M I N}-d_{3 M A X}-d_{4 M A X}-d_{5 M A X}
$$

Estes valores devem ser comparados à restrição dimensional do conjunto no processo de análise e ajustados individualmente para a adequação. 
Chase e Parkinson ${ }^{[41]}$ e Creveling ${ }^{[12]}$ - Capítulo 5 - descrevem o método para a condição não linear. Seja a equação fundamental de um conjunto mecânico formado pelos componentes $x_{i}(i=1,2, . ., n)$ :

$$
z=h\left(x_{1}, x_{2}, x_{3}, \ldots, x_{n}\right)
$$

A equação pode ser expandida através da série de Taylor. Se considerados somente os termos de primeira ordem, tem-se:

$$
\operatorname{tol}_{z}=\left|\frac{\partial h}{\partial x_{1}}\right| \operatorname{tol}_{1}+\left|\frac{\partial h}{\partial x_{2}}\right| \operatorname{tol}_{2}+\left|\frac{\partial h}{\partial x_{3}}\right| \operatorname{tol}_{3}+\cdots+\left|\frac{\partial h}{\partial x_{n}}\right| t_{0} l_{n}
$$

Os termos $\left|\frac{\partial h}{\partial x_{i}}\right|$ indicam a sensibilidade do conjunto em relação às variações dos componentes.

O método do pior caso assume que todas as dimensões dos componentes ocorrem nos limites de suas especificações simultaneamente. Obviamente, para um conjunto com grande número de componentes, os limites tem de ser muito reduzidos para que atendam aos limites de montagem do conjunto. Os custos serão consequentemente maiores. Umaras e Tsuzuki ${ }^{[45]}$ comparam a diferença na consideração de tolerâncias no pior caso com as sujeitas a distribuições estatísticas em exemplo de aplicação.

\subsubsection{Método da raiz da soma dos quadrados}

O método da raiz da soma dos quadrados (root sum of squares - RSS) baseia-se em dois conceitos fundamentais ${ }^{[4]}$ :

1. O teorema do limite central ${ }^{[4,10]}$ que afirma que a distribuição da soma de distribuições de variáveis independentes com média e variância finitas aproxima-se da distribuição normal quando o número de distribuições tornase suficientemente alto. O teorema não faz restrição quanto ao tipo de distribuições envolvidas na soma;

2. Uma distribuição normal está completamente definida pelos seus dois primeiros momentos, ou seja, sua média e sua variância.

O método é geralmente utilizado para sistemas unidirecionais, onde são aplicáveis as relações:

$$
\begin{gathered}
E\left(x_{1}\right)+E\left(x_{2}\right)+E\left(x_{3}\right)+\ldots+E\left(x_{n}\right)=\mu \\
\operatorname{Var}\left(x_{1}\right)+\operatorname{Var}\left(x_{2}\right)+\operatorname{Var}\left(x_{3}\right)+\ldots+\operatorname{Var}\left(x_{n}\right)=\sigma^{2}
\end{gathered}
$$


Com estas relações, a curva normal resultante está totalmente definida. Com o auxílio de tabelas da distribuição normal pode-se calcular a fração de rejeição do conjunto. Na Equação 3.6, que nos casos práticos representa a equação fundamental do encadeamento, os sinais das expectâncias ou médias dos componentes devem ser observados. Como será visto na próxima seção, este método é um caso específico do método dos momentos, cujas equações dos primeiro e segundo momentos podem ser utilizadas para casos não lineares para cálculo da média e variância do conjunto.

\subsubsection{Método dos momentos}

Este método é também conhecido por método de propagação dos momentos, método de propagação de erros, análise de incertezas ou, genericamente, como análise de tolerâncias ${ }^{[38]}$; ainda pode ser conhecido por propagação estatística de erros ou método delta ${ }^{[4]}$. O princípio fundamental do método é o de que, a partir do conhecimento de estimativas dos quatro primeiros momentos de uma distribuição, esta pode ser aproximada através de distribuições conhecidas. As famílias de distribuições de Pearson são as referidas na literatura de estatística. $\mathrm{Na}$ aplicação do método dos momentos, é necessário que se considere duas de suas características principais:

1. Como termos de maior ordem da expansão da série de Taylor são desprezados nas equações resultantes de cada momento, por razão de simplificação e até para viabilização de cálculo, o método apresenta resultados aproximados. Porém, segundo Hahn e Shapiro ${ }^{[4]}$, este fato não traz erros significativos para a maioria dos casos práticos;

2. O método apresenta limitações quando as equações funcionais do sistema estudado resultarem em derivadas parciais de solução complexa. Na análise de tolerâncias, muitos dos casos são de sistemas unidirecionais, de solução trivial. Sistemas bidimensionais apresentam geralmente relações trigonométricas, de solução viável. Para casos complexos, recomenda-se a utilização da simulação de Monte Carlo.

Neste texto serão apresentados somente os conceitos básicos e as equações resultantes de desenvolvimentos matemáticos relativamente extensos, cuja demonstração foge ao objetivo do trabalho. Estes desenvolvimentos podem ser obtidos, por exemplo, nas obras de Hahn e Shapiro ${ }^{[4]}$ - Apêndice e de Cox ${ }^{[38]}$. 
Seja um conjunto de componentes com a equação funcional:

$$
z=h\left(x_{1}, x_{2}, x_{3}, \ldots, x_{n}\right)
$$

Seja $E\left(x_{i}\right)$ a expectância ou média da $i$-ésima variável e seja $\mu_{k}\left(x_{i}\right)$ o $k$-ésimo momento central (ou momento em relação à média). Similarmente sejam $E(z) \mathrm{e}$ $\mu_{k}(z)$ a expectância e o $k$-ésimo momento central do conjunto, respectivamente. A ideia do método é a obtenção de uma estimativa de $E(z)$ e $\mu_{k}(z)$ para $k=2,3$ e 4 com base em:

1. Dados das variáveis para as quais estimativas de $E\left(x_{i}\right)$ e $\mu_{k}\left(x_{i}\right)(i=1,2,3, \ldots, n)$ podem ser obtidos e,

2. Conhecimento da estrutura do sistema, ou seja, sua equação funcional $h\left(x_{1}, x_{2}, x_{3}, \ldots, x_{n}\right)$

As equações dos quatro momentos são apresentadas individualmente nas subseções a seguir:

\subsubsection{Cálculo do primeiro momento - a média}

O método consiste na expansão da equação funcional $h\left(x_{1}, \cdots, x_{n}\right)$ em relação a $\left[E\left(x_{1}\right), \cdots, E\left(x_{n}\right)\right]$, pontos nos quais cada variável toma o seu valor médio, por série multi-variável de Taylor. Assumindo que as variáveis sejam não correlacionadas ${ }^{1}{ }^{2}$ a expressão final para a média de um conjunto, se desprezados os termos acima de segunda ordem, será ${ }^{3}$ :

$$
E(z)=h\left[E\left(x_{1}\right), E\left(x_{2}\right), \cdots, E\left(x_{n}\right)\right]+\frac{1}{2} \sum_{i=1}^{n} \frac{\partial^{2} h}{\partial x_{i}{ }^{2}} \operatorname{Var}\left(x_{i}\right)
$$

onde: $\frac{\partial^{2} h}{\partial x_{i}^{2}}$ é avaliado em $E\left(x_{r}\right)$, isto é, com $E\left(x_{r}\right)$ substituído por $x_{r}$ para $r=$ $1,2, \cdots, n$. A equação acima exige o conhecimento ou estimativas das médias e variâncias de cada variável (componente). É importante observar que a estimativa

\footnotetext{
${ }^{1}$ Diz-se que existe correlação (ou dependência) entre componentes quando o valor aleatório tomado por um ou mais componentes de um sistema está relacionado com o valor aleatório de um ou mais componentes no mesmo sistema ${ }^{[4]}$. Por exemplo, caso dois componentes de um conjunto sejam originados de uma fonte comum como uma mesma operação de usinagem, podem ser considerados correlacionados ${ }^{[38]}$.

${ }^{2}$ Expressões que consideram variáveis correlacionadas podem ser obtidas de forma similar ao caso das não correlacionadas. Não foram consideradas neste trabalho por não serem aplicáveis para os casos práticos de análise de tolerâncias, conforme exemplifica a nota anterior. Demonstrações podem ser obtidas de Hahn e Shapiro ${ }^{[4]}$ - Apêndice 7B.

${ }^{3}$ Nesta seção serão utilizadas as notações $E(x)$ e $\operatorname{Var}(x)$ para a expectância e a variância de $x$ no lugar de $\mu(x)$ e $\sigma^{2}(x)$, respectivamente, para maior facilidade de interpretação. A notação $\mu_{k}(x)$ será utilizada para representar o $k$-ésimo momento de $x$.
} 
da média do conjunto pela substituição das médias dos componentes na equação do sistema:

$$
E(z)=h\left[E\left(x_{1}\right), E\left(x_{2}\right), \cdots, E\left(x_{n}\right)\right]
$$

fornecerá um valor exato apenas quando as derivadas parciais de segunda e maiores ordens forem nulas, isto é, quando o conjunto for função linear dos componentes, ou seja, nos encadeamentos unidirecionais. Grande parte dos casos práticos enquadra-se neste caso.

\subsubsection{Cálculo do segundo momento - a variância}

De modo similar ao cálculo da média, também assumindo-se variáveis não correlacionadas, a equação para a variância do conjunto, se desprezados os termos acima da terceira ordem, será:

$$
\operatorname{Var}(z)=\sum_{i=1}^{n}\left(\frac{\partial h}{\partial x_{i}}\right)^{2} \operatorname{Var}\left(x_{i}\right)+\sum_{i=1}^{n}\left(\frac{\partial h}{\partial x_{i}}\right)\left(\frac{\partial^{2} h}{\partial x_{i}^{2}}\right) \mu_{3}\left(x_{i}\right)
$$

onde: $\mu_{3}\left(x_{i}\right)$ é o terceiro momento central para a $i$-ésima variável e, da mesma forma citada anteriormente, todas as derivadas são avaliadas nos seus valores médios. Muitas referências omitem o segundo termo da equação, fornecendo a expressão:

$$
\operatorname{Var}(z)=\sum_{i=1}^{n}\left(\frac{\partial h}{\partial x_{i}}\right)^{2} \operatorname{Var}\left(x_{i}\right)
$$

Esta equação fornece, segundo Hahn e Shapiro ${ }^{[4]}$, aproximação satisfatória na maioria dos casos. Os termos $\left(\frac{\partial h}{\partial x_{i}}\right)$ indicam a sensibilidade do conjunto em relação às variações dos componentes.

Pode-se notar facilmente que, para os casos de encadeamentos unidirecionais, a equação reduz-se à forma da equação das variâncias citadas para o método da raiz da soma dos quadrados.

\subsubsection{Cálculo do terceiro e quarto momentos}

Também de maneira análoga aos casos anteriores, as expressões para o terceiro e quarto momentos do conjunto podem ser obtidas e escritas se desprezados todos os termos de maior ordem:

$$
\mu_{3}(z)=\sum_{i=1}^{n}\left(\frac{\partial h}{\partial x_{i}}\right)^{3} \mu_{3}\left(x_{i}\right)
$$


$\mu_{4}(z)=\sum_{i=1}^{n}\left(\frac{\partial h}{\partial x_{i}}\right)^{4} \mu_{4}\left(x_{i}\right)+6 \sum_{i=1}^{n} \sum_{j=1}^{n}\left(\frac{\partial h}{\partial x_{i}}\right)^{2}\left(\frac{\partial h}{\partial x_{j}}\right)^{2} \operatorname{Var}\left(x_{i}\right) \operatorname{Var}\left(x_{j}\right) \quad(i>j)$

Como nos casos anteriores, todas as derivadas são avaliadas nos valores médios das variáveis.

\subsubsection{Método de monte carlo}

Monte Carlo, capital de Mônaco, é conhecida por suas operações de apostas em jogos, baseados em fatores aleatórios. De maneira semelhante, o método ou simulação de Monte Carlo se assemelha a um procedimento que utiliza uma aposta cujo resultado se baseia em um número de fatores aleatórios. No estudo de simulação, o "jogo" é uma representação funcional ou matemática de um sistema e os fatores são as variáveis aleatórias utilizadas para representar os elementos do sistema ${ }^{[39]}$. Também conhecido como amostragem sintética ou amostragem empírica, o estudo de simulação envolve os passos ilustrados na Figura 3.3.

A ideia da abordagem do método é utilizar o potencial de abstração da matemática e, simultaneamente, evitar sua limitação na solução determinística de problemas envolvendo sistemas de equações de alta complexidade, através de processos aleatórios não relacionados ao problema específico. As soluções de Monte Carlo envolvem incertezas, uma vez que elas se originam de dados brutos obtidos pela geração de números aleatórios. Elas podem ser úteis dependendo da confiança de que essa incerteza seja muito pequena e o erro envolvido seja desprezível ${ }^{[13]}$. Uma forma de reduzir o erro nas soluções do método é aumentar o número de observações na base do processo, mas isto representa um custo. De modo geral, existe uma relação quadrática entre o valor do erro de uma resposta e o número de observações necessárias, ou seja, para redução do erro pela metade, o número de observações deve ser quadruplicado. Assim, antes do início da solução prática de um problema de projeto, é preciso se considerar o número de amostras necessárias para se assegurar que as respostas tenham a mínima precisão planejada. Nas aplicações práticas de projeto, as caudas das distribuições de frequências de parâmetros aleatórios, cujas áreas contém menos de 1\% da área total sob a curva, são de particular interesse ${ }^{[13]}$. Por exemplo:

- uma amostra de 200 valores pode fornecer pouquíssima informação sobre $5 \%$ e nenhuma informação sobre $1 \%$ dos pontos;

- uma amostra de 1000 valores pode fornecer pouca informação sobre 5\% e pouquíssima informação sobre $1 \%$ dos pontos; 
- uma amostra de 2000 valores pode fornecer pouca informação sobre $1 \%$ e uma estimativa razoável sobre os $5 \%$ dos pontos.

Esta característica faz com que o tempo de processamento necessário para execução do método seja alto. Uma outra característica da simulação é que, em algum ponto, um conjunto de valores reais seja substituído pela variável aleatória e estes valores reais devem ter as mesmas propriedades dela ${ }^{[13]}$. Hahn e Shapiro ${ }^{[4]}-$ Capítulo 7 - também apontam a flexibilidade do Método de Monte Carlo na solução de problemas complexos, especialmente nos casos de inter-relacionamento entre as variáveis componentes. Porém, colocam também outras limitações, além do enorme tempo de processamento para número grande de tentativas:

- não há possibilidade de se determinar se uma variável é mais importante ou dominante sobre outras;

- exige a definição da forma da distribuição de probabilidades, requisito não necessário no método dos momentos;

- caso seja feita alguma alteração em uma das variáveis, toda a simulação deve ser refeita;

- exige a elaboração de programas complexos de computador.

O Apêndice B do trabalho ilustra um exemplo de aplicação do método de Monte Carlo.

\subsubsection{Geradores de números aleatórios}

Os números aleatórios foram originalmente gerados através de dispositivos mecânicos ou eletrônicos. Exemplos são discos ou roletas operados por motor elétrico e outros dispositivos cuja entrada eram fontes de ruído ${ }^{[4]}$. Tabelas de números aleatórios, geralmente obtidas por processos físicos, também estão disponíveis em livros de Estatística (exemplo: The Rand Corporation e C. R. C. Standard Mathematical Tables ${ }^{[13]}$.

Outra forma para a obtenção de números aleatórios é através de algoritmos desenvolvidos especialmente para esta finalidade. Os valores obtidos nestes casos são chamados pseudo-aleatórios, já que são obtidos por expressões matemáticas determinísticas em vez de mecanismos físicos. Um destes algoritmos primitivos é o método dos meios quadrados (Midsquare Method ${ }^{[13]}$, onde cada número é gerado pelo quadrado de seu sucessor e o dígito do meio do resultado é utilizado. 


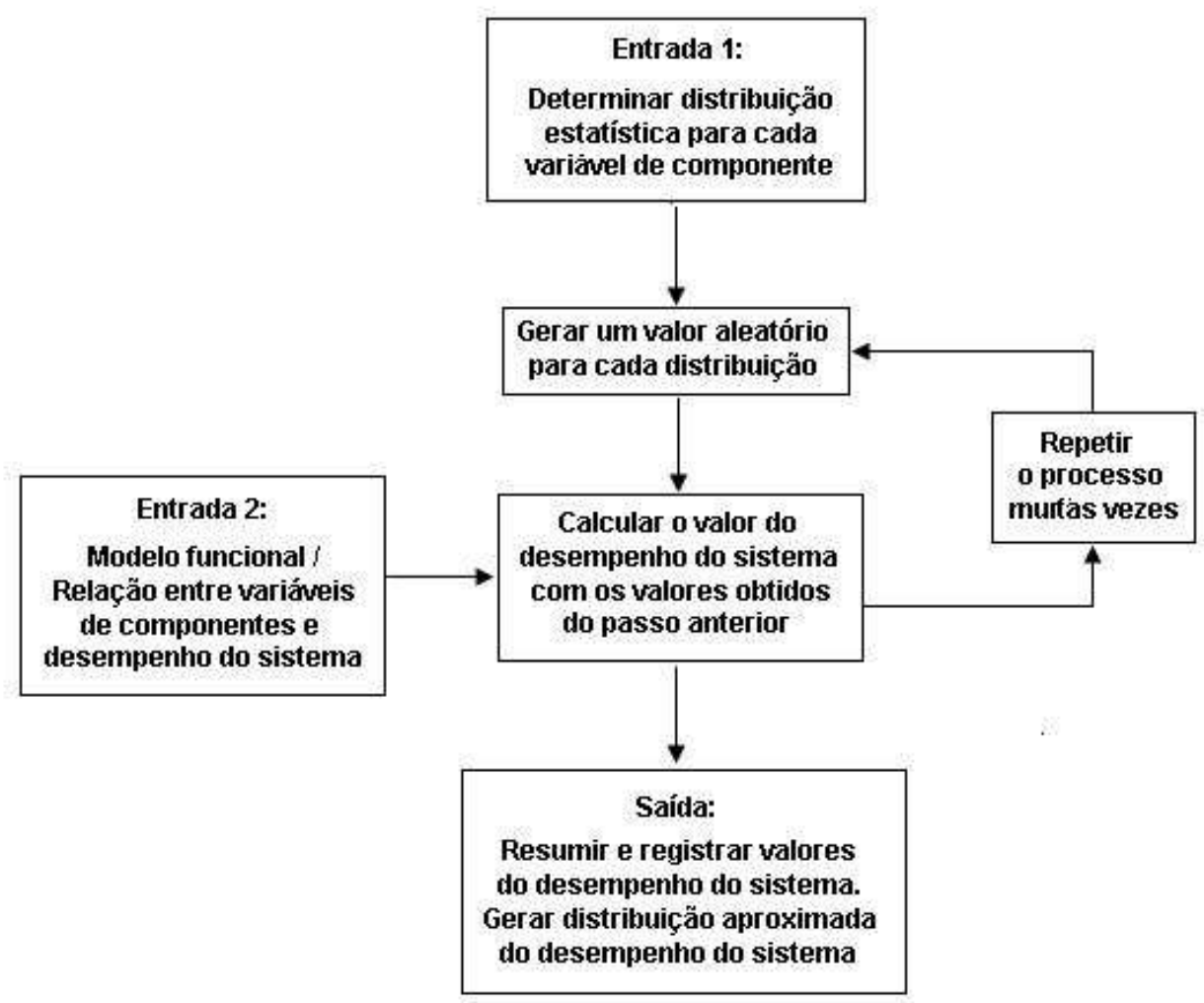

Figura 3.3: Esquema do método de simulação de Monte Carlo. Fonte: Hahn e Shapiro[ ${ }^{[4]}$ - Capítulo 7.

Um outro método de se obter números aleatórios é através do sequenciamento de números transcendentais. Os principais publicados são ${ }^{[13]}$ :

- 2556 dígitos de $e$ (National Bureau of Standards - 1951)

- 2000 dígitos de $\pi$ (Reitwiesner - 1950);

- 1312 dígitos de $\sqrt{3}$ (Uhler - 1951).

Testes estatísticos podem ser aplicados para determinar a validade dos resultados de geradores de números aleatórios através da associação destes a distribuições pré-definidas. O nível de confiança pode também ser calculado através do uso de distribuições. 


\subsection{Síntese de tolerâncias}

O processo de síntese, como já mencionado, tem objetivo inverso ao processo de análise de tolerâncias: a tolerância do conjunto deve ser distribuída entre os componentes a partir de critérios determinados. Como a tolerância do conjunto está sujeita a restrições dimensionais e/ou funcionais, os valores destas restrições são os mesmos geralmente utilizados no processo de síntese de tolerâncias. Os principais métodos de síntese são apresentados a seguir, os quais serão chamados de métodos de alocação, cuja aplicação prática é exemplificada no capítulo de resultados do estudo de caso deste trabalho.

Para todos os casos, a alocação de tolerâncias é realizada somente entre os componentes com tolerâncias determináveis. Logicamente, se houver componentes padronizados no encadeamento, a soma de suas tolerâncias deve ser considerada no conjunto, mesmo sem participação na alocação.

Para o processo de síntese de tolerâncias, são geralmente utilizados os métodos do pior caso e da raiz da soma dos quadrados, já descritos no estudo de análise de tolerâncias. As seguintes relações aplicam-se:

- Para o pior caso:

$$
T=\sum_{i=1}^{n p}\left|\frac{\partial f}{d x_{i}}\right| t_{p i}+\sum_{j=1}^{n d}\left|\frac{\partial f}{d x_{j}}\right| t_{d j}
$$

- Para a raiz da soma dos quadrados:

$$
T^{2}=\sum_{i=1}^{n p}\left(\frac{\partial f}{d x_{i}}\right)^{2} t_{p i}^{2}+\sum_{j=1}^{n d}\left(\frac{\partial f}{d x_{j}}\right)^{2} t_{d j}^{2}
$$

Para os casos de encadeamentos unidirecionais, encontrados na maioria dos casos práticos de síntese tolerâncias e objeto do exemplo de aplicação deste trabalho, as relações podem ser simplificadas pelas seguintes:

- Para o pior caso:

$$
T=\sum_{i=1}^{n p} t_{p i}+\sum_{j=1}^{n d} t_{d j}
$$

- Para a raiz da soma dos quadrados:

$$
T^{2}=\sum_{i=1}^{n p} t_{p i}^{2}+\sum_{j=1}^{n d} t_{d j}^{2}
$$

Para efeito de simplificação, as relações para os encadeamentos unidirecionais serão utilizadas a seguir para a descrição dos diversos métodos de alocação. A 
generalização para o caso geral pode ser feita com a inclusão das derivadas parciais, conforme aplicável. Na condição do pior caso a somatória das tolerâncias deve considerar o sinal positivo ou negativo das tolerâncias dos componentes, seguindo a equação fundamental do encadeamento.

\subsubsection{Alocação por tolerâncias iguais}

Neste método, a tolerância do conjunto, já adequada às restrições funcionais e diminuída das tolerâncias pré-determinadas, é dividida igualmente pelo número de componentes com tolerâncias determináveis ${ }^{[1,46]}$. Segundo Singh et al. ${ }^{[46]}$, devido à ausência de bases teóricas que o suporte, este método geralmente não apresenta resultados confiáveis, servindo apenas para uma estimativa grosseira das tolerâncias individuais. As relações para o método tornam-se:

- Para o pior caso:

$$
\begin{array}{r}
T=\sum_{i=1}^{n p} t_{p i}+n d \times t_{d j} \quad \mathrm{ou}, \\
t_{d j}=\frac{T-\sum_{i=1}^{n p} t_{p i}}{n d}
\end{array}
$$

- Para a raiz da soma dos quadrados:

$$
\begin{array}{r}
T^{2}=\sum_{i=1}^{n p} t_{p i}^{2}+n d \times t_{d}^{2} \quad \text { ou }, \\
t_{d}=\sqrt{\frac{T^{2}-\sum_{i=1}^{n p} t_{p i}^{2}}{n d}}
\end{array}
$$

Pode-se inferir, adicionalmente às críticas citadas por Singh ${ }^{[46]}$, que o método penaliza as tolerâncias de dimensões maiores em favor das tolerâncias de dimensões menores, as quais podem já estar adequadas em relação aos respectivos processos de fabricação.

\subsubsection{Alocação por fator de proporcionalidade}

Este método se inicia com a especificação de tolerâncias dos componentes por algum critério qualquer. Após o processo de análise, caso a tolerância do conjunto não atenda à restrição funcional, ela é reduzida por um fator de proporcionalidade $F_{\text {pro }}{ }^{[3,7]}$. As relações para o método tornam-se: 
- Para o pior caso:

$$
\begin{array}{r}
T=\sum_{i=1}^{n p} t_{p i}+F_{\text {pro }}\left[\sum_{j=1}^{n d} t_{d j}\right] \mathrm{ou}, \\
F_{\text {pro }}=\frac{T-\sum_{i=1}^{n p} t_{p i}}{\sum_{j=1}^{n d} t_{d j}}
\end{array}
$$

As novas tolerâncias reduzidas para atenderem ao conjunto são dadas por:

$$
t_{d j}^{\prime}=F_{p r o} t_{d j}
$$

- Para a raiz da soma dos quadrados:

$$
\begin{array}{r}
T^{2}=\sum_{i=1}^{n p} t_{p i}^{2}+F_{p r o}^{2}\left[\sum_{j=1}^{n d} t_{d j}^{2} \mathrm{ou},\right. \\
F_{\text {pro }}=\sqrt{\frac{T^{2}-\sum_{i=1}^{n p} t_{p i}^{2}}{\sum_{j=1}^{n d} t_{d j}^{2}}}
\end{array}
$$

Da mesma forma que para o método do pior caso, as novas tolerâncias reduzidas são dadas por:

$$
t_{d j}^{\prime}=F_{p r o} t_{d j}
$$

Valem para este método as mesmas críticas feitas para o método de alocação por tolerâncias iguais, pois as tolerâncias, neste caso, são também igualmente distribuídas, porém reduzidas pelo fator.

\subsubsection{Alocação por fator de precisão}

Este método parte do princípio de que peças usinadas com precisão similar apresentarão tolerâncias iguais somente se elas tiverem as mesmas dimensões. À medida que a dimensões forem aumentadas, as tolerâncias aumentarão aproximadamente com a raiz cúbica da dimensão [Fortini ${ }^{[43]}$ apud Chase $\left.{ }^{[7]}\right]$. Esta regra foi a base das normas de tolerâncias para ajustes cilíndricos [Fortini ${ }^{[43]}$ apud Singh $\left.{ }^{[46]}\right]$. O fator de precisão $F_{\text {pre }}$ é utilizado da mesma forma que o fator de proporcionalidade para a redução uniforme das tolerâncias para que atendam à restrição funcional do conjunto. A diferença entre os métodos é quanto à origem das tolerâncias: enquanto no método anterior, elas são especificadas por experiência passada ou por recorrência de normas ou manuais, neste método as 
tolerâncias são proporcionais à raiz cúbica de suas dimensões nominais. Sejam $d_{j}$ as dimensões nominais das respectivas tolerâncias determináveis $t_{d j}$ :

- Para o pior caso:

$$
\begin{array}{r}
T=\sum_{i=1}^{n p} t_{p i}+F_{p r e}\left[\sum_{j=1}^{n d} \sqrt[3]{d_{j}}\right] \mathrm{ou} \\
F_{p r e}=\frac{T-\sum_{i=1}^{n p} t_{p i}}{\sum_{j=1}^{n d} \sqrt[3]{d_{j}}}
\end{array}
$$

As tolerâncias reduzidas são dadas por:

$$
t_{d j}^{\prime}=F_{p r e} \sqrt[3]{d_{j}}
$$

- Para a raiz da soma dos quadrados:

$$
\begin{array}{r}
T^{2}=\sum_{i=1}^{n p} t_{p i}^{2}+F_{p r e}^{2}\left[\sum_{j=1}^{n d}\left(\sqrt[3]{d_{j}}\right)^{2}\right] \mathrm{ou}, \\
F_{p r e}=\sqrt{\frac{T^{2}-\sum_{i=1}^{n p} t_{p i}^{2}}{\sum_{j=1}^{n d}\left(\sqrt[3]{d_{j}}\right)^{2}}}
\end{array}
$$

Da mesma forma que no item anterior, as tolerâncias reduzidas são dadas por:

$$
t_{d j}^{\prime}=F_{p r e} \sqrt[3]{d_{j}}
$$

\subsubsection{Alocação por fatores de peso}

Neste método, fatores de peso são atribuídos a cada tolerância do encadeamento formando um banco de pesos no sistema. Através de um algoritmo, a fração correspondente do banco de pesos é distribuída a cada elemento. A atribuição de um maior fator de peso para um determinado componente significa uma maior fração do banco alocada a ele. Assim, é possível a alocação de uma maior tolerância a uma dimensão que represente um maior custo de usinagem, por exemplo, aumentando a produtividade do projeto ${ }^{[3]}$. O desenvolvimento segue rotina similar aos métodos anteriores.

Seja $F_{\text {pes }}$ o fator de peso, e seja $p_{j}$ o peso atribuído ao componente $j$ : 
- Para o pior caso:

$$
\begin{array}{r}
T=\sum_{i=1}^{n p} t_{p i}+F_{p e s}\left[\sum _ { j = 1 } ^ { n d } \left(\frac{p_{j}}{\sum_{j=1}^{n d} p_{j}} t_{d j} \mathrm{ou},\right.\right. \\
F_{p e s}=\frac{T-\sum_{i=1}^{n p} t_{p i}}{\sum_{j=1}^{n d}\left(\frac{p_{j}}{\sum_{j=1}^{n d} p_{j}}\right) t_{d j}}
\end{array}
$$

As novas tolerâncias reduzidas para atenderem ao conjunto são dadas por:

$$
t_{d j}^{\prime}=F_{p e s}\left(\frac{p_{j}}{\sum_{j=1}^{n d} p_{j}}\right) t_{d j}
$$

- Para a raiz da soma dos quadrados:

$$
\begin{array}{r}
T^{2}=\sum_{i=1}^{n p} t_{p i}^{2}+F_{p e s}^{2}\left[\sum_{j=1}^{n d}\left(\frac{p_{j}}{\sum_{j=1}^{n d} p_{j}}\right)^{2} t_{d j}^{2} \mathrm{ou},\right. \\
F_{p e s}=\sqrt{\frac{T^{2}-\sum_{i=1}^{n p} t_{p i}^{2}}{\sum_{j=1}^{n d}\left(\frac{p_{j}}{\sum_{j=1}^{n d} p_{j}}\right)^{2} t_{d j}^{2}}}
\end{array}
$$

Da mesma forma que para o método do pior caso, as novas tolerâncias reduzidas são dadas por:

$$
t_{d j}^{\prime}=F_{p e s}\left(\frac{p_{j}}{\sum_{j=1}^{n d} p_{j}}\right) t_{d j}
$$

\subsubsection{Outros tipos de alocação}

Bjorke $^{[1]}$ propõe um método de alocação proporcional ao desvio padrão do processo de fabricação de cada componente. Este método, entretanto, teria aplicação muito restrita ou inexequível pois, na fase de projeto de um novo componente os processos de fabricação ainda não estão definidos. Assim, este método não será 
considerado no presente trabalho.

\subsubsection{Alocação por otimização de custos de fabricação}

Os métodos de otimização, com foco esclusivo em custos, podem ser considerados um estágio intermediário entre os métodos de simples alocação até aqui descritos e os que consideram também requisitos de qualidade. Eles são brevemente comentados, principalmente quanto às suas limitações, já que a abordagem do custo da não qualidade é um dos focos deste trabalho.

\subsubsection{Métodos gráficos}

Os métodos gráficos são baseados em funções e parâmetros disponibilizados graficamente para os quais, através da traçagem de retas, chega-se a resultados através de pontos de intersecção. Dois métodos podem ser destacados:

1. O método de Latta ${ }^{[47]}$ apud Singh et al. ${ }^{[46]}$ seria o primeiro método de alocação vinculado ao mínimo custo, que consiste na traçagem de retas paralelas, por tentativa e erro, para que tangenciem curvas tolerância/custo. Os valores de tolerância são então utilizados nas equações de síntese de tolerâncias já referidas;

2. O método de Peters ${ }^{[4]}$ apud Bjorke ${ }^{[1]}$, no qual as tolerâncias são distribuídas em função dos respectivos custos - que consideram a fração rejeitada e o desvio padrão dos processos. O gráfico consiste em várias curvas representativas de funções, cujos pontos de intersecção com retas definidas por parâmetros fornecem os valores a serem utilizados nas equações de alocação. A grande limitação do método é a consideração de apenas dois componentes no conjunto. Conjuntos maiores devem considerar o artifício da união de subconjuntos de dois componentes.

Como crítica aos métodos, pode-se destacar a imprecisão dos resultados na manipulação de dados gráficos, que pode levar a diferentes interpretações pessoais. Outra limitação importante seria a dificuldade, ou impossibilidade de sua aplicação em algoritmos para uso em programas de cálculo por computador devido à necessidade de solução simultânea de equações não lineares. 


\subsubsection{Métodos baseados em multiplicadores de Lagrange}

Os multiplicadores de Lagrange são métodos comumente utilizados em processos de otimização. Seu princípio se baseia na seguinte afirmação ${ }^{[26]}$ : Seja a equação:

$$
L E=U_{1}(x, y, z)+\lambda_{1} \Psi_{1}(x, y, z)+\lambda_{2} \Psi_{2}(x, y, z)
$$

onde:

- LE é a expressão de Lagrange;

- $U=U_{1}(x, y, z)$ é a função objetivo;

- $\Psi_{1}=\Psi_{1}(x, y, z)$ e $\Psi_{2}=\Psi_{2}(x, y, z)$ são restrições funcionais;

- $\lambda_{1}$ e $\lambda_{2}$ são multiplicadores de Lagrange.

Para o ponto ótimo da função, as seguintes condições devem ser satisfeitas:

$$
\frac{\partial L E}{\partial x}=0 \quad \frac{\partial L E}{\partial y}=0 \quad \frac{\partial L E}{\partial z}=0 \quad \frac{\partial L E}{\partial \lambda_{1}}=0 \quad \frac{\partial L E}{\partial \lambda_{2}}=0
$$

No caso de síntese de tolerâncias otimizada em relação a custos, as derivadas podem ser escritas, para o caso geral de uma única restrição funcional:

$$
\frac{\partial}{\partial t_{i}}[C(t)]+\lambda \frac{\partial}{\partial t_{i}}[R f(t)]=0 \quad(i=1, \cdots, n)
$$

Onde:

- $C(t)$ é a função custo-tolerância aplicável;

- $R f(t)$ é a função restrição funcional.

Assim, o valor de $\lambda$ pode ser obtido em função de uma determinada tolerância:

$$
\lambda=h\left(t_{i}\right)=h\left(t_{1}\right)=h\left(t_{2}\right)=\cdots
$$

Em seguida os valores de $t_{1}$ e das demais tolerâncias podem ser obtidos. Para múltiplas restrições $\lambda_{j}(j=1, \cdots, m)$, o número de equações seria multiplicado pelo número $m$ de restrições. Como exemplo, pode-se utilizar o caso ilustrado por Singh $^{[46]}$ para a equação de custo da forma $C(t)=a+b / t$ para cada componente:

- Para a condição do pior caso:

$$
\frac{\partial}{\partial t_{i}}\left[\sum\left(a_{i}+\frac{b_{i}}{t_{i}}\right)\right]+\lambda \frac{\partial}{\partial t_{i}}\left[\sum t_{i}-T\right]=0
$$


que gera o valor do muliplicador de Lagrange $\lambda=\frac{b_{i}}{t_{i}^{2}}$

Eliminando-se $\lambda$ da equação expressando-o em termos de uma tolerância qualquer, como $\lambda=\frac{b_{1}}{t_{i}^{2}}$, todas as tolerâncias individuais podem ser obtidas em termos de $t_{1}$ e expressas por:

$$
t_{i}=\left(\frac{b_{i}}{b_{1}}\right)^{\frac{1}{2}} t_{1}
$$

Utilizando-se a condição do encadeamento do conjunto, a tolerância $t_{1}$ pode ser obtida através da relação:

$$
T=\sum_{i=1}^{n} t_{i}=t_{1}+\sum_{i=2}^{n}\left(\frac{b_{i}}{b_{1}}\right)^{\frac{1}{2}} t_{1}=t_{1}\left[1+\sum_{i=2}^{n}\left(\frac{b_{i}}{b_{1}}\right)^{\frac{1}{2}}\right]
$$

A partir do valor conhecido de $t_{1}$, todos os outros valores de tolerâncias de componentes podem ser obtidos.

- Para a condição da raiz da soma dos quadrados

$$
\frac{\partial}{\partial t_{i}}\left[\sum\left(a_{i}+\frac{b_{i}}{t_{i}}\right)\right]+\lambda \frac{\partial}{\partial t_{i}}\left[\sum t_{i}^{2}-T^{2}\right]=0
$$

que gera o valor do muliplicador de Lagrange $\lambda=\frac{b_{i}}{t_{i}^{3}}$

Eliminando-se $\lambda$ da equação expressando-o em termos de uma tolerância qualquer, como $\lambda=\frac{b_{1}}{t_{i}^{3}}$, todas as tolerâncias individuais podem ser obtidas em termos de $t_{1}$ e expressas por:

$$
t_{i}=\left(\frac{b_{i}}{b_{1}}\right)^{\frac{1}{3}} t_{1}
$$

Utilizando-se a condição do encadeamento do conjunto, a tolerância $t_{1}$ pode ser obtida através da relação:

$$
T^{2}=\sum_{i=1}^{n} t_{i}^{2}=t_{1}+\sum_{i=2}^{n}\left(\frac{b_{i}}{b_{1}}\right)^{\frac{2}{3}} t_{1}^{2}=t_{1}^{2}\left[1+\sum_{i=2}^{n}\left(\frac{b_{i}}{b_{1}}\right)^{\frac{2}{3}}\right]
$$

Da mesma forma que para a condição do pior caso, a partir do valor conhecido de $t_{1}$, todos os outros valores de tolerâncias de componentes podem ser obtidos.

Outras referências, como Chase et al. ${ }^{[49]}$ e Kumar ${ }^{[50]}$, apresentam desenvolvimentos similares para outras funções custo-tolerância. Embora a aplicação deste método seja relativamente simples e direta, as seguintes limitações devem ser levadas em consideração: 
1. Pode ser aplicada somente para funções custo-tolerância relativamente simples;

2. Não pode ser aplicada para funções custo-tolerância descontínuas e/ou não deriváveis;

3. Não são admitidos limites de precisão de processos para tolerâncias, como considera o estudo de caso deste trabalho;

4. É de difícil aplicação para condições que não sejam a do pior caso e da raiz da soma dos quadrados;

5. Não pode ser aplicada para encadeamentos inter-relacionados, pois haveria a necessidade da solução simultânea de equações não lineares.

Segundo Singh et al. ${ }^{[46]}$, alguns artifícios podem ser considerados para contornar algumas limitações:

- Em relação ao item 3, os limites inferiores das tolerâncias resultantes do processo de otimização, caso inferiores aos limites dos processos podem ser ajustados para o valor especificado e novo cálculo deve ser realizado até que valores adequados sejam conseguidos. Este procedimento também é aplicável para os limites superiores;

- Para os encadeamentos inter-relacionados referidos no item 5, pode ser tentada uma solução iterativa através da solução de cada encadeamento isoladamente, porém não há garantia de que o cálculo convirja em todos os casos.

Pode-se então concluir que a aplicação deste método deve ser considerada, preferivelmente, nos casos de encadeamentos simples, sujeitos a equações custotolerância também simples. A restrição quanto aos limites de precisão dos processos, que não podem ser pré-determinados, pode ser o maior fator limitante ao seu uso.

\subsubsection{Otimização por algoritmos genéticos}

Este método se baseia em um algoritmo de busca direta e de seleção probabilística, imitando os mecanismos de seleção natural. Ele aproveita características de robustez, eficiência e flexibilidade de sistemas biológicos em sistemas artificiais utilizando, inclusive, muita de sua terminologia. Seu funcionamento pode ser resumido nas seguintes etapas ${ }^{[11]}$ : 
- Inicia-se com uma população de possíveis soluções, em vez de uma única utilizada por outros métodos;

- A população inicia a formação e troca de informações através de seleção probabilística e permutação, similarmente aos processos naturais, a cada iteração (ou geração);

- Boas soluções, as que resultem em redução na função objetivo, são reproduzidas, enquanto outras más são eliminadas, de modo similar à "sobrevivência do mais adaptado" na natureza;

- Após um número de gerações, a população convergirá para um valor mínimo global.

Os requisitos para os problemas de otimização resolvidos pelo método são:

- Um método para a representação da potencial solução;

- Um método para a criação da população de soluções;

- Uma função objetivo para a verificação da adequação da potencial solução;

- Operadores para modificar a potencial solução inicial e as subsequentes.

O método difere de outros de otimização e busca na característica que trabalham com a codificação das variáveis de projeto e não com as próprias variáveis; ele pesquisa uma população de pontos no espaço de projeto e não de um pequeno número; usa informações da função objetivo; utiliza regras de transição probabilísticas para a seleção da potencial solução. A implementação do método segue os seguintes passos:

1. Selecionar um esquema apropriado para codificação das variáveis de projeto. O código binário é o usual. A variável codificada é chamada de cromossoma ou indivíduo;

2. Inicializar a população de potenciais soluções ou indivíduos;

3. Selecionar um indivíduo de uma subpopulação de indivíduos com base nos valores de ajustamento à função objetivo, chamada função de ajustamento. Similarmente, selecionar outro indivíduo e cruzá-los para criar dois outros com uma determinada probabilidade de cruzamento. Para cada indivíduo, aplicar mutação com determinada probabilidade; 
4. Substituir indivíduos velhos pelos novos gerados no passo 3. Repetir o passo 3 até que o número de indivíduos se iguale ao número da população;

5. Repetir os passos 3 e 4 até que o número especificado de gerações seja alcançado.

O método é tratado de forma similar em diversos artigos: os de Lee e Johnson ${ }^{[52]}$, Shan et $\mathrm{a}^{[53]}$ e de Ansary e Deiab ${ }^{[51]}$. Como pode-se observar, este método exige o desenvolvimento de algorítmo complexo específico para cada caso estudado, sendo de difícil aplicação prática. Outras limitações, tais como a de restrição a valores mínimos de tolerâncias exequíveis por processos devem ser também consideradas.

\subsubsection{Métodos para otimização simultânea de custos de fa- bricação e custos da não qualidade}

Os métodos para otimização de custos que incorporam os custos da não qualidade foram propostos em diversos artigos ${ }^{[5,54-58]}$ e são de particular interesse para este trabalho, haja vista a concordância de objetivos. O princípio básico de todos os trabalhos sobre o assunto é o de encontrar o conjunto de valores de tolerância dos componentes que produza, no processo de síntese, o mínimo custo total formado pelos custos de fabricação $C_{i}\left(t_{i}\right)$ e da não qualidade $C q_{i}$ :

$$
C T=\sum_{i=1}^{n} C_{i}\left(t_{i}\right)+\sum_{i=1}^{n} C q_{i}
$$

A tolerância do conjunto deve respeitar a uma ou mais restrições funcionais:

$$
T \leq R_{f}
$$

A Figura 3.4 ilustra graficamente a equação. Numa comparação qualitativa de todas as referências citadas, pode-se notar uma coincidência na abordagem teórica, com variações apenas nas equações de custo, nos exemplos práticos e em considerações adicionais específicas:

- Cheng et al. ${ }^{[5]}$ discutem a sensibilidade do sistema quanto à variação da média e da variância das distribuições das tolerâncias dos componentes, concluindo que o deslocamento da média afeta apenas a função perda de qualidade, ao passo que a alteração na variância afeta também, além da função perda de qualidade, a função custo e os resultados da otimização;

- Y. M. Huang et al. ${ }^{[56]}$ incluem no processo de otimização o índice de confiabilidade; 


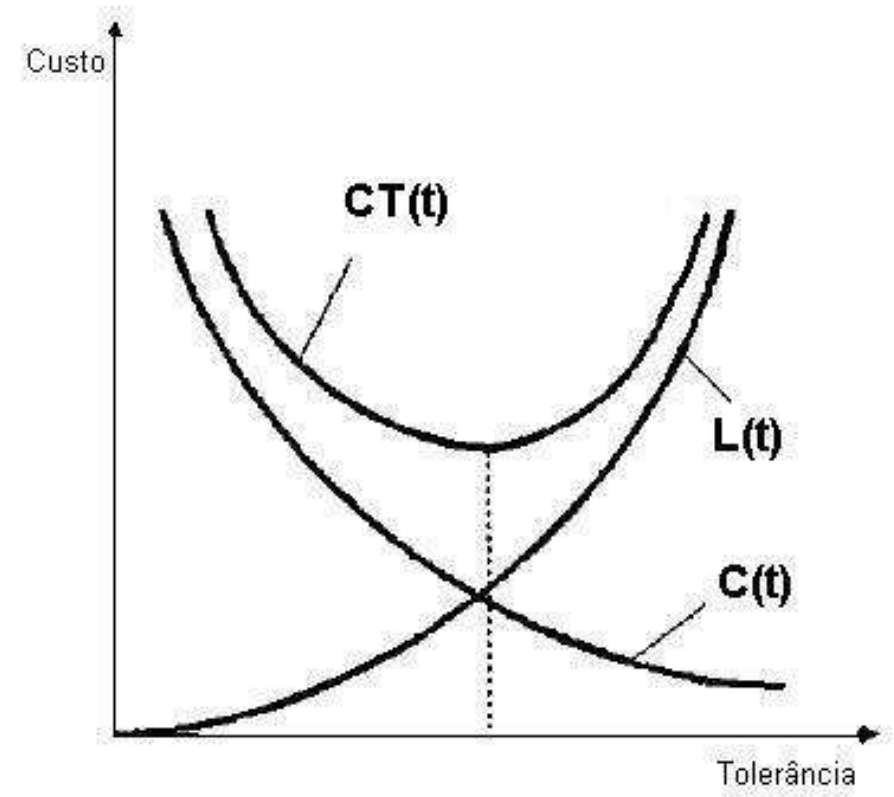

Figura 3.4: Representação gráfica da soma dos custos de fabricação $C(t)$ e da não qualidade $L(t)$. Fonte: Choi et al. ${ }^{[5]}$.

- M. F. Huang et al. ${ }^{[58]}$ consideram exemplo de aplicação de múltiplas restrições funcionais;

- Peng et al. ${ }^{[57]}$ consideram o conceito de valor presente na aplicação da função perda de qualidade para simular o efeito do desgaste no uso do produto.

Em todos os trabalhos são apresentados apenas os dados de entrada dos exemplos e os seus resultados. Informações sobre os programas de otimização não são fornecidas.

Podem-se colocar também, para a abordagem de otimização considerada em todas as referências, os seguintes quetionamentos conceituais:

1. O custo da não qualidade obtido é resultante, pela própria configuração do sistema, do processo de otimização. Portanto, não é permitido um controle externo sobre seu valor como, por exemplo, pela adoção do fator de segurança econômico proposto por Taguchi ${ }^{[28]}$.

2. Não é evidenciada, nos trabalhos analisados, a possibilidade de restrição do valor mínimo das tolerâncias dos componentes, a fim de que possa ser realizada uma seleção de processos de fabricação exequíveis para o determinado local de produção. 
A análise dessas problemáticas muito influenciaram na elaboração da proposta de otimização do presente trabalho.

\subsection{Considerações sobre desvios da média das dis- tribuições}

Os métodos de análise e síntese apresentados baseiam-se na suposição de que as distribuições estatísticas dos processos de fabricação dos componentes correspondam a uma faixa de aceitação de $\pm 3 \sigma$, ou aproximadamente $99,73 \%$ da população, com médias posicionadas no centro das distribuições. Devido à ocorrência de tendências devidas a características dos processos reais de produção, variações nestas suposições devem ser levadas em consideração ${ }^{[7,40,41]}$. Algumas sugestões são apresentadas a seguir:

- Bender ${ }^{[59]}$ apud Nigam e Turner ${ }^{[40]}$ propôs um fator igual a 1,5 como multiplicador do resultado do desvio padrão de análises pelo método da raiz da soma dos quadrados, com base apenas na sua experiência;

- Mansoor ${ }^{[60]}$ apud Chase e Parkinson ${ }^{[41]}$ propôs que o encadeamento de tolerâncias fosse representado por uma combinação dos métodos do pior caso com o método da raiz da soma dos quadrados:

$$
T=\sum t p_{i}-\sum t_{i}+\left[\sum t_{i}^{2}\right]^{1 / 2}
$$

onde:

$T$ é a tolerância do conjunto;

$t_{i}$ é a tolerância dos componentes;

$t p_{i}$ é a tolerância obtida no processo do componente $i$.

- Chase e Greenwood ${ }^{[7]}$ propuseram o uso de um fator de correção $m s_{i}$ que chamaram "desvio estimado da média" (estimated mean shift):

$$
\left.T=\sum t_{i}+\left[\sum\left(1-m s_{i}\right)^{2} t_{i}^{2}\right)\right]^{1 / 2}
$$

Segundo os autores, o valor do fator de correção deve variar entre 0 e 1. Para processos sob maior controle eles sugerem um valor entre 0,1 e 0,2. Para processos menos conhecidos ou de novos fornecedores o valor sugerido varia entre 0,7 e 0,8 . Um exame da equação 3.54 mostra que seu primeiro termo representa o método do pior caso e o segundo o método da raiz da soma dos quadrados afetado pelo fator de correção. Para $m s_{i}=1$, a equação 
representa integralmente o método do pior caso.

Pode-se inferir, com base nas sugestões apresentadas, que sua aplicação dependerá do conhecimento e do controle realizado nos processos de cada caso específico. As relações acima descritas, portanto, podem ser úteis quando dados reais de processos estiverem disponíveis. 


\section{Considerações sobre custos de fabricação}

A especificação de tolerâncias dimensionais e de acabamento superficial tem influência significativa na formação do custo de componentes mecânicos e é, portanto, um dos fatores que muito colabora na busca pela competitividade do produto.

Pode-se observar, através de pesquisa bibliográfica, que a consideração de tolerâncias dimensionais no estudo do custo de produtos iniciou-se na década de 1960. De fato, Alford ${ }^{[61]}$, em obra especializada no assunto, não faz nenhuma menção sobre a relação precisão dimensional/custo. Wade ${ }^{[44]}$ foi um dos primeiros autores a abordar a matéria de forma clara e objetiva.

\subsection{Relações tolerância-custo}

Swift ${ }^{[6]}$ apresenta um modelo geral $M_{i}$ para a formação do custo de um componente, que se baseia no volume do material e em considerações de processos utilizados na fabricação de um componente:

$$
M_{i}=V \cdot C m t+R c \cdot P c
$$

onde:

- $V=$ volume necessário de material para a produção do componente;

- $C m t=$ custo do material por unidade de volume na forma requerida;

- $P c=$ custo básico de processamento para um projeto ideal do componente por um processo específico;

- $R c=$ coeficiente de custo relativo atribuído a um projeto de componente (considerando-se a complexidade de forma, adequação do material para o 
processo, dimensões da seção, tolerâncias dimensionais e acabamento superficial).

A equação 4.1 pode ser generalizada para vários processos consecutivos necessários à fabricação do componente, resultando em:

$$
M_{i}=V \cdot C m t+\sum_{i=1}^{n o} R c_{i} \cdot P c_{i}
$$

onde:

no = número de operações necessárias para a obtenção do componente acabado. Na Equação 4.2, os fatores $V, C m t$ e $P c$ dependem das condições específicas do componente e do fabricante para cada caso. O fator de interesse para o contexto deste trabalho é o coeficiente de custo relativo, que pode ser calculado pela equação:

$$
R c=C m p \cdot C c \cdot C s \cdot C f t
$$

onde:

- $C m p=$ custo relativo associado à adequação material-processo;

- $C c=$ custo relativo associado à produção de componentes em função da complexidade geométrica;

- $C s=$ custo relativo associado com considerações de tamanho e redução da seção/espessura do componente;

- $C f t=$ maior valor entre $C f$ e $C t$;

- $C t=$ custo relativo associado com a obtenção de uma tolerância especificada;

- $C f=$ custo relativo associado com a obtenção de um acabamento superficial especificado.

A Figura 4.1 ilustra os gráficos para obtenção dos coeficientes $C f$ e $C t$, especificamente para processos de usinagem. Gráficos desses coeficientes para vários outros processos de fabricação também podem ser encontrados na mesma referência.

Trucks $^{[2]}$ fornece outro gráfico útil, ilustrado na Figura 4.2, onde são incluídos processos adequados para campos usuais de tolerância utilizados na fabricação de componentes mecânicos. Bjorke ${ }^{[1]}$ também fornece modelo para um processo isolado - Figura 4.3.

Observa-se que o custo pode ser dividido em dois componentes: 

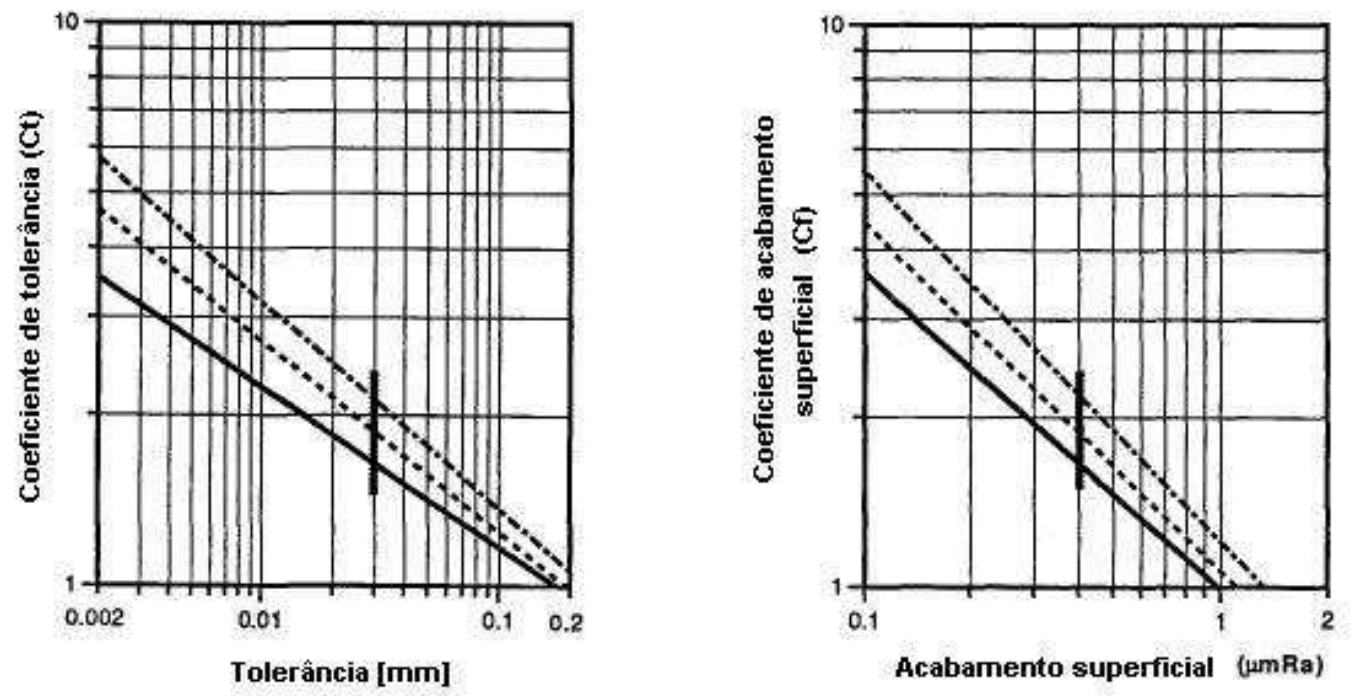

Figura 4.1: Coeficientes de tolerância e de acabamento superficial para processos de usinagem. Fonte: Swift ${ }^{[6]}$.

1. Custo de usinagem que considera: o tempo real para a obtenção de um elemento básico aceitável, despesas diversas de produção, calibres, ferramentas, fixadores, tempo de controle etc. Este componente de custo aumenta com a redução das tolerâncias, já que para a obtenção desta redução, são necessários ajustes (set-ups) e operações adicionais, dispositivos de controle mais caros etc.;

2. Custo de rejeição que ocorre sempre que a dimensão foge da tolerância especificada. Este componente de custo consiste ou no custo do retrabalho para deixar a peça em conformidade à especificação ou no custo de descarte. Quando o campo de tolerância especificado é amplo em relação à capacidade do processo, o custo de rejeição torna-se desprezível.

Como pode ser observado nas Figuras 4.1, 4.2 e 4.3, os valores dos coeficientes, e consequentemente o custo do componente, aumentam em relação direta com o aumento da precisão exigida no processo: quanto menor o valor da tolerância ou da rugosidade superficial especificadas, maior o custo do componente, independentemente de outros fatores, tais como material, forma, volume e complexidade da peça. ${ }^{1}$ Wade $^{[44]}$ e Balakshin ${ }^{[11]}$ apresentam gráficos similares aos apresentados,

\footnotetext{
${ }^{1}$ Este é o caso geral encontrado na prática industrial e na totalidade das obras sobre tolerâncias convencionais de fabricação. Casos especiais, como o citado por Nakazawa ${ }^{[62]}$, não serão considerados neste trabalho. Ele afirma que a noção de que a usinagem de alta precisão apresenta maior custo está incorreta e ilustra o caso de um motor à gasolina de um aeromodelo. Segundo o autor, se a folga entre pistão e cilindro for usinada para que fique suficientemente pequena, haverá uma redução de custos de $25 \%$ devido à eliminação dos anéis. Além deste
} 


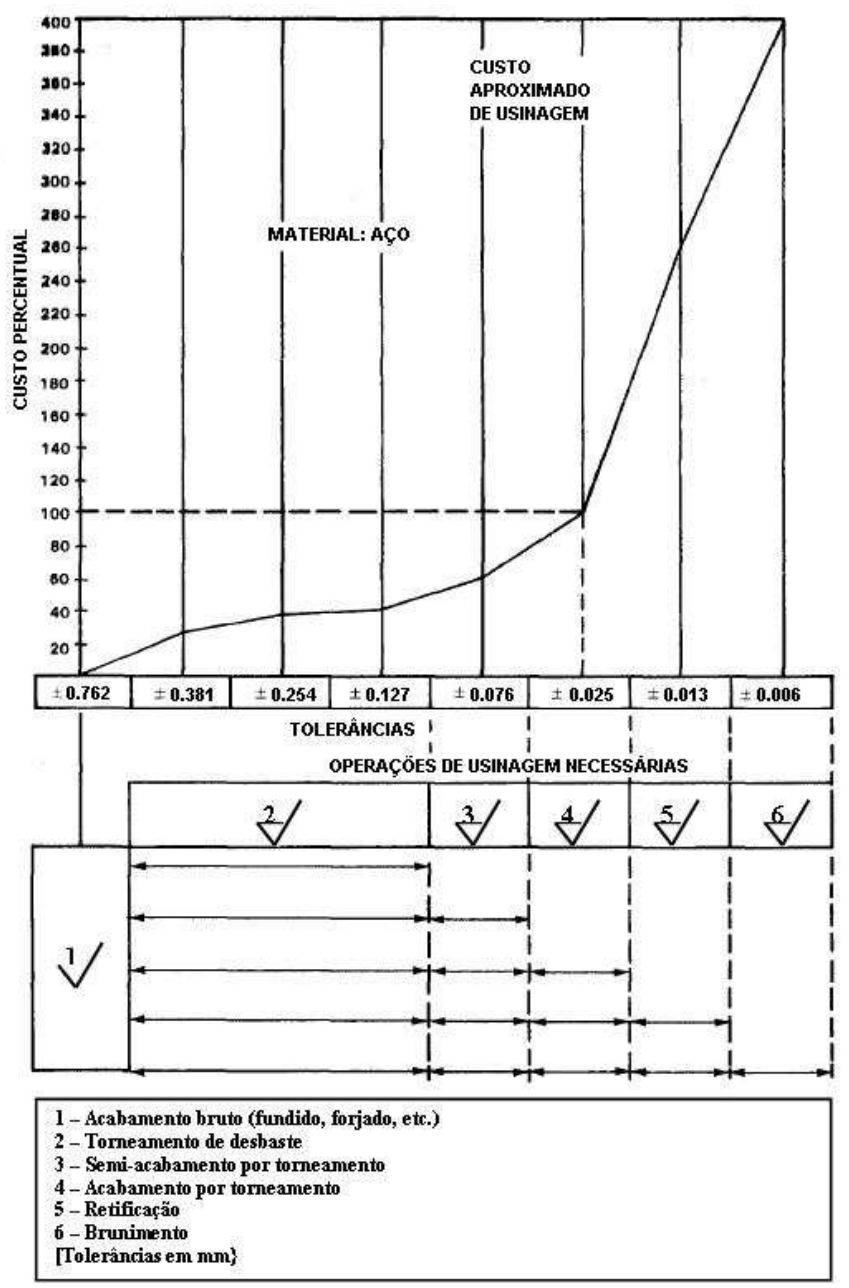

Figura 4.2: Custos relativos em função da tolerância de usinagem. Fonte: Trucks ${ }^{[2]}$.

nos quais se pode notar uma curva exponencial cuja inclinação é pequena para valores maiores de tolerâncias e que aumenta abruptamente a partir de determinada faixa de tolerâncias menores. Esta característica é de grande importância na realização de um projeto econômico e na elaboração de sistemas de otimização, como será visto adiante neste trabalho. Para que os gráficos apresentados possam ser utilizados no processo de otimização de tolerâncias, seus dados devem ser relacionados por equações que viabilizem a sua utilização em rotinas internas de cálculo dos algoritmos adotados para esta finalidade. Chase et al. ${ }^{[9]}$ apresentam uma compilação de sugestões de vários pesquisadores do assunto. Alguns foram selecionados e são apresentados na Tabela 4.1.

onde:

- A é uma constante que representa o custo fixo e inclui as atividades de ajuste (set-up), ferramental, operações anteriores etc;

fato haverá um ganho de potência pela redução do atrito e a montagem e a desmontagem serão também facilitadas pela ausência dos anéis. 


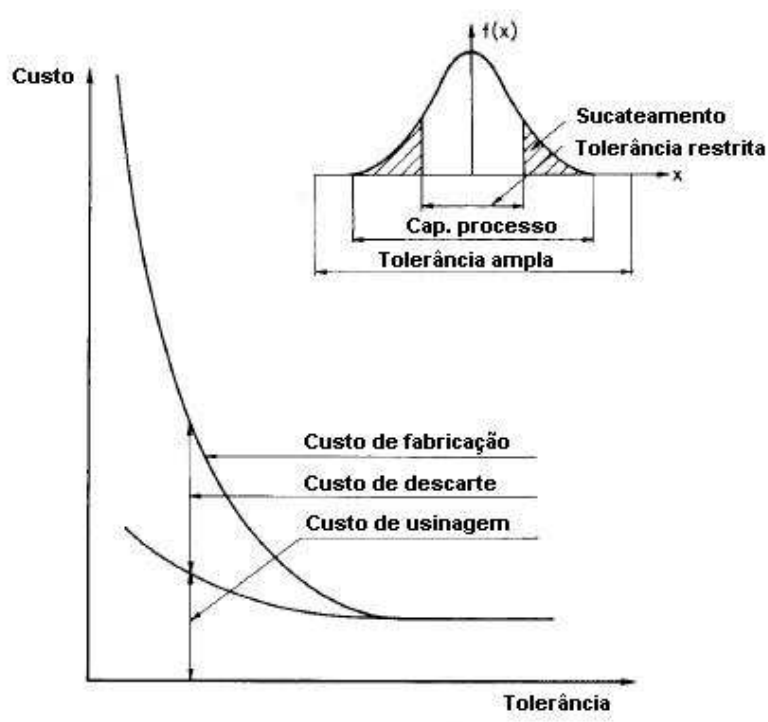

Figura 4.3: Custo de fabricação e seus componentes em função da tolerância para um processo isolado. Fonte: Bjorke ${ }^{[1]}$.

Tabela 4.1: Propostas de modelos custo-tolerância. Fonte: Chase et al. ${ }^{[7]}$

\begin{tabular}{|c|c|c|}
\hline Tipo & Modelo de custo & Autor \\
\hline Recíproco quadrado & $A+B / t^{2}$ & Spotts $^{[63]}$ \\
\hline Recíproco & $A+B / t$ & Chase e Greenwood $^{[64]}$ \\
\hline Exponencial & $A \cdot e^{-B t}$ & Speckhart $^{[65]}$ \\
\hline
\end{tabular}

- $B$ é uma constante que determina o custo para a produção de uma dimensão isolada do componente conforme determinada tolerância;

- $t$ é a variável tolerância.

A grande dificuldade no tratamento do problema envolvendo custos e tolerâncias de fabricação é que eles são dependentes das condições locais de fabricação e por isso não são disponibilizados. Mesmo empresas que se utilizam dos mesmos equipamentos podem apresentar valores diferentes em diferentes unidades de manufatura. Algumas vezes também estes custos podem ser considerados como itens estratégicos de concorrência comercial. Outro fator que influencia favoravelmente no custo real ou absoluto de um componente é sua escala de produção: o custo do material e de insumos é geralmente menor para uma maior quantidade produzida devido a fatores de negociação comercial, também, o processo é ajustado para um maior tamanho de lote, ou seja, o custo relacionado ao tempo de ajuste do processo (set-up) é rateado por um número maior de peças. Porém, para a finalidade a que se destina este trabalho de análise e otimização, somente os custos 
relativos em função das tolerâncias dimensionais devem ser considerados.

Chase e Greenwood ${ }^{[7]}$ citam um trabalho de Jamielson baseado em estudos governamentais (EUA) de custos relativos determinados por diferentes processos de remoção de material. Os resultados experimentais, ilustrados na Figura 4.4, aparecem comparados a dados submetidos à regressão linear através dos modelos citados na Tabela 4.1. Dong et al. ${ }^{[66]}$ apresentam outros modelos custo-tolerância

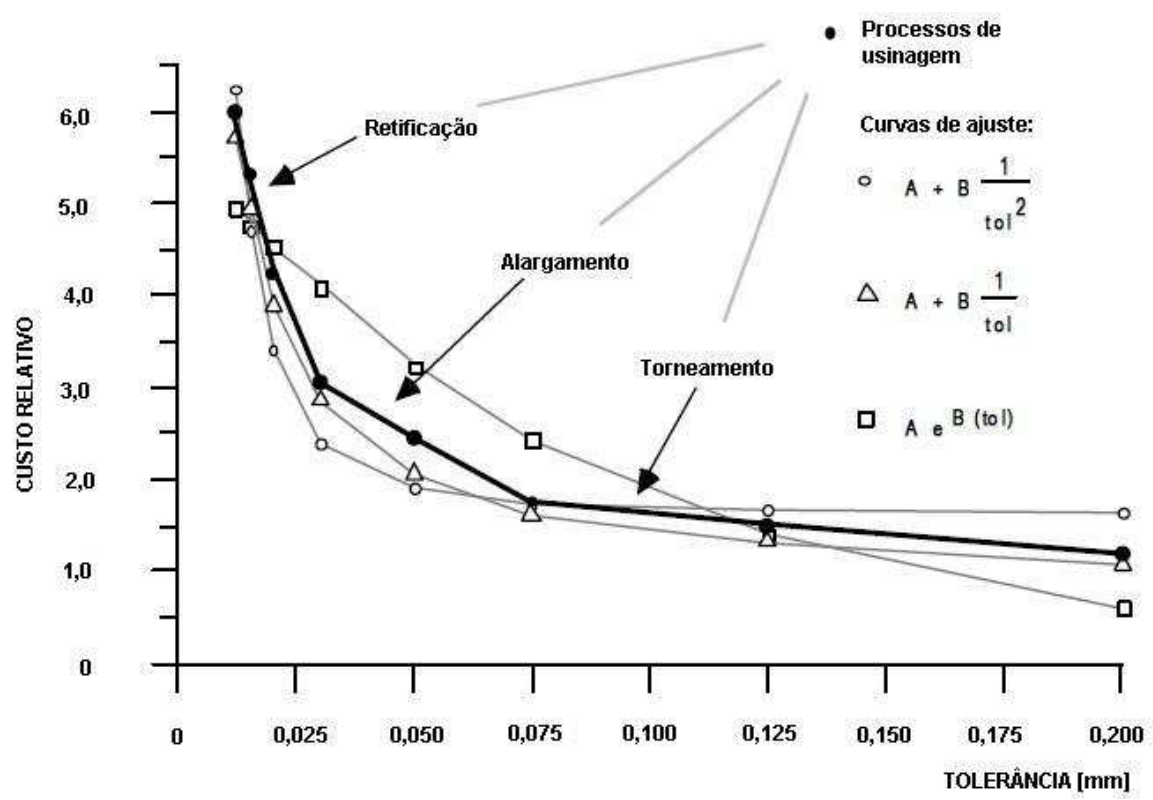

Figura 4.4: Comparação de modelos tolerância x custo com dados experimentais. Fonte: Chase e Greenwood ${ }^{[7]}$

híbridos e polinomiais que, segundo os autores, fornecem maior precisão no ajuste das curvas empíricas.

Alguns outros trabalhos contemplam os custos relativos em função das tolerâncias de fabricação, principalmente para utilização na elaboração de programas de CAD. Dimitrellou et al. ${ }^{[67]}$, Nieminen e Tuomi ${ }^{[68]}$ relacionam o custo relativo em função da tolerância de fabricação e de diferentes formas de peças.

\subsection{Algoritmo para o cálculo do custo relativo da tolerância}

Desde que os dados de custos relativos a tolerâncias de fabricação sejam dependentes de fatores e condições específicas do local nos quais os componentes são produzidos, as relações precisas custo-tolerância podem ser somente definidas através das condições específicas do local de produção. O uso de relações simples, tais como as descritas na Tabela 4.1 são passíveis de erros de ajuste significativos e relação a dados empíricos, conforme Dong et al. ${ }^{[66]}$. Para a elaboração deste 
trabalho e demonstração da viabilidade de seus resultados, procurou-se obter uma solução alternativa através de pesquisa de dados empíricos disponíveis na literatura sobre o assunto, a fim de que se obtivesse o comportamento ou forma de curva, genéricos para a representação. Porém, caso outros estudos específicos relativos a custo estejam disponíveis, as equações disponibilizadas podem ser facilmente adaptadas às novas condições. Os conceitos fundamentais na dispo-

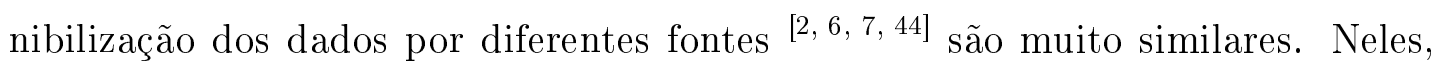
pode-se observar as seguintes características:

1. Os dados são baseados em custos relativos a partir de um valor de tolerância como base de referência. Estes valores são diferentes em cada fonte;

2. A função custo é continuamente ascendente com o aumento da precisão ou diminuição do valor da tolerância. Este fator é fundamental para o desenvolvimento da proposta do trabalho, pois a ausência de valores mínimos intermediários facilita o desenvolvimento do algoritmo;

3. A consideração da condição de linearidade para cada intervalo de tolerâncias onde são definidos os valores da função custo não resulta em erros significativos em relação ao ajuste não linear dos pontos - por exemplo, através de métodos polinomiais - haja vista a forma da curva citada no item anterior. A condição de linearidade da curva em cada intervalo diminui consideravelmente o tempo de processamento do programa de otimização;

4. Os valores diferenciais encontrados nas citadas fontes apresentam variações consistentes com a sua ordem de grandeza. Os resultados registrados em negrito na Tabela 4.2 foram obtidos pela divisão, na coluna relativa à cada fonte, de valores de custo relativo às respectivas tolerâncias, já que o valor de referência é diferente em cada fonte. Pode-se observar que as diferenças entre valores são pequenas.

O custo real de qualquer tolerância $C r_{i}$ pode ser obtido pela multiplicação do custo real da tolerância de referência $C r_{\text {ref }}$ pelo seu respectivo custo relativo $C_{i}$ :

$$
C r_{i}=C r_{r e f} \times C_{i}
$$

Os intervalos de tolerâncias, nos quais a função custo varia linearmente, estão ilustrados na Figura 4.5, conforme proposta para o desenvolvimento do algoritmo mostrado na Figura 4.6. 
Tabela 4.2: Valores de tolerância calculados por interpolação linear a partir de gráficos custo relativo-tolerância de três fontes bibliográficas

\begin{tabular}{|c|c|c|c|c|}
\hline & Fonte & Chase $^{[7]}$ & Trucks $^{[2]}$ & Wade $^{[44]}$ \\
\hline Item & Tolerância $[\mathrm{mm}$ & \multicolumn{3}{|c|}{ Custo relativo ao valor base de referência } \\
\hline 1 & 0,018 & 4,8 & 1,9 & - \\
\hline 2 & 0,06 & 2,2 & 0,9 & 10,3 \\
\hline 3 & 0,20 & 1,1 & 0,4 & 3,8 \\
\hline 4 & 0,50 & - & 0,2 & 1,7 \\
\hline \multicolumn{2}{|c|}{ Valor de referência $[\mathrm{mm}]$} & 0,20 & 0,025 & 0,76 \\
\hline \multicolumn{5}{|c|}{ Relações entre valores de custo relativo de itens de cada fonte } \\
\hline & $1 / 2$ & 2,2 & 2,1 & - \\
\hline & $1 / 3$ & 4,3 & 4,7 & - \\
\hline & $1 / 4$ & - & 9,5 & - \\
\hline & $2 / 3$ & 2,0 & 2,2 & 2,7 \\
\hline & $2 / 4$ & - & 4,5 & 6,0 \\
\hline & $3 / 4$ & - & 2,0 & 2,2 \\
\hline
\end{tabular}

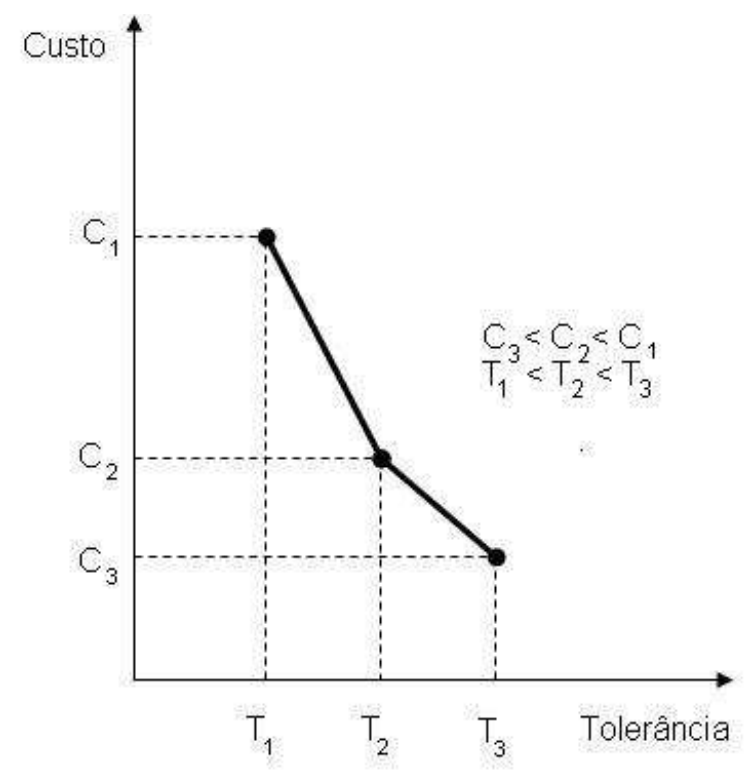

Figura 4.5: Gráfico Custo x Tolerância. 


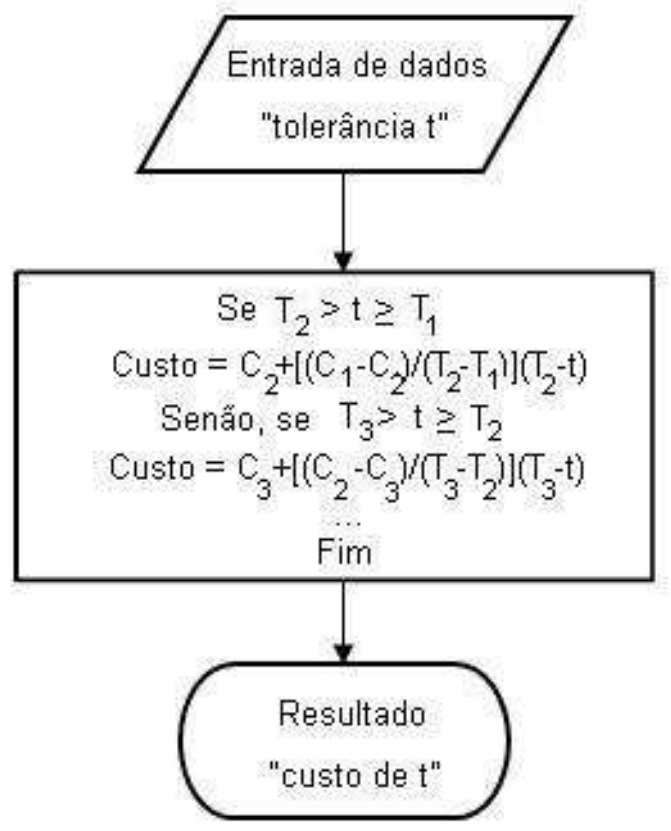

Figura 4.6: Algoritmo para cálculo da função custo relativo. 


\section{Custo da não-qualidade}

A abordagem do custo da não-qualidade, também denominado perda de qualidade (quality loss), foi concebida por Genichi Taguchi. Ela consiste no estudo da interação entre qualidade de um produto e o custo que ele ocasiona a seu usuário, ou seja, o custo relativo à perda de função por problemas de qualidade. Segundo Taguchi et al. ${ }^{[8] ~ " P e r d a ~ d e ~ q u a l i d a d e ~ e ́ ~ d e f i n i d a ~ c o m o ~ a ~ p e r d a ~ q u e ~ u m ~}$ produto custa à sociedade a partir do momento que ele é liberado para despacho. Perdas tais como falha na função, riscos à saúde, poluição, custos operacionais e custos de manutenção estão todos incluídos"; "o preço representa a perda por ocasião da compra e baixa qualidade representa uma perda adicional ao cliente durante o uso do produto. A meta da Engenharia da Qualidade deve ser a de reduzir a perda total ao cliente. Muitas empresas ainda utilizam a porcentagem de defeitos como medida de qualidade. Produtos defeituosos, entretanto, não são geralmente embarcados. Somente os produtos entregues causam problemas de qualidade aos clientes. Por esta razão, a perda causada por produtos defeituosos não embarcados devem ser considerados como custo e não perda de qualidade". A teoria está também detalhadamente descrita em outras obras do autor ${ }^{[28,69]}$. A ideia central da teoria é a de que os problemas de qualidade estão associados a variações funcionais ocasionadas por tolerâncias de características especificadas no projeto (não somente dimensionais) em relação a um valor nominal que define a funcionalidade ideal do produto. Estas variações são causadas por dois fatores indesejáveis e incontroláveis:

- fatores de ruído externos, tais como variáveis ambientais de operação (exemplo: umidade, temperatura);

- fatores de ruído internos, que podem ser subdivididos em deterioração (exemplo: desgastes de peças por atrito, perda de resiliência de molas) e imperfeições dos processos de fabricação (exemplo: variações no ajuste de máquinas). 
Um produto é dito robusto quando não é sensível a variações causadas por fatores de ruído. A teoria de Taguchi identifica três fases no desenvolvimento de um produto robusto. Estas três fases aplicam-se simultaneamente ao projeto de produto e ao projeto dos processos de produção ${ }^{[28]}$ :

- Projeto do sistema, onde são especificados materiais, componentes e o conjunto, são desenvolvidos protótipos e onde é determinado o processo de manufatura. O objetivo do projeto do sistema é que as variações sejam as menores possíveis em relação ao valor nominal especificado;

- Projeto dos parâmetros, onde os valores dos fatores controláveis - parâmetros de projeto - são selecionados visando à minimização dos fatores de ruído nas características funcionais do produto;

- Projeto de tolerâncias, que é aplicável quando a redução da variação das características funcionais resultantes do projeto dos parâmetros for insuficiente. Nestes casos, tolerâncias mais restritas são especificadas nas variações em relação aos níveis determinados pelo projeto dos parâmetros. Nesta fase há uma negociação entre custo e perda de qualidade, pois estes fatores são antagônicos: a redução nas tolerâncias implica em aumento de custo, conforme descrito na seção anterior. A proposta de otimização deste trabalho utiliza-se deste conceito para seu desenvolvimento.

$\mathrm{Na}$ abordagem tradicional de qualidade, o índice de capacidade de processo $C p$ - e o custo de garantia são utilizados como índices de qualidade dos produtos despachados ao cliente. Taguchi et al. ${ }^{[8]}$ consideram o uso do índice de capacidade de processo e do custo de garantia como indicadores não apropriados para a medição do nível de qualidade de um produto: o primeiro pela dúvida quanto à significância do índice de rejeição no custo assumido pelo cliente, o segundo pelo atraso envolvido desde a reclamação de garantia e a efetiva reação na solução do problema.

\subsection{A função perda de qualidade (Loss function)}

Supondo-se que $m$ seja o valor nominal da especificação, a função perda de qualidade $L(y)$ pode ser obtida através de expansão por série de Taylor:

$$
\begin{gathered}
L(y)=L(m+y-m) \\
L(y)=L(m)+\frac{L^{\prime}(m)}{1 !}(y-m)+\frac{L^{\prime \prime}(m)}{2 !}(y-m)^{2}+\ldots
\end{gathered}
$$


Como, por definição, a função perda de qualidade apresenta o valor nulo para o valor objetivo e seu valor mínimo é atingido neste ponto, como ilustra a Figura 5.1, sua primeira derivada também é nula; assim, os dois primeiros termos da equação são nulos. Se os termos de maiores potências forem também desprezados, tem-se:

$$
\begin{gathered}
L(y)=0 \quad \text { para } \quad y=m \\
L(y)=\frac{L}{2}(y-m)^{2}=c(y-m)^{2}
\end{gathered}
$$

onde $c$ é uma constante.

Segundo Taguchi ${ }^{[8]}$, a consideração de uma função quadrática é válida e tem sido aplicada extensamente na literatura de estatística e teoria de controle.

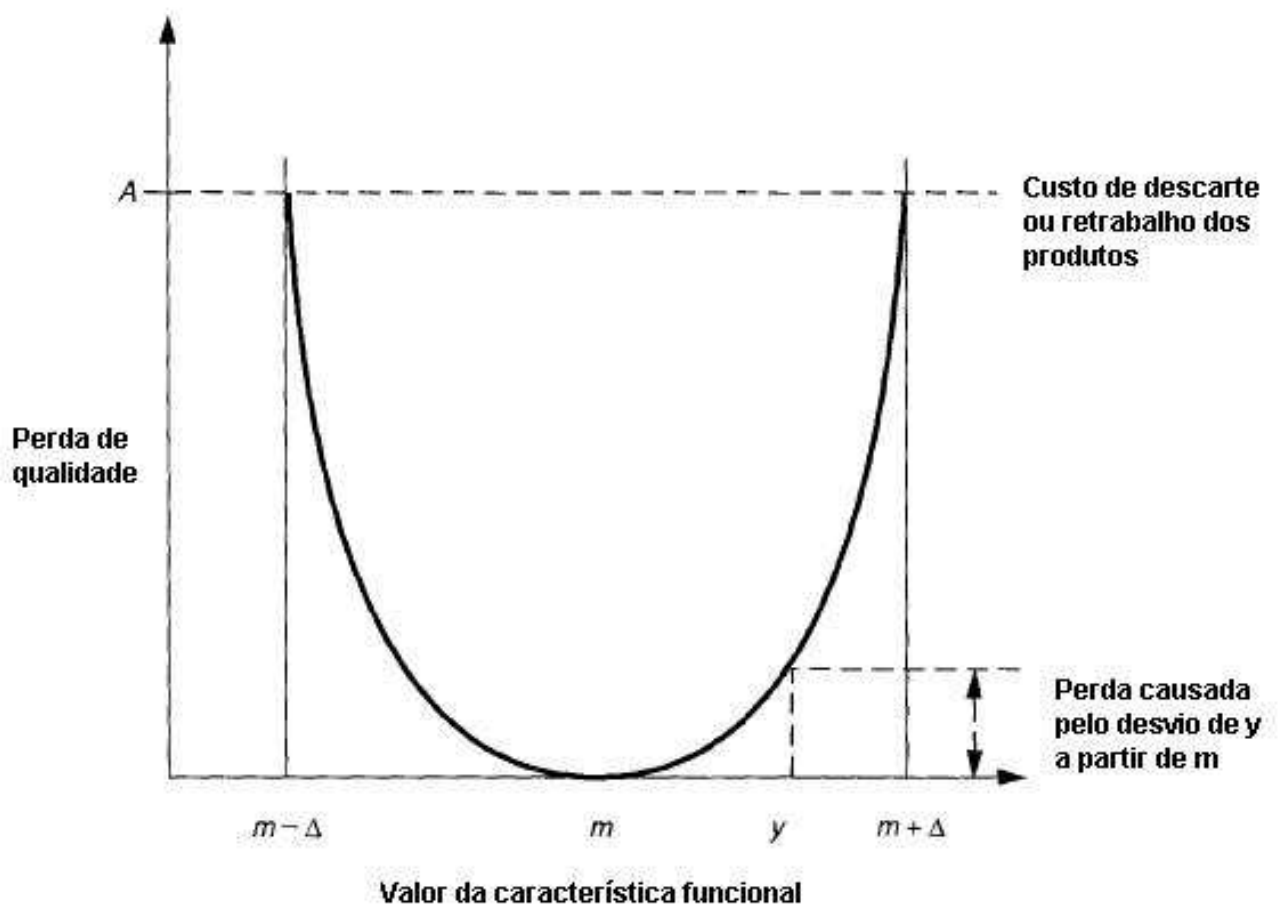

Figura 5.1: Relação entre perda de qualidade e desvio a partir de valor objetivo $(m)$. Fonte: Taguchi et al. ${ }^{[8]}$

Se o valor $A$ for assumido como a perda relativa ao descarte, reparação ou outros danos quando o desvio tiver o valor $\triangle$, ter-se-á a condição de contorno:

$$
A=c \triangle^{2}
$$

$\mathrm{Ou}$

$$
c=\frac{A}{\triangle^{2}}
$$

Então, na prática, quando existir uma restrição de projeto onde um valor conhe- 
cido de uma tolerância $\triangle$ possa causar um dano com custo $A$ também conhecido ou que possa ser estimado, a equação da perda de qualidade estará definida para o caso. Também o efeito no custo relativo à perda de qualidade poderá ser calculado em função do aumento ou diminuição do campo de tolerâncias. Neste trabalho, este recurso será utilizado na proposta para otimização de tolerâncias. Nos casos onde exista assimetria nas tolerâncias para mais e para menos, a Equação 5.4 pode ser escrita:

$$
L=\frac{A_{1}}{\triangle_{1}^{2}}(y-m)^{2}+\frac{A_{2}}{\triangle_{2}^{2}}(y-m)^{2}
$$

Esta condição está ilustrada pela Figura 5.2.

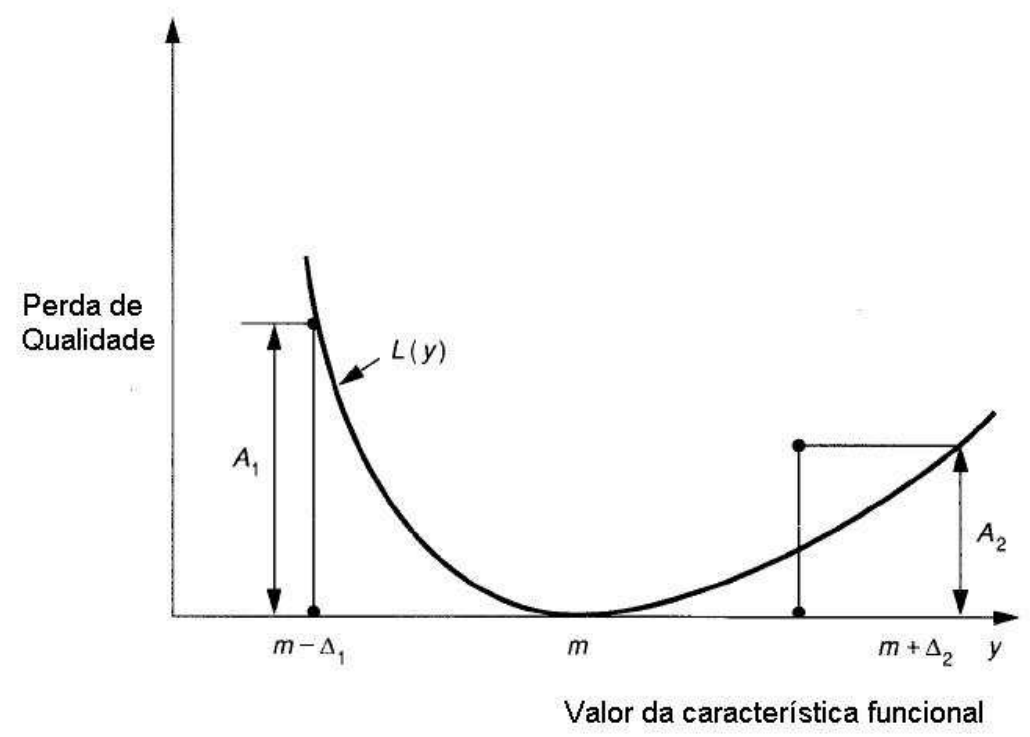

Figura 5.2: Relação entre perda de qualidade e desvio a partir de valor objetivo $(m)$ para condição assimétrica. Fonte: Taguchi et al ${ }^{[8]}$.

\subsection{O fator de segurança econômico}

Os fatores de segurança de projeto são geralmente determinados por experiência de engenharia e levam em consideração todos os problemas técnicos e falhas de um produto ou tecnologia. Seus valores são geralmente determinados em torno de 4 para especificações de tolerâncias. Em algumas áreas, tais como as de defesa e comunicações, os valores são ainda maiores ${ }^{[28]}$. Os coeficientes de segurança podem ser também determinados por métodos de simulação baseados em teoria de probabilidades. Segundo Taguchi ${ }^{[28]}$, estes métodos apresentam um alto custo e são ineficientes, pois não consideram todos os possíveis efeitos de ruídos aos quais as simulações estão sujeitas. Ele propõe métodos mais práticos baseados 
na função perda de qualidade para a determinação do fator de segurança.

Seja $\triangle_{0}$ o limite funcional de uma característica objetivo de um produto (ou componente), ou seja, assumindo-se que outras características objetivo estejam na faixa normal (condições normais ou nominais) de funcionamento, quando a característica objetivo de interesse desviar-se de um valor $\triangle_{0}$ do seu valor nominal, o produto não funcionará apropriadamente ou perderá sua função. O limite funcional é determinado pela alteração de sua característica até que o produto cesse seu funcionamento. O método de Monte Carlo pode ser utilizado, segundo Taguchi, para a verificação de vários ruídos ou fatores externos que afetam a função do produto simultaneamente. As condições padrão (ou condições médias) para uma característica objetivo são definidas como a faixa de valores entre o limite funcional superior e o limite funcional inferior. O valor LD50, no qual o produto falha $50 \%$ do tempo, é usualmente definido para a determinação experimental, em aplicações gerais, dos limites funcionais superior e inferior.

Para tolerâncias bilaterais ou simétricas, o fator de segurança econômico $\phi$ é definido por:

$$
\phi=\frac{\triangle_{0}}{\Delta}
$$

onde:

- $\triangle_{0}$ é o limite funcional do produto.

- $\Delta$ é o valor da tolerância superior ou inferior da especificação.

Para o caso geral, de tolerâncias assimétricas, a Equação 5.8 toma a forma:

$$
\phi_{i}=\frac{\triangle_{0 i}}{\Delta_{i}} \quad i=1,2
$$

onde:

- $\triangle_{0 i}$ é o respectivo limite funcional superior ou inferior do produto.

- $\Delta_{i}$ é o respectivo valor da tolerância superior ou inferior da especificação.

\subsection{Relação entre a função perda de qualidade e o fator de segurança econômico}

O método a seguir, baseado em teorias estatísticas e de probabilidade ${ }^{[28]}$, é recomendado no cálculo dos fatores de segurança para a especificação de tolerâncias no desenvolvimento de produtos ou tecnologias. O fator econômico $\phi$ pode ser 
calculado através da seguinte equação:

$$
\phi=\sqrt{\left(\frac{A_{0}}{A}\right)}
$$

onde:

- $A_{0}=$ Perda financeira média quando a característica objetivo do produto excede os limites funcionais.

- $A=$ Perda financeira média quando a característica objetivo do produto apenas excede as especificações de tolerância dos planos de produção.

O fator de segurança econômico $\phi$ apresenta implicações financeiras determinadas por implicações técnicas, em vez de ser apenas um fator técnico. Neste trabalho utilizaremos o fator de segurança definido para o caso de tolerâncias bilaterais. Taguchi define outros dois tipos para tolerâncias unilaterais ${ }^{[28]}$. Como ilustração para o caso utilizado, será citado o exemplo da mesma referência:

Considere-se o caso da instalação de placas de vidro em molduras de janelas, onde tanto a placa de vidro quanto a moldura (alojamento) tenham suas próprias tolerâncias. Supõe-se para o exemplo que a moldura tenha as dimensões próximas do valor nominal e sua variância seja desprezível. Devido à variância nas dimensões das placas de vidro, estas podem ser muito grandes ou muito pequenas para a montagem. Sejam os limites inferior e superior das dimensões das placas $m_{1}$ e $m_{2}$, respectivamente. Estes limites podem ser horizontais ou verticais, mas serão apenas considerados os horizontais como dimensão objetivo do exemplo. $\mathrm{O}$ valor objetivo da dimensão $m$ e os limites funcionais $\pm \triangle_{0}$ são calculados pelas seguintes equações:

$$
\begin{gathered}
m=\frac{1}{2}\left(m_{1}+m_{2}\right) \quad \mathrm{e} \\
\triangle_{0}=\frac{1}{2}\left(m_{1}-m_{2}\right)
\end{gathered}
$$

Portanto, a especificação de tolerâncias para as dimensões (neste caso horizontais) das placas de vidro, para que seja possível a montagem nas molduras, será $m \pm \triangle_{0}$. Estes são os limites funcionais para os clientes, mas não para os fabricantes de vidro ou revendedores. Supõe-se ainda que:

- $A_{0}$ seja o custo médio quando a placa não puder ser montada na moldura do cliente, o qual inclui o custo da placa original (que não pode ser montada), os custos correspondentes de corte e o custo da compra de outra placa já 
cortada. $A_{0}$ também inclui todo o custo de transporte entre o fabricante (ou revendedor) e o cliente;

- A seja o custo médio de fabricação da placa de vidro.

Certamente $A_{0}$ será muitas vezes maior do que $A$. As tolerâncias e os fatores de segurança econômicos deste problema (nominal o melhor) podem ser calculados pelas equações 5.8 e 5.10 .

Assumindo-se valores de $\$ 25$ para $A_{0}$ e de $\$ 3$ para $A$, o fator de segurança econômico pode ser calculado pela equação:

$$
\phi=\sqrt{\frac{A_{0}}{A}}=\sqrt{\frac{25}{3}}=2,9
$$

Assumindo-se agora que os limites funcionais para as dimensões da placa de vidro sejam $\pm 4 \mathrm{~mm}$, pode-se calcular a especificação de tolerância para os fabricantes de vidro pela equação:

$$
\triangle=\frac{\triangle_{0}}{\phi}=\frac{4}{2,9}=1,4 \quad[\mathrm{~mm}]
$$

Se os valores para os limites superior e inferior forem diferentes, os limites para as tolerâncias de fabricação devem ser calculadas separadamente. Entretanto, em muitos casos, as tolerâncias são as mesmas. 


\section{Proposta para um novo método de síntese de tolerâncias}

Os métodos de otimização de tolerâncias são processos de síntese, onde a alocação é condicionada a critérios adicionais, tais como os voltados a custos de fabricação. A elaboração do método proposto objetivou uma solução competitiva para o problema da especificação de tolerâncias dimensionais, para que fossem contornadas as limitações já comentadas dos métodos similares, principalmente quanto à complexidade de utilização, para que sua aplicação prática pudesse ser viabilizada em ambientes industriais. Não há a pretensão de que este método substitua os atualmente existentes mas que, também consideradas suas limitações, possa ser utilizado como alternativa nos casos nos quais possa ser aplicado.

\subsection{Considerações para o desenvolvimento do mé- todo}

As dimensões toleradas de um conjunto mecânico são resultantes do encadeamento de dimensões toleradas dos componentes que o integram através de superfícies acabadas geralmente por processos de usinagem ou estampagem. Os campos de tolerâncias obtidos nos referidos processos de fabricação apresentamse na forma de distribuições estatísticas contínuas em torno de um valor central. Para processos de usinagem, as distribuições normais ou gaussianas mostram-se geralmente como aproximações adequadas e, portanto úteis, como representação da variação dimensional. Para o objetivo da descrição da proposta para o modelo de análise de tolerâncias, considerar-se-á, por simplificação, o encadeamento unidirecional, que é geralmente utilizado na prática industrial. Uma vez entendido o objetivo conceitual da proposta, este poderá ser estendido para os encadeamentos bi e tri-dimensionais, com os ajustes adequados que inevitavelmente trazem aumento na complexidade da abordagem. A Figura 6.1 ilustra esquematicamente 
o conceito de encadeamento unidirecional elementar de componentes de um conjunto mecânico. A montagem de cada componente está representada em relação à média da distribuição do componente anterior, mas pode logicamente estar posicionada em qualquer ponto do campo de distribuição deste componente.

Como nos trabalhos similares, os campos de tolerância serão considerados cen-

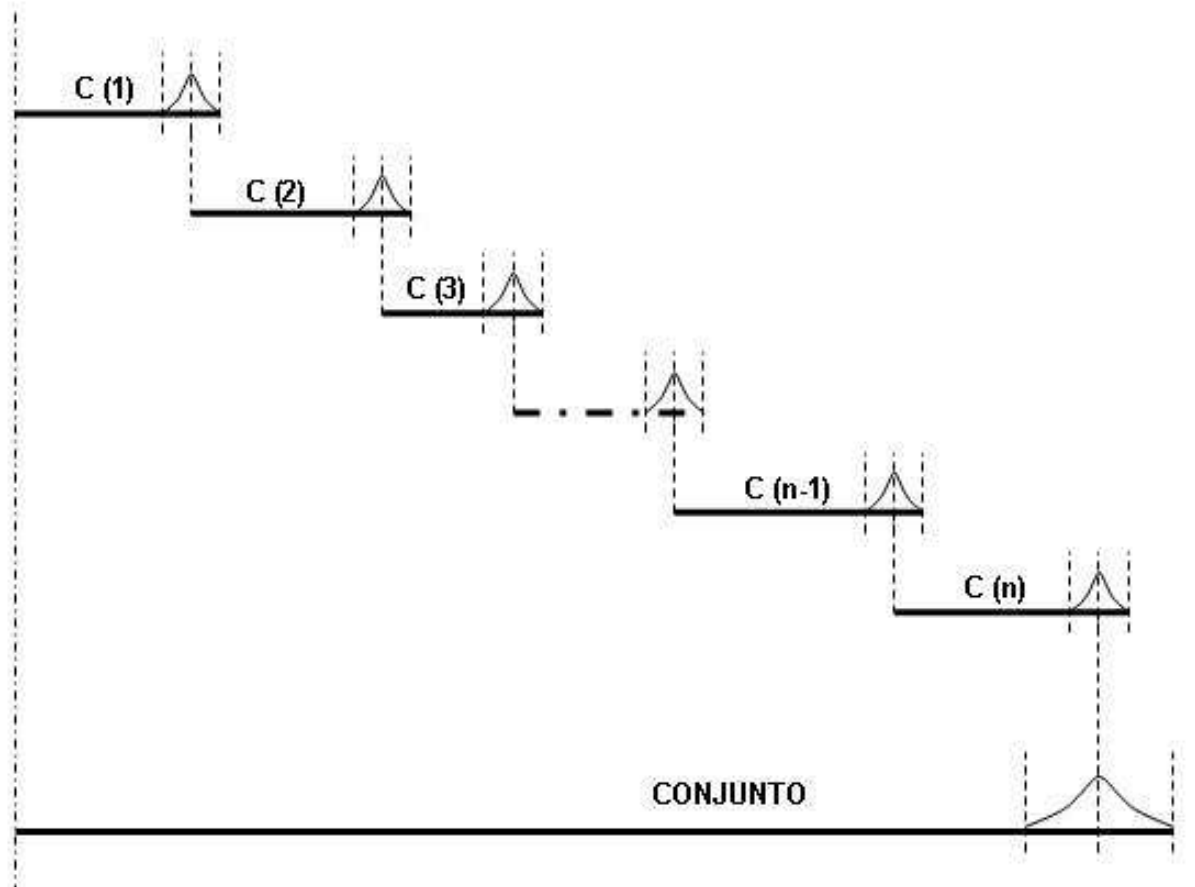

Figura 6.1: Encadeamento elementar de componentes em um conjunto mecânico.

trados em torno da média da distribuição, com semi-tolerâncias iguais a 3 desvios padrões. Para a distribuição normal, a tolerância do conjunto $T=6 \sigma$ equivalerá a um limite de aceitação aproximado de 99,7\%.

Vale mencionar que qualquer processo de otimização de tolerâncias nunca resultará em valores precisos. Os conceitos estatísticos referidos anteriormente foram definidos através de suposições que levam a resultados aproximados. Nesta proposta também são feitas algumas suposições. Porém, é importante se considerar que, apesar das imprecisões envolvidas, o processo pode ser de muita utilidade como fator de controle do projeto, haja vista as considerações feitas durante sua descrição, ou seja, a otimização de custos será efetivada conjuntamente com a avaliação e decisão sobre o nível de segurança que garantirá que problemas de qualidade não atingirão o cliente. 


\subsection{Requisitos do sistema}

O projeto de qualquer sistema inicia-se pela pesquisa e seleção dos requisitos que devem ser atendidos para o cumprimento de seus objetivos. A primeira característica do método é a de facilitar o processo de especificação de tolerâncias já na fase inicial do detalhamento de componentes. Assim, os seguintes requisitos fundamentais podem ser enumerados:

1. Especificação de campos de tolerâncias sem grandes restrições iniciais para as dimensões participantes do processo de análise do encadeamento do conjunto, baseados em tabelas disponíveis em normas, literatura ou, preferencialmente, em dados desenvolvidos pela empresa. Esta prática viabiliza a obtenção dos menores custos de produção possíveis já na fase inicial do processo de especificação e diminui o tempo de execução do projeto por evitar a necessidade de consultas preliminares aos especialistas em processo. A validação definitiva dos valores apropriados para a fabricação pode ser realizada após a obtenção dos resultados do processo de otimização;

2. Racionalização do projeto para eliminação de campos de tolerâncias desnecessários e/ou por agregação de componentes. Assim, podem ser evitados esforços desnecessários no processo de síntese de tolerâncias e, adicionalmente, redução do custo total por dois motivos: diminuição do número de componentes e rateio do campo de tolerância por número menor de itens participantes. Esta racionalização do projeto pode ser conduzida através de técnicas adequadas, tais como EAV - Engenharia e Análise de Valor ${ }^{1}$ e Projeto para fabricação e montagem ${ }^{2}$;

3. Análise de tolerâncias do encadeamento através da técnica da raiz da soma dos quadrados descrita no Capítulo 3, em função do tipo e características específicas do caso e de sua equação fundamental do encadeamento. A análise resultará nos valores da média $\mu_{c o n j}$ e da variância $\sigma_{c o n j}^{2}$ da distribuição

\footnotetext{
${ }^{1}$ Engenharia e Análise de Valor é uma metodologia estruturada para a maximização do valor e minimização dos custos de componentes e processos. Foi concebida por Lawrence Delos Miles entre 1941 e 1947 para permitir à empresa General Electric Company, para a qual colaborou, conviver produtivamente durante a fase de racionamento de materiais ocorrido na Segunda Grande Guerra. Em princípio, a Engenharia de Valor aplica-se na fase de desenvolvimento do projeto e a Análise de Valor em fases posteriores, para fins de redução de custos. A descrição detalhada da metodologia pode ser encontrada em referências específicas ${ }^{[70,71]}$.

${ }^{2} \mathrm{O}$ Projeto para a fabricação e montagem é uma combinação de duas técnicas ${ }^{[72]}$ : (1) $\mathrm{O}$ Projeto para a Fabricação (Design for Manufacture - DFM) pode ser definido como o projeto voltado à facilitação da fabricação dos componentes que formam o conjunto após a montagem; (2) O Projeto para a Montagem (Design for Assembly - DFA) pode ser definido como o projeto do produto para facilitar a montagem.
} 
do conjunto. O sistema, entretanto não impede a consideração do Método dos Momentos, quando a complexidade do caso permitir a elaboração de rotinas no programa de cálculo considerado;

4. Definição de restrições funcionais do conjunto através de critérios de qualidade voltados tanto à satisfação das necessidades do cliente como também ao custo de utilização do produto devido a problemas de qualidade. A aplicação do fator de segurança econômico de Taguchi é recomendado. Estes critérios devem ter prevalência sobre os custos de fabricação, sendo o resultado otimizado para o compromisso custo/qualidade;

5. Síntese de tolerâncias por otimização dos custos de fabricação dos componentes segundo respectivos campos de tolerâncias. O algoritmo deve encontrar a melhor distribuição dos campos de tolerâncias dos componentes que atenda ao campo de tolerâncias do conjunto definido pela(s) restrição(ões) funcional(is) adotada(s). Para maior abrangência de utilização, o algoritmo deve ser capaz de atender a encadeamentos simples e também a inter-relacionados. O cálculo pode ser realizado sequencialmente no caso de mais de um encadeamento;

6. Permitir a especificação de limites máximos e mínimos para campos de tolerâncias determináveis. Esta característica é importante para a seleção e/ou restrição de processos de fabricação na fase de projeto do componente.

\subsection{Algoritmo para a otimização}

O algoritmo de otimização é executado a partir das tolerâncias dos componentes especificadas a fim de refletir valores de custo mínimo e de valores para restrições funcionais definidos a partir de conceitos que assegurem níveis determinados de qualidade do produto ao cliente. O algoritmo proposto para a otimização, ilustrado na Figura 6.2 apresenta a seguinte sequência:

\section{Entrada de dados}

A rotina de entrada de dados do programa é constituída por parâmetros de projeto, de processo e do algoritmo:

$>$ tolerâncias determináveis e pré-determinadas dos encadeamentos. Tolerâncias determináveis podem ser especificadas através de critérios de projeto, tais como, experiência de projetos anteriores, recorrência a normas e manuais ou a referências bibliográficas. Valores maiores podem ser especificados para que apresentem menores custos iniciais - a única restrição é a 
do valor máximo admitido pela função custo. Tolerâncias pré-determinadas devem ser especificadas a partir de especificações de fornecedores de itens normalizados;

$>$ valores da(s) restrição(ões) funcional(is) $R f X \operatorname{do}(\mathrm{s})$ encadeamento(s), onde $X$ é o número de ordem do encadeamento, definidas através de critérios de custo da não qualidade de Taguchi;

$>$ valores mínimos de tolerâncias determináveis $t_{j}$ min para que atendam a parâmetros dos processos de produção previstos;

$>$ valor $d c$ do decremento de tolerância adotado para o algoritmo, que define a precisão e o número de iterações de cálculo. A especificação do valor do decremento pode considerar a precisão na especificação das tolerâncias determináveis;

$>$ cálculo para registro das tolerâncias iniciais do(s) encadeamento(s) através do método da raiz da soma dos quadrados:

$$
T i X=\sqrt{\sum_{i=1}^{n p} t_{i}^{2}+\sum_{j=1}^{n d} t_{j}^{2}}
$$

Outros métodos de síntese de tolerâncias podem ser considerados, desde que as respectivas equações sejam utilizadas. Este(s) valor(es) inicial(is) serve(m) como referência de comparação em relação ao(s) valor(es) otimi$\operatorname{zado}(\mathrm{s})$;

$>$ cálculo para registro do(s) custo(s) relativo(s) inicial(is) do(s) encadeamento(s):

$$
C i X=\sum_{j=1}^{n d} C_{j} \quad \text { onde } \quad C_{j}=\text { Custo }\left(t_{j}\right)
$$

O algoritmo da função Custo está descrito no Capítulo 4. Este(s) valor(es) inicial(is) serve(m) como referência de comparação em relação ao(s) valor(es) otimizado(s).

\section{Síntese de tolerâncias otimizada por custos}

A rotina de síntese de tolerâncias utiliza os dados de entrada para cálculo das novas tolerâncias determináveis a partir da comparação de valores diferenciais discretos de custo calculados segundo valores de decremento de tolerâncias especificado. A cada iteração é adotada a tolerância reduzida pelo decremento que apresente o menor acréscimo de custo. Simultaneamente é realizada a comparação do valor da tolerância com o valor mínimo especificado para o processo de produção. O processo continua até que o valor da tolerância do encadeamento atenda ao valor especificado para a 
respectiva restrição funcional:

$>$ calcular a tolerância do primeiro encadeamento considerado, o que apresente a menor restrição funcional, conforme equação do método já utilizada na rotina de entrada de dados para registro da tolerância inicial;

$$
T X=\sqrt{\sum_{i=1}^{n p} t_{i}^{2}+\sum_{j=1}^{n d} t_{j}^{2}}
$$

$>$ realizar iterações até que a tolerância do encadeamento seja satisfeita, através da condição $T X-R f X<0$. Se o valor de qualquer tolerância dos componentes exceder o valor máximo definido para o cálculo da função custo, o programa é interrompido para que o devido ajuste possa ser realizado;

$>$ decrementar todas as tolerâncias segundo o passo do algoritmo e determinar o componente que apresente a menor variação. Considerar que a tolerância decrementada com a menor variação de custo será a alterada e determinar a nova tolerância do encadeamento. Observar a cada passo a condição de valor mínimo da tolerância para atendimento do respectivo processo de produção;

$>$ repetir processo para outros encadeamentos, se aplicável, considerando as tolerâncias já otimizadas como tolerâncias pré-determinadas. 


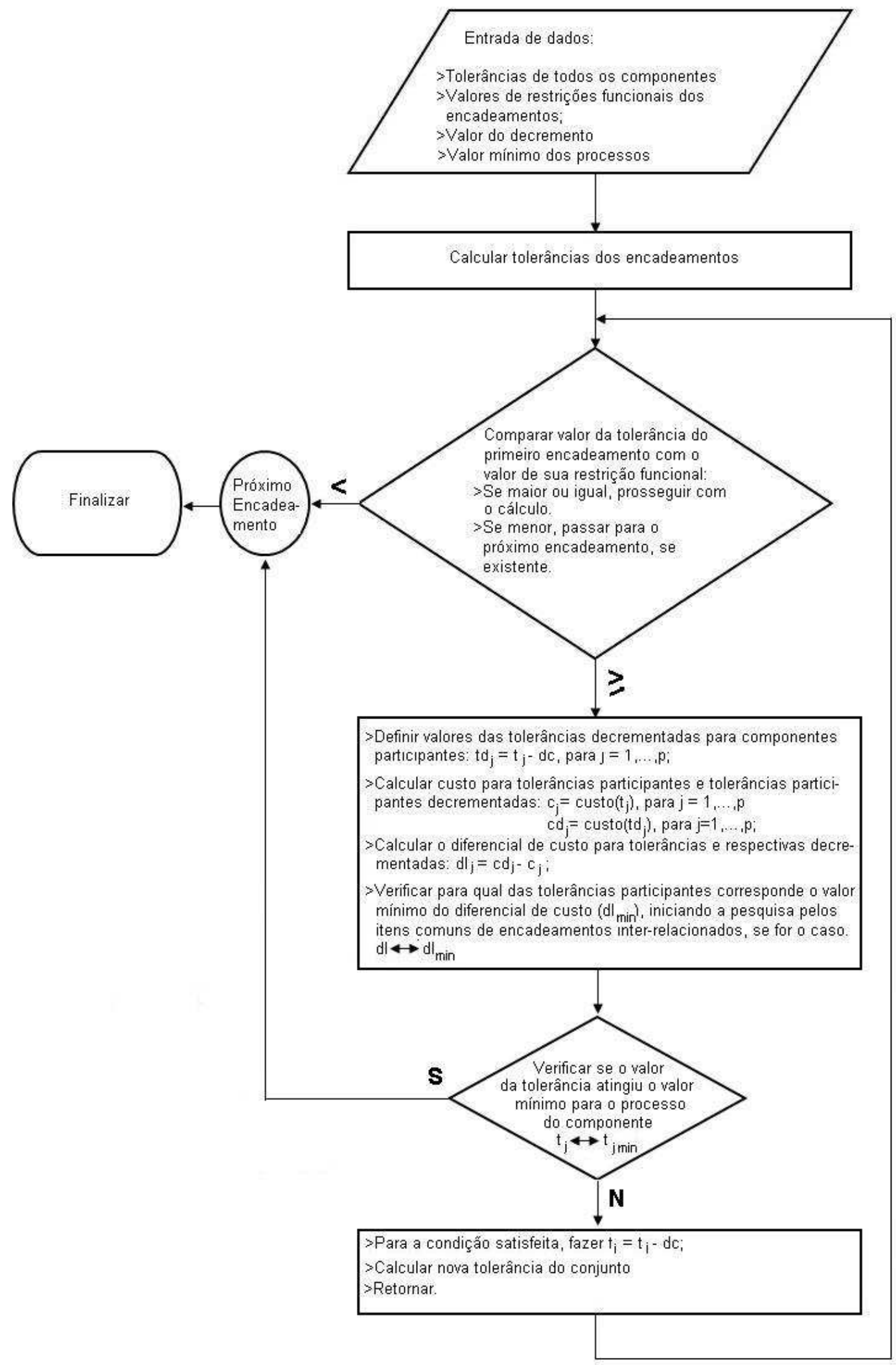

Figura 6.2: Algoritmo de otimização. 


\section{Exemplo de aplicação}

Para a aplicação prática do método, foram pesquisados sistemas que apresentassem as seguintes características:

1. Possuíssem encadeamentos inter-relacionados para a simulação do caso geral de otimização;

2. Apresentassem condições de demonstração para aplicação da função perda de qualidade de Taguchi através do coeficiente de segurança econômico;

3. Pudessem ser representadas por equações fundamentais lineares nos encadeamentos para que a solução fosse simplificada, pois objetivo do presente trabalho é, principalmente, a demonstração da eficácia do algoritmo. Observa-se também, na prática industrial, que a maioria dos casos de estudos de tolerância envolvem sistemas unidirecionais, tal como o proposto.

\subsection{Descrição do sistema}

Para atendimento das características requeridas, foi selecionado um sistema baseado em um problema real: o de alinhamento do sistema de correias de acionamento de equipamentos periféricos de um motor de combustão interna, cuja representação frontal é ilustrada na Figura 7.1. A polia inferior, conectada à árvore de manivelas (AM) do motor, aciona o alternador (ALT) e a bomba hidráulica (BH) do sistema assistido de direção. As duas outras polias (PC) fazem contato com a parte posterior da correia para garantir os ângulos de abraçamento requeridos e para evitar comprimento excessivo em balanço, respectivamente. Estas restrições são baseadas em valores normatizados ${ }^{[73]}$. Os comprimentos em balanço L1, L2, L4 e o comprimento de abraçamento L3 são utilizados no cálculo da restrição funcional.

A Figura 7.2 ilustra a vista transversal do sistema, referindo as dimensões e os componentes utilizados para a elaboração do esquema de encadeamento e da tabela de tolerâncias. A Tabela 7.1 descreve os itens do conjunto. 


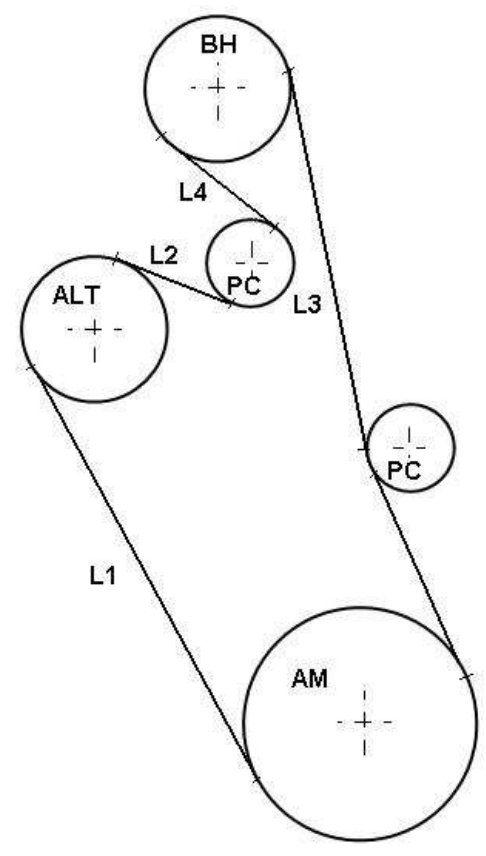

Figura 7.1: Vista frontal do sistema de transmissão de potência por correia de um motor de combustão interna.

\subsection{Cálculo das restrições funcionais}

Os valores das restrições funcionais neste trabalho foram calculados a partir dos conceitos do fator de segurança econômico, associado à função perda de qualidade desenvolvida por Taguchi ${ }^{[69]}$.

\subsubsection{Limites funcionais}

O valor de desalinhamento entre polias multi-V, para que haja a soltura da correia, não está disponível na literatura sobre o assunto. Após exaustiva pesquisa, valor limite $\alpha_{0}=4,5^{\circ}$ foi encontrado em citação de produtos convencionais em patente de novo produto ${ }^{[74]}$. Este valor foi adotado para o ângulo do comprimento em balanço do tipo de correia considerada para o projeto, acima do qual pode haver sua soltura das polias. A Figura 7.3 ilustra a relação entre os fatores. A Figura 7.1 define os comprimentos L1, L2, L3 e L4.

Como dados do projeto e Figura 7.3 tem-se, para o encadeamento principal, $\mathrm{L}=\mathrm{L} 1=250 \mathrm{~mm}$ :

$$
\Delta_{01}=250 \times \tan \left(4,5^{\circ}\right)=19,7 \mathrm{~mm}
$$

Para o encadeamento secundário, o comprimento $\mathrm{L}=\mathrm{L} 2+\mathrm{L} 3+\mathrm{L} 4=200 \mathrm{~mm}$ é equivalente, para efeito de cálculo, ao comprimento em balanço entre as polias 

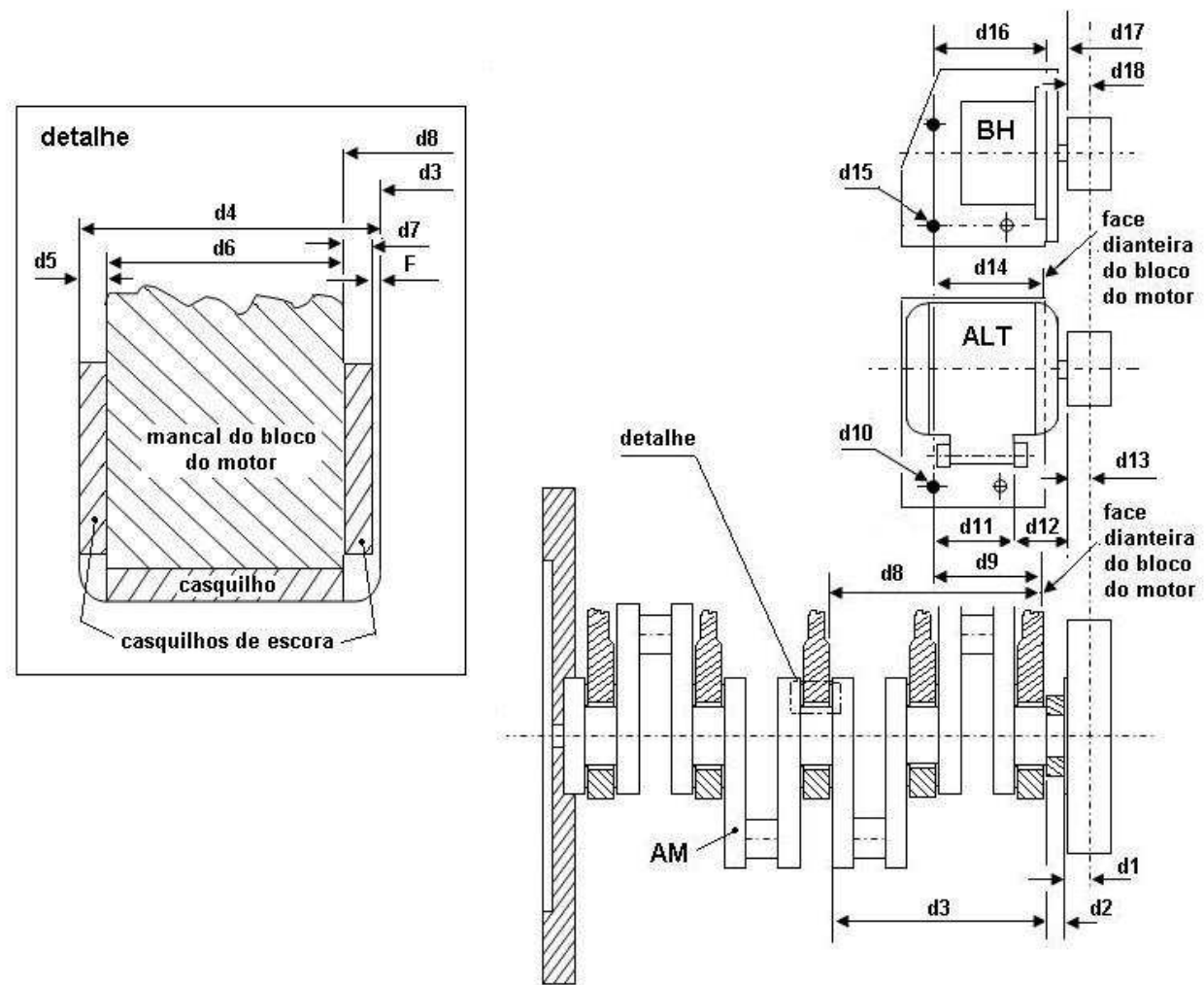

Figura 7.2: Vista lateral do sistema estudado.

do alternador e da bomba hidráulica:

$$
\Delta_{02}=200 \times \tan \left(4,5^{\circ}\right)=15,7 \mathrm{~mm}
$$

\subsubsection{O fator de segurança econômico}

Considerações de ordem financeira que envolvam custos da não qualidade devem incluir necessariamente a avaliação de riscos de segurança. Campanhas para retrabalhos de produtos têm se tornado frequentes, principalmente na Indústria Automotiva. Ferramentas de avaliação de riscos de qualidade, tais como a de Análise de modos e efeitos de falha - FMEA - devem ser consideradas para este objetivo. O Apêndice D refere conceitos básicos do método e ilustra sua aplicação para o exemplo, onde o problema de alinhamento entre polias é identificado como fator de causa do modo de falha de soltura e desgaste da correia. Assim, a perda financeira média pode ser estimada para os limites funcionais: se atingidos, estes limites gerariam comprometimento da função do sistema de direção assistida e do alternador, podendo causar acidentes com danos materiais e físicos aos ocupantes do veículo, e podendo resultar em uma perda financeira estimada, devida a indenizações, de:

$$
A_{0}=\$ 500.000,00
$$


Tabela 7.1: Identificação dos componentes do sistema conforme Figura 7.2

\begin{tabular}{|l|l|l|}
\hline Item & Componente & Descrição \\
\hline 1 & Polia árvore manivelas & Dist. face encosto/LC. correia \\
2 & Espaçador & Espessura \\
3 & Árvore de manivelas & Dist. face dia./face encosto mancal \\
4 & Árvore de manivelas & Largura do munhão de escora \\
5 & Casquilho de encosto & Espessura \\
6 & Bloco do motor & Espessura do mancal de escora \\
7 & Casquilho de encosto & Espessura \\
F & Árvore de manivelas & Folga axial \\
8 & Bloco do motor & Dist. face encosto mancal/face dianteira \\
9 & Bloco do motor & Dist. face dianteira/furação suporte alternador \\
10 & Pino elástico & Aj. montagem furação bloco/furação suporte \\
11 & Suporte & Dist. furação/face montagem alternador \\
12 & Alternador & Dist. face de montagem/face encosto polia \\
13 & Polia do alternador & Dist. face de encosto polia/centro da correia \\
14 & Bloco do motor & Dist. face dianteira/furação suporte bba. hidr. \\
15 & Pino elástico & Aj. montagem furação bloco/furação suporte \\
16 & Suporte & Dist. furação/face montagem bomba hidráulica \\
17 & Bomba hidráulica & Dist. face de montagem/face encosto polia \\
18 & Polia da bomba hidráulica & Dist. face de encosto polia/centro da correia \\
\hline
\end{tabular}

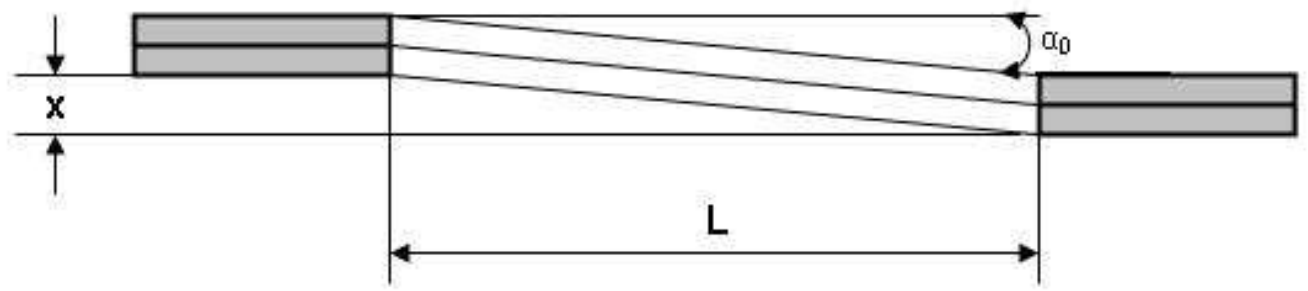

Figura 7.3: Relação entre ângulo, deslocamento axial das polias e comprimento em balanço da correia.

O custo do reparo de reclamação de ruído de funcionamento durante a garantia do produto (substituição de peças, mão de obra, custos administrativos e despesas diversas) para desvios no limite da especificação:

$$
A=\$ 800,00
$$

O fator de segurança econômico, a partir dos dados dos itens anteriores:

$$
\phi=\sqrt{\frac{A_{0}}{A}}=\sqrt{\frac{500.000}{800}}=25
$$




\subsubsection{Cálculo das restrições funcionais}

Os limites para as restrições funcionais:

- Para o encadeamento principal:

$$
\Delta_{1}=\frac{\Delta_{01}}{\phi}=\frac{19,7}{25}=0,79 \mathrm{~mm}
$$

- Para o encadeamento secundário:

$$
\Delta_{2}=\frac{\Delta_{02}}{\phi}=\frac{15,7}{25}=0,63 \mathrm{~mm}
$$

O valor $\Delta_{1}$ poderia ser aumentado em função do uso do produto (desgaste do casquilho de encosto). No exemplo, entretanto, esta característica não será considerada, haja vista a diferença entre o valor especificado e o valor máximo recomendado para o desalinhamento ${ }^{[73]}$, que é de $0,58 \mathrm{~mm}$ a cada $100 \mathrm{~mm}$, ou seja, para o caso $0,58 \times 2,5=1,45 \mathrm{~mm}$. A segunda restrição funcional não está sujeita a efeitos de desgaste.

\subsection{Considerações sobre restrições de projeto}

Antes da especificação dos encadeamentos necessários à análise de tolerâncias do exemplo, algumas considerações são necessárias: a folga axial da árvore de manivelas é resultante de um encadeamento formado pelos itens 4-5-6-7 listados na Tabela 7.1 e ilustrado pelo detalhe da Figura 7.2. Como existem restrições de funcionamento interno do motor, deve ser garantida a condição de não interferência através do cálculo preciso da folga axial e, portanto, é recomendável que os componentes a ela relacionados tenham as tolerâncias calculadas pelo método do pior caso.

O valores da folga máxima e mínima são dados por:

$$
\begin{aligned}
& F_{\text {max }}=d 4_{\text {max }}-d 5_{\text {min }}-d 6_{\text {min }}-d 7_{\text {min }} \\
& F_{\text {min }}=d 4_{\text {min }}-d 5_{\text {max }}-d 6_{\text {max }}-d 7_{\text {max }}
\end{aligned}
$$


Para valores especificados em $m m$ :

$$
\begin{array}{r}
d 4=30,07 \pm 0,04 \\
d 5=4,00 \pm 0,03 \\
d 6=21,91 \pm 0,05 \\
d 7=4,00 \pm 0,03
\end{array}
$$

Tem-se:

$$
\begin{aligned}
& F_{\text {max }}=30,11-21,86-3,97-3,97=0,31 \\
& F_{\text {min }}=30,03-21,96-4,03-4,03=0,01
\end{aligned}
$$

E, portanto, o valor da folga pode ser expresso por:

$$
F=0,16 \pm 0,15 \quad \mathrm{~mm}
$$

\subsection{Racionalização de projeto}

Este estudo de caso pode ser utilizado como exemplo de aplicação para atividades de racionalização de projeto através de dois itens que afetam diretamente o cálculo de tolerâncias dimensionais:

\subsubsection{Referências de cotação}

A escolha das referências de cotação de dimensões na elaboração do detalhamento do projeto deve ser realizada a partir de critérios funcionais, os quais, muitas vezes, não são observados ${ }^{[23]}$. No exemplo, pode-se observar na Figura 7.2 que as furações de posicionamento dos suportes do alternador e da bomba hidráulica foram cotadas a partir da face dianteira do bloco do motor. Se o critério funcional do alinhamento das polias for observado, a cotação pode partir diretamente da face do mancal de encosto do bloco do motor. Além de resultar na redução de um item no encadeamento, este apresentará uma menor dimensão e consequentemente um menor valor de tolerância afetando o conjunto.

\subsubsection{Integração de componentes}

Outro fator a ser considerado é a integração dos suportes do alternador e da bomba hidráulica em um único item. Assim, outras tolerâncias podem ser eliminadas, reduzindo componentes nos encadeamentos sujeitos aos processos de 
análise e de síntese de tolerâncias.

A nova configuração proposta, resumindo as considerações feitas nas Seções 7.3

e 7.4 para o exemplo, é ilustrada na Figura 7.4. O encadeamento resultante é resumido na Figura 7.5.
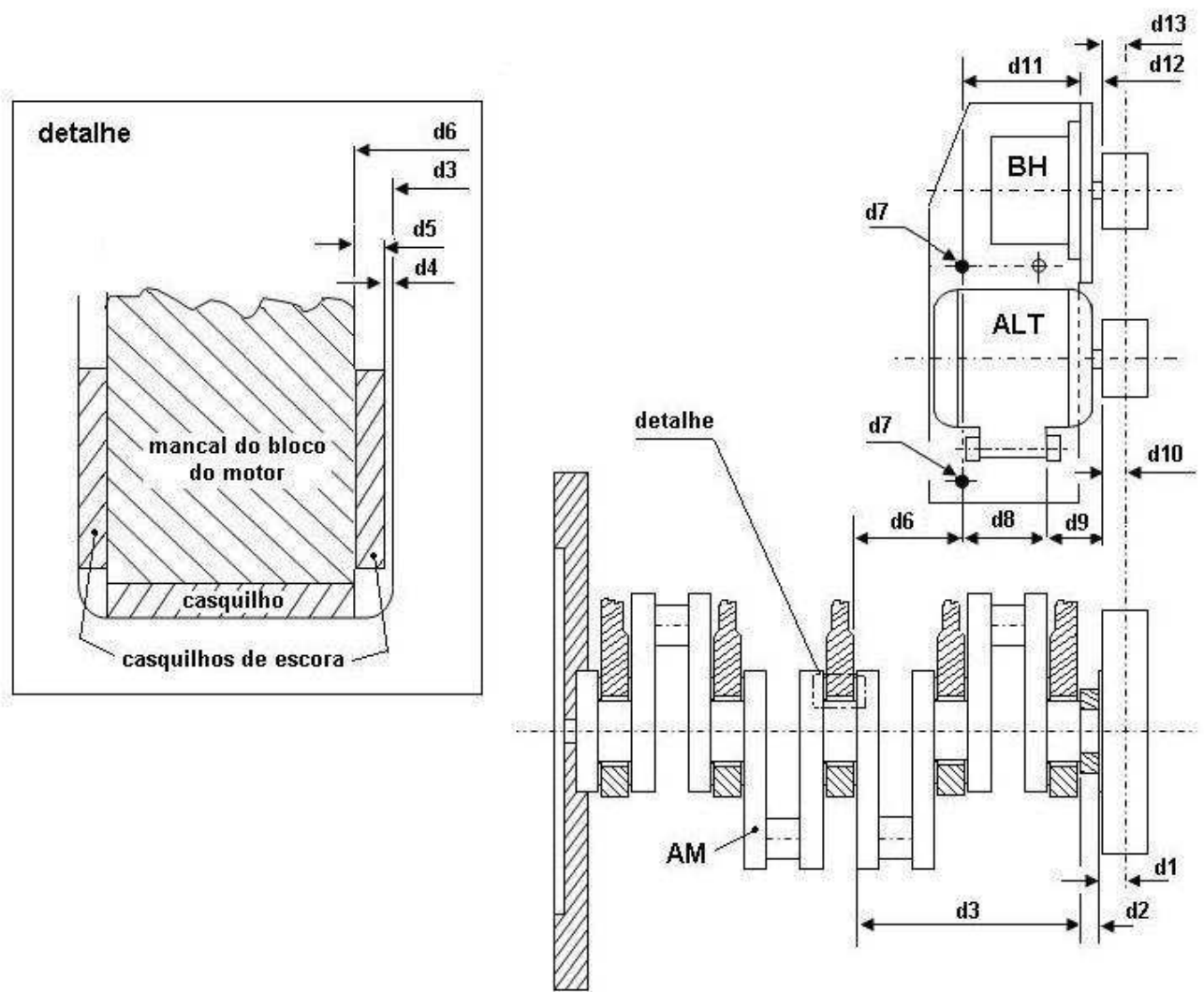

Figura 7.4: Configuração definitiva para o sistema.

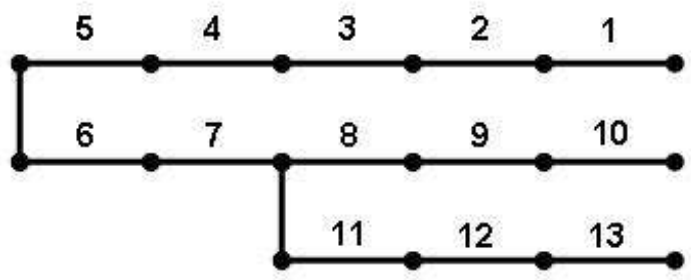

Figura 7.5: Representação esquemática dos encadeamentos inter-dependentes: Encadeamento principal: itens 1-2-3-4-5-6-7-8-9-10; Encadeamento secundário: itens 8-910-11-12-13.

Alguns itens, apesar de participarem do cálculo da tolerância do conjunto, não participam do processo de otimização, por diferentes motivos:

- Item 4 - folga axial - o valor da folga axial da árvore de manivelas é especificado bilateralmente em função do valor nominal nulo. Apesar de seu valor 
Tabela 7.2: Identificação dos componentes do sistema e respectivas médias de distribuições conforme Figura 7.4

\begin{tabular}{|l|l|l|l|}
\hline Item & Componente & Descrição & Média \\
\hline 1 & Polia árvore manivelas & Dist. face encosto/LC. correia & 35,0 \\
2 & Espaçador & Espessura & 5,00 \\
3 & Árvore de manivelas & Dist. face dia./face encosto mancal & 255,0 \\
4 & Árvore de manivelas & Folga axial & 0,00 \\
5 & Casquilho de encosto & Espessura & 4,00 \\
6 & Bloco do motor & Dist. face encosto mancal/furação fix. suporte & 190,00 \\
7 & Pino elástico & Aj. montagem furação bloco/furação suporte & 0,00 \\
8 & Suporte & Dist. furação/face montagem alternador & 55,00 \\
9 & Alternador & Dist. face de montagem/face encosto polia & 29,00 \\
10 & Polia do alternador & Dist. face de encosto polia/centro da correia & 25,00 \\
11 & Suporte & Dist. furação/face montagem bomba hidráulica & 65,00 \\
12 & Bomba hidráulica & Dist. face de montagem/face encosto polia & 14,00 \\
13 & Polia da bomba hidráulica & Dist. face de encosto polia/centro da correia & 30,00 \\
\hline \multicolumn{2}{|l|}{ Médias dos encadeamentos } & Principal [1+2+3+4+5-6-7-8-9-10] & 0,00 \\
& & Secundário [8+9+10-11-12-13] & 0,00 \\
\hline
\end{tabular}

ter sido calculado através do método do pior caso, considera-se-á o valor de sua tolerância estatística, já que seus componentes também estão sujeitos a variações estatísticas em seus processos de produção. Assim, a partir dos valores referidos na seção 7.3 :

$$
T=\sqrt{0,04^{2}+0,03^{2}+0,05^{2}+0,03^{2}} \approx 0,08
$$

- Item 5 - casquilho de escora - é um item padronizado de fornecimento externo;

- Item 9 - pino elástico - o posicionamento do suporte da bomba hidráulica e alternador é realizado através da fixação por três parafusos e dois pinos elásticos montados concentricamente a dois dos parafusos de fixação. Seu diâmetro de montagem acomoda-se ao menor dos furos ajustados, localizados no bloco do motor e no suporte. Assim, a tolerância da montagem será regida pela variação entre os valores máximo e mínimo dos furos ajustados. Devido à precisão necessária, optou-se por considerar este item como não participante do processo. Desprezou-se também a eventual variação angular originada pela tolerância dos furos ajustados e por sua distância relativa;

- Itens 9 e 12 - dimensões dos conjuntos da bomba hidráulica e do alternador - considerados também como itens padronizados, pois suas tolerâncias são fixadas e garantidas pelos respectivos fornecedores, resultantes da montagem entre os respectivos eixos, rolamentos e carcaças de cada conjunto. A bomba hidráulica é montada através de flange e o alternador através de fi- 
xação por encaixe em ressaltos no suporte. Um sistema de bucha flutuante garante o posicionamento do alternador através do contato da face frontal do encaixe com a face traseira do ressalto dianteiro do suporte.

\subsection{Desenvolvimento do programa de otimização}

As seguintes rotinas foram elaboradas a partir dos algoritmos descritos na seção 6.3 em linguagem MatLab ${ }^{\circledR}$ :

1. Entrada de dados;

2. Cálculo do custo relativo da tolerância. A função Custo $=f$ (tolerância) foi gerada a partir dos dados disponíveis na obra de Trucks ${ }^{[2]}$, que apresenta o maior espectro de valores de tolerâncias;

3. Cálculo das tolerâncias otimizadas, sujeitas às restrições dos valores máximo e mínimo definidos para a tolerância de cada componente participante e das restrições funcionais calculadas para cada encadeamento. Como os encadeamentos são inter-relacionados, isto é, apresentam componentes comuns, o cálculo do encadeamento secundário foi priorizado pelo fato de apresentar restrição funcional de menor valor. Assim, o cálculo do encadeamento primário foi executado na sequência, com as tolerâncias dos componentes comuns já otimizadas;

4. Apresentação dos resultados. 


\section{Resultados}

O objetivo desta seção do trabalho é apresentar a eficácia do algoritmo proposto na otimização de tolerâncias por custos de produção. Os requisitos de qualidade foram considerados na especificação das restrições funcionais e observações sobre a racionalização do projeto foram ilustradas na descrição do estudo de caso. Primeiramente é mostrado o resultado do processo de análise de tolerâncias, seguido dos resultados do processo de síntese de tolerâncias em função dos valores das restrições funcionais especificadas. Estes últimos são comparados com resultados de alocação de tolerâncias através dos métodos descritos no Capítulo 3.

\subsection{Processo de análise de tolerâncias}

A especificação de tolerâncias em um desenho de detalhe de um componente pode ser realizada pelo projetista por diferentes critérios:

- Por experiência adquirida em projetos anteriores;

- Pelo uso de normas externas;

- Pelo uso de normas ou manuais internos da empresa;

- Através de tabelas disponíveis na literatura.

Para a simulação de uma situação real para a aplicação do método proposto, foi utilizada, para o estudo de caso, a tabela de classes de tolerâncias em função das dimensões disponibilizada pela norma internacional ISO-286-1 ${ }^{[20]}$. A Tabela 8.1 ilustra a aplicação das tabelas de classe para as dimensões nominais, ou médias de distribuições, dos componentes do exemplo. A coluna Esp. mostra uma especificação adicional de valores superiores aos da Classe IT14. As linhas inferiores resumem os resultados de cálculo do programa para o processo de análise de tolerâncias, ou seja, para o cálculo das tolerâncias resultantes dos encadeamentos primário e secundário (vide figura 7.5), assim como dos seus respectivos custos. A última linha mostra o custo total do conjunto para cada coluna.

Embora todos os componentes estejam listados na tabela, é importante observar que somente as tolerâncias do respectivo encadeamento participam do resultado 
e que somente os custos dos componentes participantes do processo de análise são considerados - os itens identificados em itálico na tabela não participam do cálculo do custo, pois suas tolerâncias não são alteradas no processo de análise, conforme justificativas feitas na seção anterior: sejam $t$ (item) e $C($ item) as tolerâncias e custos referentes aos componentes de determinado encadeamento, respectivamente.

Para o primeiro encadeamento:

$$
\begin{array}{r}
T 1=\sqrt{t^{2}(1)+t^{2}(2)+t^{2}(3)+t^{2}(4)+t^{2}(5)+t^{2}(6)+t^{2}(7)+t^{2}(8)+t^{2}(9)+t^{2}(10)} \\
C 1=C(1)+C(2)+C(3)+C(6)+C(8)+C(10)
\end{array}
$$

Para o segundo encadeamento:

$$
\begin{array}{r}
T 2=\sqrt{t^{2}(8)+t^{2}(9)+t^{2}(10)+t^{2}(11)+t^{2}(12)+t^{2}(13)} \\
C 2=C(8)+C(10)+C(11)+C(13)
\end{array}
$$

O encadeameno secundário, por estar sujeito a restrição funcional de menor valor, é considerado prioritariamente no cálculo de otimização pelo algoritmo. Assim, as tolerâncias dos itens comuns aos dois encadeamentos são definidas para atenderem à restrição funcional do encadeamento secundário e utilizadas na sequência no cálculo do encadeamento principal. O custo total não é a soma simples dos custos $C 1$ e $C 2$, pois existem itens comuns nos dois encadeamentos, que seriam considerados duplamente, assim:

$$
C T=C(1)+C(2)+C(3)+C(6)+C(8)+C(10)+C(11)+C(13)
$$

Conforme já discutido na Seção 4, os custos utilizados neste trabalho não são absolutos, mas relativos a uma tolerância tomada como base de referência. O objetivo do cálculo do custo relativo para cada encadeamento é apenas o de compará-lo nas diversas condições apresentadas. Os custos de cada item foram calculados através da rotina CUSTO do programa, referida no Capítulo 4.

Considerando os valores das respectivas restrições funcionais $R f_{1}=0,79 \mathrm{~mm}$ e $R f_{2}=0,63 \mathrm{~mm}$ atribuídas aos encadeamentos em função do custo da não qualidade, observa-se que os dados de entrada referentes à Classe IT14, à especificação adicional e ao segundo encadeamento referente à classe IT13 não as atendem. Estes valores estão identificados em negrito na Tabela 8.1. As colunas referentes aos valores utilizados estão repetidas na Tabela 8.2, utilizada para o processo de síntese de tolerâncias.

As últimas linhas apresentam, para cada coluna, os seguintes resultados:

- As tolerâncias T1 e T2 do primeiro e do segundo encadeamentos, respectivamente, calculadas pelo método da soma da raiz dos quadrados, através da rotina de entrada de dados do programa a partir das Equações 8.1 e 8.3; 
Tabela 8.1: Valores opcionais para especificação - os valores das classes IT (ISO 286-1) referem-se às respectivas semi-tolerâncias; valores em itálico referem-se a itens com tolerâncias pré-determinadas

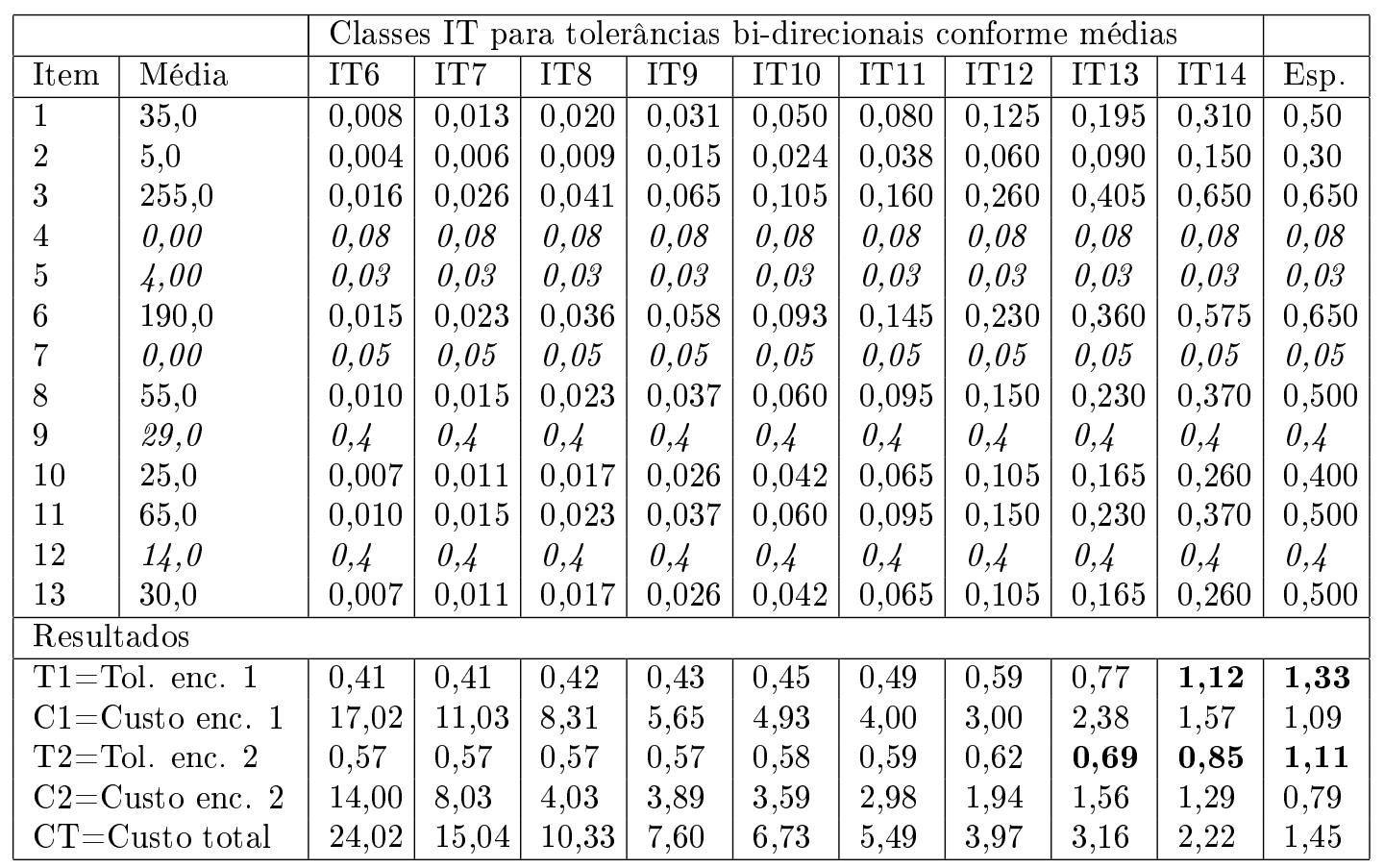

- Os custos relativos $\mathrm{C} 1$ e $\mathrm{C} 2$ dos encadeamentos, calculados através da rotina de cálculo de custo do programa através das Equações 8.2 e 8.4;

- O custo relativo total CT, do conjunto formado pelos dois encadeamentos, calculado através da Equação 8.5.

\subsection{Processo de síntese de tolerâncias}

A Tabela 8.2 mostra, na quarta e na sexta colunas, os resultados do cálculo de otimização do programa para valores da Classe IT14 e da especificação adicional do exemplo. As demais colunas mostram os resultados de cálculo realizados através dos métodos convencionais de alocação de tolerâncias, descritos no Capítulo 3 e ilustrados no memorial de cálculo no Apêndice E.

\subsection{Discussões}

Através de análise dos dados dos processos de análise e síntese de tolerâncias do exemplo, resumidos nas Tabelas 8.1 e 8.2, pode-se observar que:

1. Na Tabela 8.1 existe uma variação significativa dos valores dos custos re- 
Tabela 8.2: Resultados do processo de síntese de tolerâncias: Otimiz. Classe IT14= Otimização relativa à Classe IT14; Esp.: Especificação adicional; Otimiz. Esp.= Otimização relativa à especificação adicional; Tol. Iguais= Alocação por tolerâncias iguais; Fat. Prop.= Alocação por fator de proporcionalidade; Fat. Prec.= Alocação por fator de precisão; Fat. Peso= Alocação proporcional ao fator de peso

\begin{tabular}{|c|c|c|c|c|c|c|c|c|c|}
\hline Item & Média & $\begin{array}{l}\text { Classe } \\
\text { IT14 }\end{array}$ & $\begin{array}{l}\text { Otimiz. } \\
\text { Classe } \\
\text { IT14 }\end{array}$ & Esp. & $\begin{array}{l}\text { Otimiz } \\
\text { Esp. }\end{array}$ & $\begin{array}{l}\text { Tol. } \\
\text { Iguais }\end{array}$ & $\begin{array}{l}\text { Fat. } \\
\text { Prop. }\end{array}$ & $\begin{array}{l}\text { Fat. } \\
\text { Prec. }\end{array}$ & $\begin{array}{l}\text { Fat. } \\
\text { Peso }\end{array}$ \\
\hline 1 & 35,0 & 0,31 & 0,31 & 0,50 & 0,31 & 0,322 & 0,214 & 0,227 & 0,414 \\
\hline 2 & 5,0 & 0,15 & 0,13 & 0,30 & 0,18 & 0,322 & 0,104 & 0,119 & 0,401 \\
\hline 3 & 255,0 & 0,65 & 0,39 & 0,65 & 0,38 & 0,322 & 0,449 & 0,440 & 0,217 \\
\hline 4 & 0,00 & 0,08 & 0,08 & 0,08 & 0,08 & 0,08 & 0,08 & 0,08 & 0,08 \\
\hline 5 & 4,00 & 0,03 & 0,03 & 0,03 & 0,03 & 0,03 & 0,03 & 0,03 & 0,03 \\
\hline 6 & 190,0 & 0,575 & 0,38 & 0,65 & 0,38 & 0,322 & 0,397 & 0,399 & 0,192 \\
\hline 7 & 0,00 & 0,05 & 0,05 & 0,05 & 0,05 & 0,05 & 0,05 & 0,05 & 0,05 \\
\hline 8 & 55,0 & 0,37 & 0,13 & 0,50 & 0,13 & 0,139 & 0,160 & 0,151 & 0,114 \\
\hline 9 & 29,0 & 0,40 & 0,40 & 0,40 & 0,40 & 0,40 & 0,40 & 0,40 & 0,40 \\
\hline 10 & 25,0 & 0,26 & 0,13 & 0,40 & 0,13 & 0,139 & 0,113 & 0,116 & 0,160 \\
\hline 11 & 65,0 & 0,37 & 0,16 & 0,50 & 0,13 & 0,139 & 0,160 & 0,160 & 0,114 \\
\hline 12 & 14,0 & 0,40 & 0,40 & 0,40 & 0,40 & 0,40 & 0,40 & 0,40 & 0,40 \\
\hline 13 & 30,0 & 0,26 & 0,13 & 0,50 & 0,16 & 0,139 & 0,113 & 0,123 & 0,160 \\
\hline \multicolumn{10}{|c|}{ Resultados } \\
\hline \multicolumn{2}{|c|}{ T1=Tol. enc. 1} & 1,12 & 0,79 & 1,33 & 0,79 & 0,79 & 0,79 & 0,79 & 0,79 \\
\hline \multicolumn{2}{|c|}{$\mathrm{C} 1=$ Custo enc. 1} & 1,57 & 1,57 & 1,09 & 2,04 & 2,06 & 2,33 & 2,20 & 2,16 \\
\hline \multicolumn{2}{|c|}{$\mathrm{T} 2=$ Tol. enc. 2} & 0,85 & 0,63 & 1,11 & 0,63 & 0,63 & 0,63 & 0,63 & 0,63 \\
\hline \multirow{2}{*}{\multicolumn{2}{|c|}{$\mathrm{C} 2=$ Custo enc. 2}} & 1,29 & 1,59 & 0,79 & 1,59 & 1,59 & 1,81 & 1,71 & 1,79 \\
\hline & & 2,22 & 2,83 & 1,45 & 2,83 & 2,86 & 3,24 & 3,02 & 3,05 \\
\hline
\end{tabular}


lativos dos encadeamentos e total à medida que os valores das tolerâncias diminuem para classes de maior precisão. Esta característica, já esperada, mostra a evolução dos custos relativos dos conjuntos estudados em função das curvas de custo-tolerância utilizadas;

2. As tolerâncias dos encadeamentos principal e secundário das colunas da Classe IT14 e da especificação na Tabela 8.1 apresentam os menores custos relativos em relação a todas as outras classes, porém não atendem às restrições funcionais devido aos valores das tolerâncias especificadas para os componentes;

3. Os custos relativos dos encadeamentos, assim como o custo total dos processos de alocação não otimizada disponíveis nas últimas colunas da Tabela 8.2, são maiores que os dos processos otimizados, o que mostra a eficácia do método proposto;

4. Para o método convencional de alocação por tolerâncias iguais, entretanto, os resultados de custo dos encadeamentos e custo total são surpreendentemente próximos aos valores da otimização. Ao se analisar os valores alocados aos componentes observa-se, porém, que eles podem não estar em conformidade com a viabilidade dos processos de produção se consideradas as dimensões maiores. O método proposto permite, além da otimização dos custos de produção, uma limitação para que este fato não ocorra;

5. O método proposto para otimização, assim como os métodos similares, apresenta uma grande sensibilidade em relação à função custo adotada, o que pode ser observado através de análise das colunas de valores especificados e resultantes de otimização na Tabela 8.2. Recomenda-se, portanto, que os valores especificados sejam compatíveis com os valores das dimensões especificadas;

6. Devido à simplicidade e rapidez de resposta do método, pode-se conduzir várias tentativas de melhoria dos valores de otimização após validação dos mesmos pelos especialistas de processo, até que uma solução ótima definitiva seja adotada;

7. A variação do custo relativo, tanto nos resultados do processo de otimização, quanto nos resultantes dos métodos de alocação, é pequena quando comparada aos valores dos processos de análise de tolerância das outras classes IT de tolerâncias referidas na Tabela 8.1, conforme ilustra a Figura 8.1. Este fato pode ser explicado pelo atendimento destes conjuntos aos 
valores exatos das restrições funcionais e às características da função custo adotada. Porém, deve-se observar que, em produções em larga escala, pequenos ganhos de custos em componentes individualmente podem resultar em ganhos significativos durante a vida de um produto;

8. A comparação dos valores dos eventuais erros envolvidos no cálculo das tolerâncias dos componentes, tais como os relativos ao deslocamento da média da distribuição, em relação aos valores da variação dos custos relativos do processo de otimização, não pode ser realizada facilmente. Avaliação destes erros depende de vários fatores, principalmente aos relativos a processos específicos de fabricação, não conhecidos na fase de projeto do produto. Este fato, porém, não é inerente ao método proposto, mas afeta também métodos similares de otimização. Independentemente do valor das variações de custo relativo obtidas, o método garante otimização, ou seja, o valor encontrado será o mínimo desde que os dados utilizados para entrada da função custo estejam corretos.

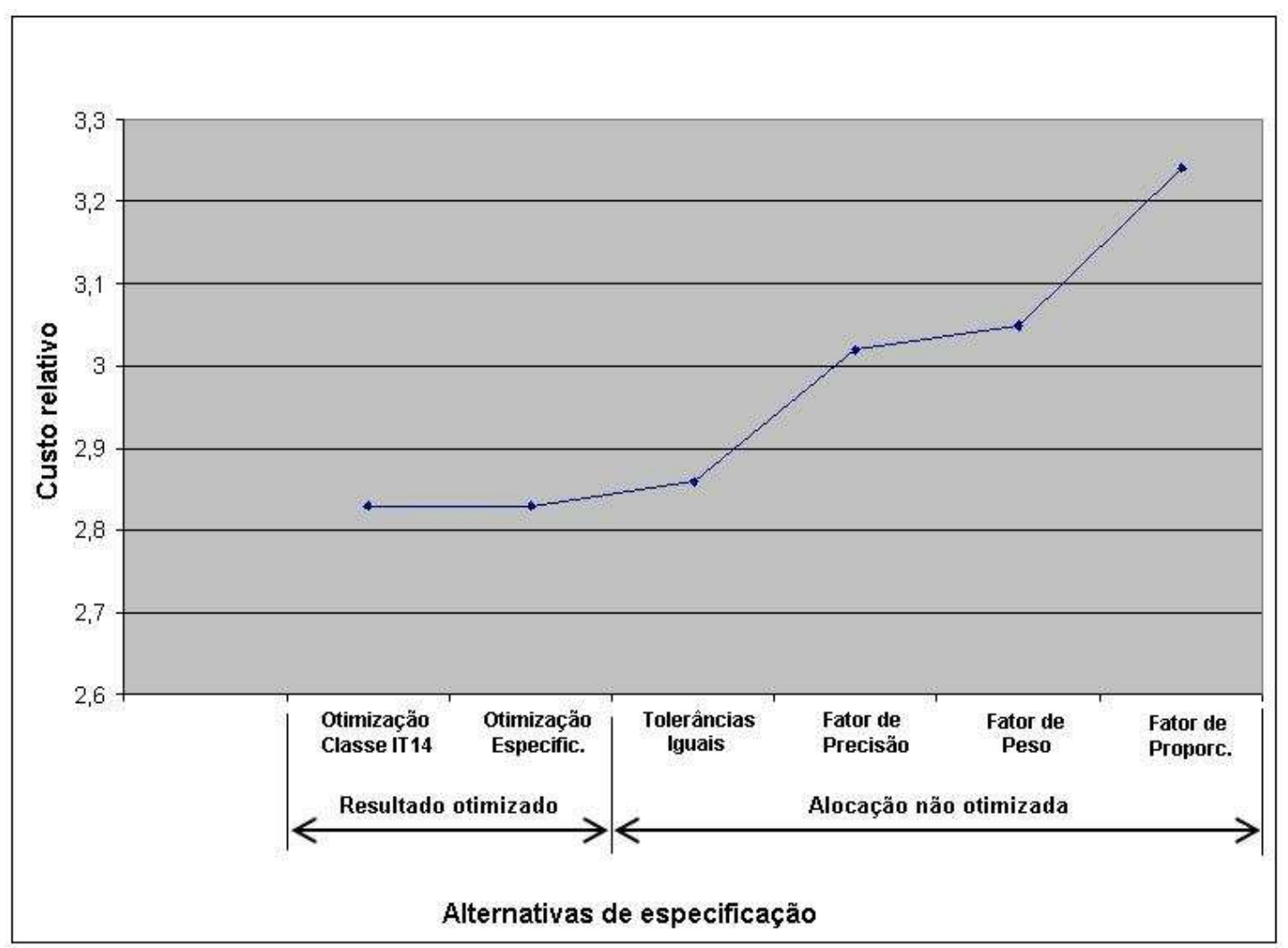

Figura 8.1: Variação do custo relativo entre alternativas de especificação que atendam às restrições funcionais do sistema.

As vantagens na aplicação do método proposto podem, portanto, ser resumidas em: 
- Os custos da não qualidade são considerados prioritariamente através da determinação das restrições funcionais;

- A viabilidade dos processos de produção de cada componente pode ser considerada individualmente;

- Os custos de produção relativos às tolerâncias são otimizados através de processo de baixa complexidade e de tempo reduzido de processamento, permitindo a utilização de programas de computador de fácil disponibilidade. 


\section{Conclusões}

O presente trabalho apresenta um estudo sobre tolerâncias dimensionais no projeto de conjuntos mecânicos. O método de otimização proposto, ilustrado através de estudo de caso, apresenta vantagens competitivas em relação a métodos similares disponíveis, isto é, os que consideram a otimização por custos de fabricação e custos da não qualidade simultaneamente:

- A primeira é a maior simplicidade na determinação da função para cálculo do custo de fabricação, que se baseia em intervalos conectados por funções lineares. Quando houver possibilidade do levantamento de custos de fabricação localmente, este procedimento facilita a determinação da função custo, que apresenta a característica adicional de um menor tempo de processamento. Nos trabalhos pesquisados a função custo é definida por uma equação única gerada por aproximação a partir de dados empíricos e, por apresentar forma simplificada, herda erros significativos do processo de ajuste de pontos;

- Os trabalhos mencionam a utilização de programas de cálculo, porém não apresentam a descrição dos mesmos e as eventuais dificuldades na elaboração dos respectivos códigos. Sua utilidade prática, portanto, fica assim comprometida. O algoritmo proposto para o exemplo foi desenvolvido para utilização em linguagem de programa de fácil disponibilidade, podendo ser utilizado como referência para outros casos;

- O algoritmo proposto considera limites mínimos de tolerâncias para que a capacidade do processo de produção previsto para o componente possa ser considerada;

- Outra vantagem é o controle sobre o valor estabelecido para o custo da não qualidade, realizado através da especificação de um fator de segurança econômico que considera as perdas financeiras projetadas para valores de tolerâncias que excedam limites determináveis. Esta pode ser uma decisão 
estratégica da empresa, controlada pelo gerente do projeto. Nos casos similares a otimização é realizada para a obtenção de um custo total mínimo da função que considera a soma dos custos de fabricação e da não qualidade, não havendo um controle sobre seu resultado.

Os conceitos teóricos apresentados neste trabalho, assim como o método para a especificação de tolerâncias dimensionais proposto, podem servir como base para novos desenvolvimentos relativos ao tema. 


\section{Referências}

1 BJORKE, O. Computer-Aided Tolerancing: Tapir Publishers, 1978.

2 TRUCKS, H. E. Designing for Economical Production. 2nd.. ed. Michigan: Society of manufacturing Engineers, 1987.

3 CHASE, K. W. Tolerance allocation methods for designers. ADCATS, n. 99-6, 1999.

4 HAHN, G. H.; SHAPIRO, S. S. Statistical Models in Engineering. New York: John Wiley and Sons, 1967.

5 CHOI, H.-G. R.; PARK, M.-H.; SALISBURY, E. Optimal tolerance allocation with loss functions. Journal of Manufacturing Science and Engineering, v. 122, p. 529-535, August 2000.

6 SWIFT, K. G.; BOOKER, J. D. Process Selection from Design to Manufacture. London: Arnold - John Wiley and Sons Inc., 1998.

7 CHASE, K. W.; GREENWOOD, W. H. Design issues in mechanical tolerance analysis. Manufacturing Review, ASME, v. 1, n. 1, p. 50-59, Mar. 1988.

8 TAGUCHI, G.; ELSAYED, E.; HSIANG, T. Quality Engineering in Production Systems. New York: McGraw-Hill, Inc., 1989.

9 KUME, H. Statistical Methods for Quality Improvement. Tokyo: The Association for Overseas Technical Scholarship-AOTS-ISBN 85-85247-43-6, 1987.

10 NETO, P. L. O. C. Estatística. São Paulo: Editora Edgard Blücher Ltda., 1977 .

11 BALAKSHIN, B. Fundamentals of Manufacturing Engineering. Moscow: Mir Publishers, 1971.

12 CREveling, C. M. Tolerance Design. New York: Addison-Wesley Longman, Inc., 1997.

13 HAUGEN, E. B. Probabilistic Approaches in Design. New York: John Wiley and Sons, 1968.

14 SPOTTS, M. F. Dimensioning and Tolerancing for Quantity Production. New Jersey: Prentice-Hall Inc., 1983.

15 FOSTER, L. W. Geo-Metrics III - The Application of Geometric Dimensioning and Tolerancing Techniques. Massachusetts: Addison-Wesley Longman Inc., 1994. 
16 NBR 6049:1997 Tolerâncias geométricas - Tolerâncias de forma, orientação, posição e batimento - Generalidades, símbolos, definições e indicações em desenho. .

17 WIRTZ, A. Vektorielle Tolerierung zur Qualitätssteuerung in der Mechanischen Fertigung. Annals of the CIRP, v. 37, p. 493-498, 1998.

18 MARTINSEN, K. Statistical process control using vectorial tolerancing. Proceedings of the 4 th CIRP Seminar on Computer-Aided Tolerancing, p. 195-210, April 1995.

19 ASME Y14.5.1M: 1994 - Matematical Definition of Dimensioning and Tolerancing Principles.

20 ISO 286-1:1988- ISO systems of limits and fits - Part 1- bases of tolerances, deviations and fits.

21 ASME ANSI B4.2:1978 - Preferred metric limits and fits.

22 ASME Y14.5M: 1994 - Dimensioning and Tolerancing.

23 UMARAS, E.; TSUZUKI, M. S. G. Design considerations on optimum application of geometric dimensioning and tolerancing. SAE Technical Papers2007-01-2594, 2007.

24 UMARAS, E.; TSUZUKI, M. S. G. Tolerâncias dimensionais e de forma: Fatores de influência nos processos de estampagem. Corte e Conformação de Metais 2009, 2009.

25 Ullman, D. G. The Mechanical Design Process. Singapore: McGraw-Hill Inc., 1992.

26 DIETER, G. E. Engineering Design - A Materials and Procesing Approach. New York: McGraw-Hill Book Company, 1983.

27 PAHL, G.; BEITZ, W.; FELDHUSEN, J.; GROTE, K.-H. Projeto na Engenharia. São Paulo: Editora Edgar Blucher, 2005.

28 TAGUCHI, G. Taguchi on Robust Technology Development. New York: ASME Press, 1993.

29 ISO1101:1993 Technical Drawings - Geometrical Tolerancing - Tolerances of form, orientation, location and runout.

30 NBR 6158:1995 Sistemas de tolerâncias e ajustes.

31 BRAlLA, J. C. Handbook of Product Design for Manufacturing - A

Practical Guide to Low Cost Production: McGraw-Hill, 1986.

32 YANKEE, H. W. Manufacturing Processes. New Jersey: Prentice Hall Inc., 1979 .

33 ISO 286-2:1988- ISO systems of limits and fits - Part 2- tables of standard tolerance grades and limit deviations for holes and shafts.

34 FANG, X. D.; ZHANG, Y. A new algorithm for minimizing the surplus parts in selective assembly. Computers Ind. Engng., v. 28, n. 2, p. 341-350, 1995. 
35 KANNAN, S.; JAYABALAN, V. A new grouping method to minimize surplus parts in selective assembly for complex assemblies. International Journal of Production Research, v. 39, n. 9, p. 1851-1863, 2001.

36 KANNAN, S.; JAYABALAN, V.; JEEVANANTHAM, K. Genetic algorithm for minimizing asembly variation in selective assembly. International Journal of Production Research, v. 41, n. 14, p. 3301-3313, 2003.

37 KANNAN, S.; JEEVANANTHAM, K.; JAYABALAN, V. Modelling and analysis of selective assembly using Taguchi's loss function. International Journal of Production Research, v. 46, n. 15, p. 4309-4330, 2008.

38 COX, N. D. How to Perform Statistical Tolerance Analysis. Milwaukee, Wisconsin: ASQC, 1986.

39 SHAPIRO, S. S.; GROSS, A. J. Statistical Modeling Techniques. New York: Marcel Dekker, Inc., 1981.

40 NIGAM, S. D.; TURNER, J. U. Review of statistical approaches to tolerance analysis. Computer Aided Design, v. 27, n. 1, p. 6-15, 1995.

41 CHASE, K. W.; PARKINSON, A. R. A survey of research in the application of tolerance analysis to the design of mechanical assemblies. Research in Engineering Design, n. 3, p. 23-37, Apr. 1991.

42 SPOTTS, M. F. Mechanical Design Analysis. New Jersey: Prentice-Hall Inc., 1964.

43 FORTINI, E. Dimensioning for Interchangeable Manufacture: Industrial Press Inc., 1967.

44 WADE, O. R. Tolerance Control in Design and Manufactuting. New York: Industrial Press Inc., 1967.

45 UMARAS, E.; TSUZUKI, M. S. G. Tolerance optimization considerations applied to the chain dimensioning of mechanical assemblies. SAE Technical Papers-2008-36-010\%, 2008.

46 SINGH, P. K.; JAIN, P. K.; JAIN, S. C. Important issues in tolerance design of mechanical asemblies. part 2: tolerance synthesis. J. Engineering Manufacture, v. 223, p. 1249-1287, Apr. 2009.

47 LATTA, L. W. Least cost tolerancing. Product Engng., v. 16, p. 111-113, 1963.

48 PETERS, J. Tolerancing the components of an assembly for minimum cost. J. Engng. for Industry, v. 92, p. 677-682, 1970.

49 CHASE, K. W.; GREenwoOd, W. H.; LOOSLI, B. G.; HAUGLUnd, L. F. Least cost tolerance allocation for mechanical assemblies with automated process selection. Manufacturing Review, v. 3, n. 1, p. 49-59, Mar. 1990.

50 KUMAR, V. Optimization of tolerance for minimum cost of satisfactory journal bearings manufacturing. Wear, n. 86, p. 21-27, 1983. 
51 ANSARY, M. D. A.; DEIAB, I. M. Concurrent optimization of design and machining tolerances using the genetic algorith method. Int. J. Mach. Tools Manufact., v. 37, n. 12, p. 1721-1731, 1997.

52 LEE, J.; JOHNSON, G. E. Optimal tolerance allotment using a genetic algorithm and truncated monte carlo simulation. Computer-Aided Design, v. 25, n. 9, p. 601-611, Sept. 1993.

53 SHAN, A.; ROTH, R. N.; WILSON, R. J. Genetic algorithms in statistical tolerancing. Mathematical and Computer Modelling, n. 38, p. 1427-1436, 2003.

54 WU, C.-C.; CHEN, Z.; TANG, G.-R. Component tolerance design for minimum quality loss and manufacturing cost. Computers in Industry, n. 35, p. 223-232, 1998.

55 CHENG, B.-W.; MAGHSOODLOO, S. Optimization of mechanical assembly tolerances by incorporating Taguchi's quality loss function. Journal of Manufacturing Systems, v. 14, n. 4, p. 264-276, 1995.

56 HUANG, Y. M.; SHIAU, C.-S. An optimal tolerance allocation model for assemblies with consideration of manufacturing cost, quality loss and reliability index. Assembly Automation, v. 29, n. 3, p. 220-229, 2009.

57 PENG, H. P.; JIANG, X. Q.; XU, Z. G.; LIU, X. J. Optimal tolerance design for products with correlated characteristics by considering the present worth of quality loss. Int. J. Adv. Manuf. Technol., v. 39, p. 1-8, 2008.

58 HUANG, M. F.; ZHONG, Y. R.; XU, Z. Z. Concurrent process tolerance design based on minimum product manufacturing cost and quality loss. Int. J. Adv. Manuf. Technol., v. 25, p. 714-722, 2005.

59 BENDER, A. Statistical tolerancing as it relates to quality control and the designer. SAE Trans., v. 77, p. 1965-1971, May 1968.

60 MANSOOR, E. M. The application of probability to tolerances used in engineering designs. Proc. Inst. Mech. Eng., v. 178, p. 29-51, 1963.

61 ALFORD, L. R. Cost and Production Handbook. New York: The Ronald Press Company, 1943.

62 NAKAZAWA, H. Principles of Precision Engineering. Oxford: Oxford University Press, 1994.

63 SPOTTS, M. F. Allocation of tolerances to minimize cost of assembly. Journal of Engineering for Industry, Transactions of ASME, v. 95, p. 762-764, August 1973.

64 CHASE, K. W.; GREENWOOD, W. H. Computer-aided tolerance selection-cats user guide. ADCATS Report, n. 86-2, May 1986.

65 SPECKHART, F. H. Calculation of tolerance based on a minimum cost approach. Journal of Engineering for Industry, Transactions of ASME, v. 94, p. 447-453, May 1972. 
66 DONG, Z.; HU, W.; XUE, D. New production cost-tolerance models for tolerance synthesis. Journal of Engineering for Industry, v. 116, p. 199-206, May 1994.

67 Dimitrellou, S. C.; DIPLARIS, S. C.; SFANTSIKOPOUlOS, M. M. Cost-competent tolerancing in cad. Int. Journal of Advanced Manufacturing Technology, n. 35, p. 519-526, 2007.

68 NIEMINEN, J.; TUOMI, J. Design with features for manufacturing cost analysis. Product Modeling for Computer-Aided Design and Manufacturing J. Turner, J. Pegna and M. Wozny (Editors)- Elsevier Science Publishers RV. (North-Holland), p. 317-330, 1991.

69 TAGUCHI, G. Introduction to Quality Engineering. Hong Kong: Asian Productivity Organization, 1986.

70 FOWLER, T. C. Value Analysis in Design: Van Nostrand Reinhold, 1990.

71 PARK, R. J. Value Engineering: a plan for invention: St. Lucie Press, 1999.

72 BOOTHROYD, G. Product Design for Manufacture and Assembly: Martin Dekker, 1994.

73 SAEJ1596:2000 Automotive V-Ribbed Belt Drive General Guidelines.

74 BELT - United States Patent Application Publication No. US2004/0018906A1.

75 MADSEN, D. A. Geometric Dimensioning and Tolerancing: The Goodheart-Willcox Company Inc., 2003.

76 SWEENEY, S. Statistical tolerancing for combinations of coaxial features and clearance fits. Quality Engineering, v. 16, n. 1, p. 13-20, April 2003.

77 NGOI, B. K. A.; LIM, L. E. N.; ONG, A. S.; LIM, B. H. Applying the coordinate tolerance system to tolerance stack analysis involving position tolerance. Int. J. Adv. Manuf. Technol., v. 15, p. 404-408, 1999.

78 NGOI, B. K. A.; LIM, L. E. N.; ANG, P. S.; ONG, A. S. Assembly tolerance stack analysis for geometric characteristics in form control - the catena method. Int. J. Adv. Manuf. Technol., v. 15, n. 292-298, 1999.

79 NGOI, B. K. A.; TAN, C. S.; GOH, L. C. Graphical approach to assembly tolerance stack analysis the quickie gdt method. Proc. Instn. Mech. Engrs., v. 211-B, p. 463-472, 1997.

80 NGOI, B. K. A.; LIM, B. H.; ANG, P. S. Nexus method for stack analysis of geometric dimensioning and tolerancing (GDT) problems. International Journal of Production Research, v. 38, n. 1, p. 21-37, 2000.

81 NGOI, B. K. A. The generic capsule approach to tolerance stack analysis. International Journal of Production Research, v. 36, n. 12, p. 3273-3293, 1998.

82 GOOLDY, G. Geometric Dimensioning and Tolerancing: Prentice Hall, 1995. 
83 MEADOWS, J. D. Geometric Dimensioning and Tolerancing: Marcel Dekker Inc., 1995.

84 WILSON, B. A. Design Dimensioning and Tolerancing: The GoodheartWillcox Company Inc., 1992.

85 HENZOLD, G. Handbook of Geometric Tolerancing: John Wiley and Sons, 1997.

86 JENSEN, C. Geometric Dimensioning and Tolerancing: Delmar Publishers Inc., 1993.

87 KRULIKOWSKI, A. Fundamentals of Geometric Dimensioning and Tolerancing: Delmar Publishers Inc., 1991.

88 PUNCOCHAR, D. E. Interpretation of Geometric Dimensioning and Tolerancing. New York: Industrial Press Inc., 1996.

89 WIRTZ, A. Vectorial tolerancing for production quality control and functional analysis in design. Proceedings of the CIRP International Working Seminar on Computer-Aided Tolerancing, p. 77-84, 1991.

90 FORD DESIGN INSTITUTE Failure Mode and Effects Analysis., February 2004 .

91 MIL-STD-1629A:1980- Procedures for performing a failure mode, effects and criticality analysis - Dept. of Defense-USA.

92 SAEJ1739:2002 - Potential Failure Mode and Effects Analysis in Design (Design FMEA),Potential Failure Mode and Effects Analysis in Manufacturing and Assembly Processes (Process FMEA), and Potential Failure Mode and Effects Analysis for Machinery (Machinery FMEA). 


\section{Apêndice A - Conceitos de estatística aplicados a processos de fabricação}

O conceito de tolerâncias dimensionais somente existe devido à impossibilidade da fabricação de uma dimensão especificada num valor exato. Se esta restrição não existisse, o problema das tolerâncias dimensionais também não existiria e componentes do mesmo tipo apresentariam intercambiabilidade perfeita, não existiriam problemas de montagem e as restrições funcionais de conjuntos poderiam ser tratadas de modo simplificado, pois abordariam principalmente variações decorrentes do uso, tais como desgastes e deformações estruturais e/ou térmicas. Assim sendo, a questão que surge é a de quanto e como a dimensão pode variar em função do processo de fabricação e como esta variação afeta o conjunto, para que exista a viabilidade técnica da produção de cada componente e do conjunto em condições econômicas aceitáveis para a formação do custo do produto. Observase, na prática, que variações são inevitáveis por maior que seja o esforço para a manutenção da dimensão nominal especificada. Esta seção do trabalho aborda, de modo sucinto e objetivo, os conceitos relativos ao processo de fabricação e os conceitos estatísticos fundamentais ao entendimento da análise e síntese de tolerâncias.

\section{A.1 O conceito de variação}

Vários fatores de influência sobre tolerâncias dimensionais estão envolvidos em um processo de fabricação. Nas peças usinadas há a participação do equipamento, do dispositivo de posicionamento e fixação, do dispositivo de fixação da ferramenta, da própria ferramenta, do material bruto e do ambiente de trabalho ${ }^{[11]}$. Por diversas razões, estes fatores variam constantemente, resultando em variações nas características dimensionais da peça usinada. Portanto, mesmo que componentes sejam produzidos através de um mesmo processo de fabricação, eles diferem tanto entre si quanto de um protótipo ideal em relação às suas características de 
qualidade. Este fenômeno é chamado de variação $\left(\right.$ scatter $^{[11]}$, variability $^{[1,14]}$. As variações de um processo são devidas a dois tipos de causas ${ }^{[9,14]}$ :

- causas aleatórias ( a fatores aleatórios, complexos e desconhecidos, que não podem ser nem rastreados nem medidos. São consequências naturais do processo e ocorrem mesmo quando todas as condições tenham sido mantidas constantes a um nível econômico possível. Embora estas causas possam ter pouca influência individualmente, seu efeito cumulativo afeta significativamente a variabilidade das medições do processo;

- causas assinaláveis (assignable causes ${ }^{[14]}$ ), também conhecidas como causas especiais, não ocorrem aleatoriamente, mas são causadas por fatores dominantes, resultantes de alterações específicas que tenham ocorrido nos processos de produção ou inspeção. Estas alterações podem ocorrer, por exemplo, por:

- pequenas variações nas propriedades do material em diferentes lotes;

- desgaste e substituição de ferramentas;

- alterações na rotação, potência, propriedades dos lubrificantes e vários outros fatores.

Não é sempre possível fazer uma diferenciação rápida e precisa entre as causas aleatórias e assinaláveis. Em muitos casos, as variações devidas às causas aleatórias são tão grandes que as causas assinaláveis são difíceis de serem reconhecidas e removidas. Quando as variações devidas às causas assinaláveis são localizadas e eliminadas individualmente, o estado desejado de estabilidade ou controle é atingido. O processo é considerado então sob controle estatístico. O método utilizado para esta finalidade é conhecido por Controle Estatístico de Processo CEP (Statistical Process Control - SPC). Caso as variações em um processo sob controle estatístico sejam muito grandes, geralmente é recomendável transferi-lo para equipamento mais robusto do que despender mais tempo na tentativa de melhorá-lo ${ }^{[11]}$.

\section{A.2 Variáveis aleatórias}

Como o conceito de tolerâncias está associado fundamentalmente à variabilidade dos processos de produção, o entendimento do que sejam variáveis aleatórias 
faz-se necessário, pois elas são resultado natural dos processos e permitem o desenvolvimento do estudo de tolerâncias através da teoria estatística. Conforme Hahn e Shapiro ${ }^{[4]}$ - Capítulo 2, "uma variável aleatória é uma função definida em um espaço amostral". As variáveis aleatórias podem ser de dois tipos: discretas e contínuas. As variáveis aleatórias discretas estão associadas a espaços amostrais discretos, isto é, formados por um número finito ou infinito de valores que possam ser contados. Por exemplo, o espaço amostral das possibilidades de resultados do lançamento de dois dados é formado por 36 possíveis pares de valores. As variáveis aleatórias associadas a este espaço amostral discreto podem ser definidas como a soma, a meia soma, o quadrado da soma e quaisquer outras combinações dos valores resultantes de cada lançamento. Outro exemplo poderia ser o de um processo que resulte em características atributivas como lotes de peças "sem defeito" e "com defeito". Neste caso as variáveis aleatórias poderiam ser números inteiros associados a combinações de peças com e sem defeito em cada lote. As variáveis aleatórias contínuas, por outro lado, estão associadas a espaços amostrais de valores contínuos e infinitos. Podem assumir quaisquer valores em um ou mais intervalos; devido à sua natureza, não podem ser contadas, mas podem ser medidas. Exemplos poderiam ser: a altura de um indivíduo em um grupo de pessoas, ou o percentual de defeitos em diferentes lotes de fundição. A interpretação de uma variável contínua é a de que se trata de um valor aproximado, já que não existem instrumentos de medição capazes de oferecer precisão absoluta e, mesmo que existissem, não haveria interesse nem sentido em se querer determinar uma grandeza contínua com todas as casas decimais ${ }^{[10]}$. Assim, ao se executar uma medição de uma dimensão, esta deve ser interpretada como uma aproximação compatível com o nível de precisão e com o critério de medição utilizados. Por exemplo, se o resultado da medição de um diâmetro de uma peça, com um instrumento adequado à precisão centesimal, for 12,78 mm, deve-se considerar que o valor exato esteja entre 12,775 e 12,785 mm. Assim, a aproximação implícita ao se considerar o valor de uma variável aleatória contínua será de, no máximo, metade da precisão com que os dados são medidos ${ }^{[10]}$. Conforme definições acima, as dimensões de características de componentes utilizadas para o estudo de tolerâncias, que são o objetivo deste trabalho, são consideradas variáveis aleatórias contínuas, já que suas dimensões podem ser consideradas em nível infinitesimal. Porém, considerada a característica da precisão de medição, as técnicas de extração de informações de dados da Estatística Descritiva ${ }^{1}$ são idênticas às variáveis aleatórias discretas. Diferenças são consideradas apenas na

\footnotetext{
${ }^{1}$ A Estatística Descritiva é a parte da ciência Estatística que trata da organização e descrição dos dados experimentais.
} 
interpretação e descrição gráfica dos resultados. Uma propriedade importante das variáveis aleatórias é a de que uma função de uma variável aleatória é também uma variável aleatória ${ }^{[4]}$.

\section{A.3 Gráficos de controle}

O melhor método para a avaliação da variação do processo e para a observação do seu controle em relação às causas assinaláveis e aleatórias é a elaboração do gráfico de controle, proposto originalmente por W. A. Shewart em 1924 ${ }^{[9]}$. Na coordenada das abcissas são colocados os dados de medição da característica de controle (exemplo: diâmetro acabado por torneamento) de um componente produzido em um lote de fabricação, na ordem de fabricação. Na coordenada das ordenadas é marcada a posição de uma linha central, que identifica a dimensão nominal da peça, por exemplo, e as posições de outras linhas simétricas em relação à central, indicando limites de controle. A Figura A.1 ilustra a forma básica de um gráfico de controle. Vários tipos de gráfico foram criados para finalidades distintas e estão identificados na obra de Kume ${ }^{[9]}$. Através da observação do gráfico de controle, pode-se identificar se o processo está sob controle estatístico, isto é, não sujeito a causas assinaláveis. Várias evidências levam à conclusão de que o processo esteja fora de controle, tais como uma sequência de sete pontos ${ }^{2}$, tendência ${ }^{3}$ e pontos fora do limite de controle - como ilustra a Figura A.2. Kume $^{[9]}$ - Capítulo 7 - reporta vários outros casos de interpretação dos gráficos de controle.

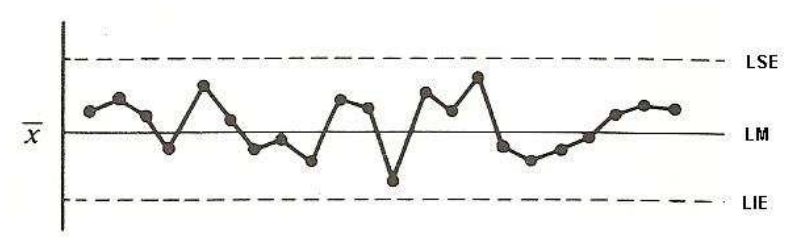

Figura A.1: Gráfico de controle. Fonte: Kume ${ }^{[9]}$.

\footnotetext{
${ }^{2}$ Entende-se por sequência a situação de pontos consecutivos em um mesmo lado da linha central.

${ }^{3}$ Entende-se por tendência a situação na qual os pontos formam uma linha contínua ascendente ou descendente.
} 


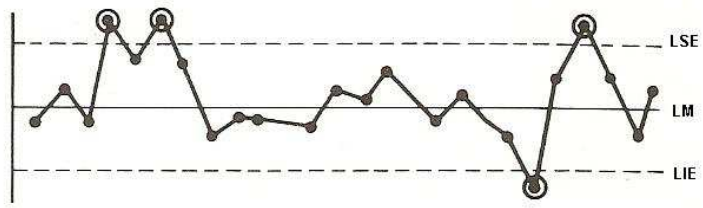

Figura A.2: Processo fora de controle por pontos fora da especificação. Fonte: Kume $^{[9]}$.

\section{A.4 O comportamento estatístico de um processo}

Como visto nas seções anteriores, é inevitável que os valores de um conjunto de dados apresentem alguma variação. Porém, o fato de serem diferentes não significa que sejam determinados de maneira desordenada, ou seja, eles são regidos por uma lei. Na prática, experiências no levantamento de dados em processos sob controle estatístico, mostram que estes dados seguem padrões determinados. A Figura A.3 ilustra uma folha de verificação obtida experimentalmente da coleta de dados de um processo produtivo. Pode-se observar uma forma bem definida que se mantém aproximadamente constante, mesmo com o aumento no número de dados coletados. Como será visto adiante neste texto, o estudo das tolerâncias

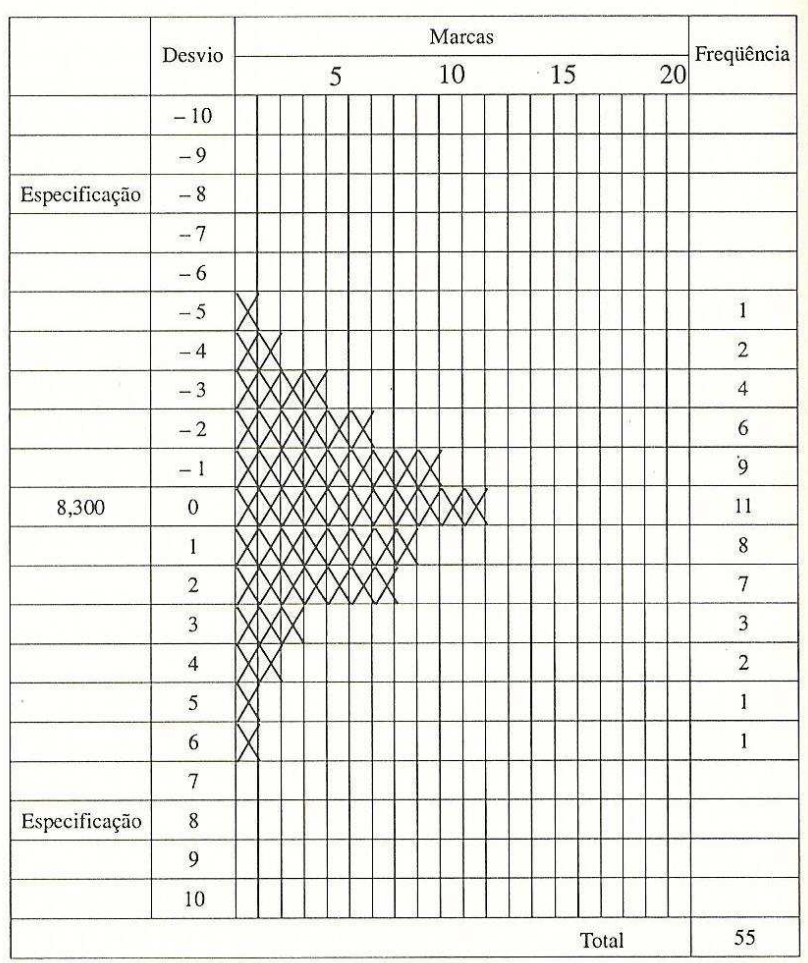

Figura A.3: Folha de verificação de processo. Fonte: Kume ${ }^{[9]}$ - Capítulo 2.

dimensionais baseia-se na interação entre distribuições de valores relativos a cada componente para a avaliação da distribuição resultante do conjunto formado por 
Tabela A.1: Valores de diâmetro de uma peça produzidas por processo de torneamento. Fonte: Costa Neto ${ }^{[10]}$

\begin{tabular}{|lllll|}
\hline \hline 21,5 & 21,4 & 21,8 & 21,5 & 21,6 \\
21,7 & 21,6 & 21,4 & 21,2 & 21,7 \\
21,3 & 21,5 & 21,7 & 21,4 & 21,4 \\
21,5 & 21,9 & 21,6 & 21,3 & 21,5 \\
21,4 & 21,5 & 21,6 & 21,9 & 21,5 \\
\hline
\end{tabular}

estes componentes. O problema inicial, portanto, é a determinação destas distribuições a partir do comportamento estatístico de um processo. Isto pode ser realizado a partir de um conjunto de dados relativos às medições de características de interesse, denominado amostra, em um processo sob controle estatístico (sem influência de causas assinaláveis). A ferramenta utilizada para esta determinação é denominada histograma. Para a sua construção deve ser elaborada uma tabela de frequências através do procedimento que será descrito a seguir. Para maior clareza, será utilizado o exemplo apresentado por Costa Neto ${ }^{[10]}$, referindo diâmetros de peças produzidas por um processo de torneamento, totalmente aplicável ao tema deste trabalho:

1. Cálculo da amplitude: os dados são classificados e os valores extremos são identificados. Sendo $X_{\min }$ e $X_{\max }$ os valores mínimo e máximo encontrados no conjunto de valores observados, a amplitude de variação $R$ é calculada pela relação:

$$
R=X_{\max }-X_{\min }
$$

Nos dados da Tabela A.1, $X_{\min }=21,2$ e $X_{\max }=21,9 \mathrm{~mm}$.

2. Determinação do número de classes: a questão do número de classes é teoricamente controversa ${ }^{[10]}$, sendo que diversos autores apresentam soluções diferentes. O número de classes escolhido afeta a forma da curva de frequências determinada pela amostra de dados. Costa Neto ${ }^{[10]}$ - Capítulo 2 - diferencia limites aparentes e limites reais através de exemplo, sugerindo a existência de um número máximo de classes representativo da distribuição real dos dados. Costa Neto ${ }^{[10]}$ apresenta um diagrama prático que pode ser utilizado como referência na determinação do número de classes $k$. Quando o número de valores for pequeno, não é recomendada a divisão em número de classes, mas a utilização dos próprios valores. No exemplo, o número de classes foi definido como $k=8$. 
Tabela A.2: Distribuição de freqüências e freqüências acumuladas a partir dos dados da Tabela A.1. Fonte: Costa Neto ${ }^{[10]}$

\begin{tabular}{|l|l|l|l|l|}
\hline \hline$x_{i}$ & $f_{i}$ & $F_{i}$ & $p_{i}$ & $P_{i}$ \\
\hline 21,2 & 1 & 1 & 0,04 & 0,04 \\
21,3 & 2 & 3 & 0,08 & 0,12 \\
21,4 & 5 & 8 & 0,20 & 0,32 \\
21,5 & 7 & 15 & 0,28 & 0,60 \\
21,6 & 4 & 19 & 0,16 & 0,76 \\
21,7 & 3 & 22 & 0,12 & 0,88 \\
21,8 & 1 & 23 & 0,04 & 0,92 \\
21,9 & 2 & 25 & 0,08 & 1,00 \\
\hline & 25 & & 1,00 & \\
\hline
\end{tabular}

3. Determinação da amplitude ou intervalo de classe: a amplitude total é dividida em intervalos de mesmo tamanho $h$ através da relação: $h=R / k$. É importante salientar que a amplitude das classes não deve ser fracionária em relação à precisão com que os dados são apresentados - caso isto ocorra, ajustes no número de classes devem ser realizados.

4. Obtenção da frequência de ocorrência de valores em cada classe: os dados são agrupados em relação às respectivas classes. Define-se a frequência $f_{i}$ pelo número de vezes que o valor foi observado na classe $i$. Se o número total de elementos observados for $n$ e o número de classes for $k$, resulta a relação:

$$
\sum_{i=1}^{k} f_{i}=n
$$

Pode-se definir também a freqüência relativa $p_{i}$, através da relação:

$$
p_{i}=\frac{f_{i}}{n}
$$

Das relações anteriores, resulta que:

$$
\sum_{i=1}^{k} p_{i}=1
$$

A definição de freqüência relativa mostrar-se-á útil adiante no texto. Para o exemplo foi elaborada a distribuição de freqüências ilustrada na Tabela A.2.

5. Construção do histograma: identificação de classes no eixo das abcissas e de frequências no eixo das ordenadas. Os limites da especificação podem 
ser agregados ao gráfico. Os valores de $x_{i}$ no caso das variáveis aleatórias contínuas devem ser considerados nos pontos médios das classes de frequências, haja vista a questão da precisão de medição referida na seção A.2. A ilustração do histograma do exemplo está representada através das linhas tracejadas da Figura A.4. A união dos pontos médios do histograma resulta em outra representação, a do polígono de frequências, representado na mesma figura através de linhas contínuas. A Figura A.5 ilustra outra representação importante do conjunto de dados do exemplo, o polígono de frequências acumuladas. Pode-se notar que quanto menores forem as amplitudes de classe, mais contínua será a forma das curvas gerada nas Figuras A. 4 e A.5.

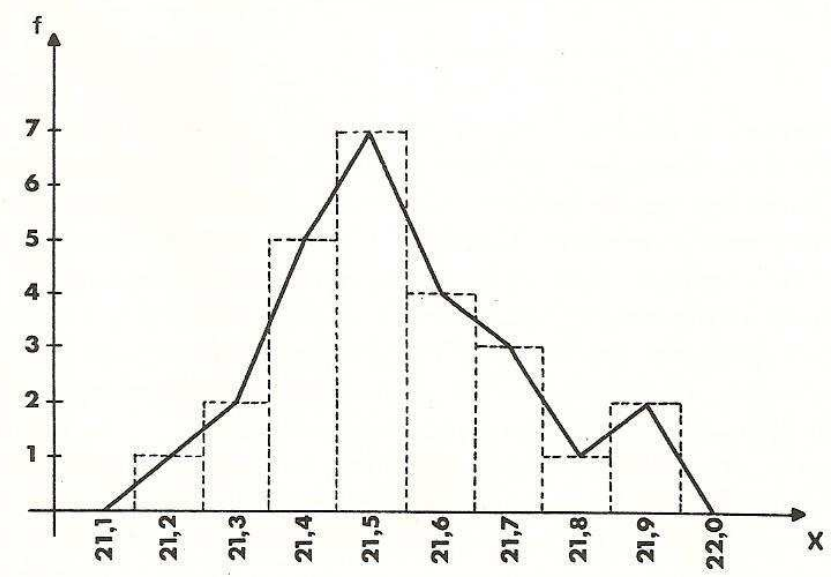

Figura A.4: Histograma e polígono de frequências gerados a partir dos dados da Tabela 4.2. Fonte: Costa Neto ${ }^{[10]}$

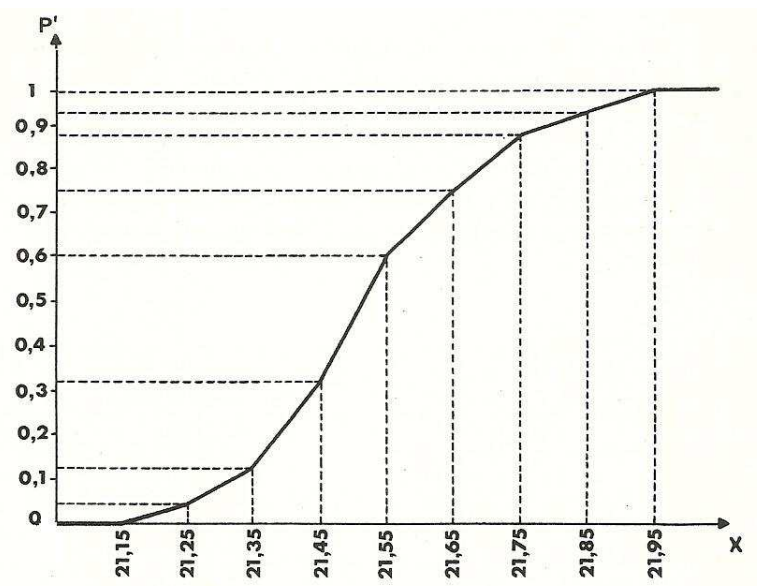

Figura A.5: Polígono de freqüências relativas acumuladas gerados a partir dos dados da Tabela 4.2. Fonte: Costa Neto ${ }^{[10]}$ 


\section{A.5 Considerações sobre amostragem nos proces- sos de produção}

Como as variáveis aleatórias de um processo sob controle dependem do espaço amostral (Seção A.2), a composição da amostra é de importância fundamental para a construção do modelo estatístico e sua adequada interpretação, sob risco de que todo o trabalho seja comprometido e os resultados estejam incorretos. O estudo estatístico do processo de fabricação de cada componente que gerará a análise de tolerâncias de um conjunto mecânico, objeto deste trabalho, é baseado no conceito de população de valores que representam o processo. O único meio para a inferência destes valores é através de amostragem, que deve, portanto, ser representativa desta população, ou seja, a amostra deve possuir suas mesmas características básicas. Dois tipos de amostragem são conhecidos: a probabilística e a não probabilística. A amostragem é probabilística quando todos os elementos da população tiverem probabilidade conhecida, diferente de zero, de pertencer à amostra. Caso contrário, a amostragem é não probabilística. Segundo essa definição, a amostragem probabilística implica num sorteio com regras bem determinadas, cuja realização só é possível se a população for finita e totalmente acessível $^{[10]}$. As técnicas de Estatística Indutiva ${ }^{4}$ pressupõem que as amostras utilizadas sejam probabilísticas. Neste trabalho consideraremos como população os valores obtidos de um processo sob controle, isto é, sujeito a condições que garantam que as variáveis sejam aleatórias, em um período de tempo finito. As amostras neste caso podem ser consideradas probabilísticas, pois partem de uma população finita e acessível.

\section{A.5.1 Tipos de amostragem probabilística}

A seguir são descritas as principais técnicas de amostragem probabilística ${ }^{[10]}$. Na próxima seção serão abordados alguns problemas específicos relativos à amostragem de características em processos produtivos:

\section{A.5.1.1 Amostragem casual simples}

Nesta técnica, todos os elementos da população tem igual probabilidade de pertencer à amostra e todas as possíveis amostras tem também igual probabilidade

\footnotetext{
${ }^{4}$ Entende-se por Estatística Indutiva o processo de se tirar conclusões sobre populações com base nos resultados observados em amostras extraídas destas populações. O termo "indutiva" decorre do processo de indução, ou raciocínio pelo qual, partindo-se do conhecimento de uma parte, procura-se tirar conclusões sobre a realidade do todo ${ }^{[10]}$.
} 
de ocorrer. Pode ser comparada a um sorteio lotérico, ou através de uma tabela ou programa de geração de números aleatórios, com o descarte dos elementos que não pertençam à população.

\section{A.5.1.2 Amostragem sistemática}

Esta técnica é aplicada quando os elementos da população se apresentam ordenados e a retirada dos elementos da amostra é realizada periodicamente. Um exemplo num sistema produtivo seria a retirada de um elemento para constituir a amostra em cada dez itens produzidos. A principal vantagem da utilização desta técnica está na grande facilidade na determinação dos elementos da amostra. Porém, seu grande risco implícito, está na possibilidade de ciclos de variação da variável de interesse, especialmente se o período destes ciclos - por exemplo o desgaste da ferramenta de corte - coincidir com o período de retirada dos elementos da amostra.

\section{A.5.1.3 Amostragem por conglomerados}

Quando a população apresenta uma subdivisão em pequenos grupos - conglomerados - consiste no sorteio de um número suficiente destes conglomerados, os quais formarão a amostra. Ou seja, as unidades de amostragem sobre as quais é realizado o sorteio, passam a ser os conglomerados e não mais os elementos da população. Esta técnica é adotada por motivos de ordem prática ou econômica em itens produzidos em larga escala.

\section{A.5.1.4 Amostragem estratificada}

Quando a população se divide em subpopulações - estratos - onde a variável de interesse apresente comportamento substancialmente diverso, mas razoavelmente homogêneo dentro de cada estrato, pode-se aplicar a amostragem estratificada. Nestes casos, se o sorteio dos elementos da amostra for realizado sem a consideração da existência dos estratos, pode ocorrer que os diversos estratos não sejam convenientemente representados na amostra, o que poderia representar a existência de tendência, prejudicando a condição de aleatoriedade. Esta tendência será tanto maior quanto menor for o tamanho da amostra. Três tipos de amostragem estratificada podem ser considerados dependendo do número de elementos do estrato: uniforme, proporcional e ótima ${ }^{[10]}$. 


\section{A.5.1.5 Amostragem múltipla}

$\mathrm{Na}$ amostragem múltipla, a amostra é retirada em diversas etapas sucessivas. Dependendo dos resultados observados, etapas suplementares podem ser dispensadas. Esta técnica é empregada na inspeção por amostragem, sendo particularmente importante a amostragem dupla. Sua finalidade é diminuir o número médio de itens inspecionados a longo prazo, baixando consequentemente o custo de inspeção.

\section{A.5.2 Considerações especiais na amostragem de processos de produção}

Balakshin $^{[11]}$ - Capítulo 4 - coloca alguns conceitos interessantes sobre o problema da amostragem em processos de usinagem e sobre sua característica aleatória. Como exemplo, ele cita que, em condições normais, a variação do sobremetal em um lote de peças pode ser considerada aleatória. Porém, se as peças brutas forem medidas e ordenadas em ordem crescente em relação à dimensão do sobremetal, as peças usinadas resultantes estarão sujeitas a um fator sistemático e variarão conforme lei definida pela variação ordenada do sobremetal das peças brutas. Os processos de usinagem são dependentes da utilização de ferramentas sujeitas a desgaste devido ao atrito com a peça usinada. A Figura A.6 ilustra um caso típico de uma peça torneada. Como pode ser observado, devido ao desgaste da

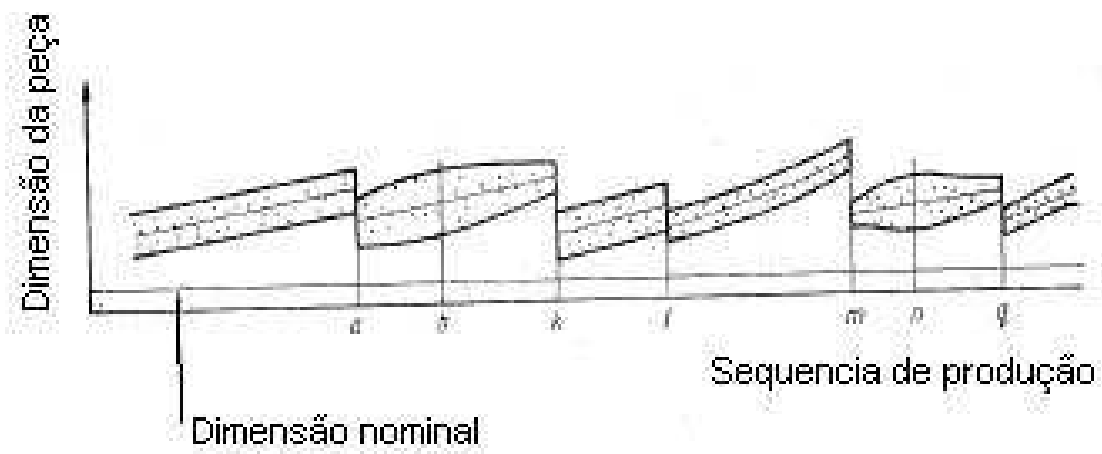

Figura A.6: Gráfico de medições individuais mostrando como o processo de usinagem é afetado por ajustes no sistema máquina-fixação-ferramenta-peça. Fonte: Balakshin [11]

ferramenta, o campo de variação dos fatores aleatórios é gradualmente deslocado em direção ao limite superior da especificação, até que o ajuste seja realizado através do reposicionamento ou da substituição da ferramenta de corte. Assim, 
durante o período entre dois ajustes, existe uma tendência, ou não aleatoriedade envolvida, que deve ser considerada para efeito de amostragem. Se as peças usinadas forem enviadas à próxima operação ou à montagem final na mesma ordem na qual foram produzidas, estarão sujeitas a fatores não aleatórios que comprometerão análises estatísticas de tolerâncias dimensionais. Porém, se as peças forem acumuladas em lotes e misturadas antes da próxima etapa, a variação pode ser considerada aleatória. Daí a importância dos tipos de amostragem citados no item anterior. Nos processos de estampagem, o problema é mais complexo ${ }^{[24]}$ : o projetista da ferramenta geralmente considera o limite superior da especificação para o início da vida da ferramenta. Assim, com o desgaste lento mas progressivo da ferramenta, o limite inferior da especificação será atingido apenas no fim da vida da ferramenta, ou nunca será atingido. Como esta tendência é considerada em um longo período de tempo, a variação resultante pode ser considerada aleatória, mas a variação da dimensão característica deve ser considerada no estudo de análise de tolerâncias conforme aplicável.

\section{A.6 Medidas descritivas de uma distribuição}

Embora a descrição detalhada do tipo de distribuição e da função que represente o comportamento estatístico de um processo seja importante nas aplicações práticas, o conhecimento de alguns fatores característicos destas distribuições já é suficiente para o desenvolvimento da maioria dos estudos relativos às tolerâncias dimensionais. Segundo Bjorke ${ }^{[1]}$ - Capítulo 5 - as dimensões de uma peça usinada são dependentes de dois fatores:

1. A distribuição probabilística do processo, ou seja, o modelo matemático que represente aproximadamente a distribuição de um grande número de dimensões;

2. O posicionamento da distribuição probabilística.

Estes fatores estão em acordo com o cálculo do encadeamento das tolerâncias dos componentes de um conjunto, onde se observa que as dimensões de cada componente são compostas por uma parte fixa - o posicionamento, ou a dimensão básica - e uma parte variável - a distribuição, ou o campo de tolerâncias. Estes fatores são representados respectivamente pelas medidas de posição e de dispersão, que serão apresentados a seguir, juntamente com outras medidas representativas da distribuição - as de assimetria e de achatamento. 


\section{A.6.1 Medidas de posição}

As medidas de posição localizam a distribuição de frequências sobre o eixo da variável. Três tipos de medidas de posição são conhecidos: a média, a mediana e a moda. A média e a mediana indicam o centro da distribuição de frequências, através de diferentes critérios. A moda indica a região de maior concentração de frequências na distribuição. ${ }^{5}$

\section{A.6.1.1 A média}

A média (mean), também chamada por média aritmética (arithmetic mean) e expectância (expected value), é a medida de posição mais utilizada para fins de análise estatística dentre as três citadas. Pode ser definida em função do tipo de variável aleatória considerada. Como já observado, devido à precisão de medição de valores de um processo, as variáveis contínuas podem ser tratadas como discretas, devido ao intervalo de medição considerado. Para variáveis aleatórias discretas, sendo $x_{i}(i=1,2,3, \ldots, n)$ um conjunto de dados, a média pode ser definida por ${ }^{[4,9,10]}$

$$
\bar{x}=\frac{\sum_{i=1}^{n} x_{i}}{n}
$$

Se observadas as Equações A.2 e A.3, a Equação A.5 pode ser reescrita

$$
\bar{x}=\frac{\sum_{i=1}^{k} f_{i}}{n}=\sum_{i=1}^{n} x_{i} p_{i} .
$$

Para uma variável contínua, a expectância é dada por ${ }^{6},{ }^{7}$

$$
E(x)=\mu(x)=\int_{-\infty}^{\infty} x f(x) d x .
$$

Como citado na seção A.2, uma função de uma variável aleatória é também

\footnotetext{
${ }^{5} \mathrm{~A}$ tradução de termos em inglês para o português, referentes à literatura voltada ao estudo da estatística, foi baseada no livro do Prof. Pedro Luiz de Oliveira Costa Neto ${ }^{[10]}$ e também na tradução do livro de Kume ${ }^{[9]}$ pelos professores Dario Ikuo Miyake e Alberto W. Ramos do Depto. de Engenharia de Produção da EPUSP. Os termos em inglês são apresentados entre parênteses para que não haja dúvidas de interpretação.

${ }^{6}$ Uma notação usual é a de representar a variável por letra maiúscula e seu valor por letra minúscula, por exemplo, $X$ e $x$ respectivamente. Neste texto será utilizada para os dois casos, por simplificação, a representação por letra minúscula, conforme sugerido por Hahn e Shapiro ${ }^{[4]}$.

${ }^{7} \mathrm{~A}$ notação $\mu(x)$ - média de uma população da variável aleatória contínua $x$ - é utilizada no estudo da Estatística Indutiva. No âmbito do Cálculo de probabilidades a notação $E(x)$ expectância de $x$ - é preferível.
} 
uma variável aleatória, então se $y(x)$ é uma função de $x$, tem-se:

$$
E(y)=\mu(y)=\sum_{i=1}^{n} y\left(x_{i}\right) p\left(x_{i}\right)
$$

para o caso discreto, e

$$
E(y)=\mu(y)=\int_{-\infty}^{\infty} y(x) f(x) d x
$$

para o caso contínuo.

A partir das equações anteriores, as seguintes propriedades da média podem ser consideradas $^{[4,10]}$ :

$$
\mu(c)=c
$$

Onde $c=$ constante

$$
\begin{gathered}
\mu(c \cdot x)=c \cdot \mu(x) \\
\mu\left(\sum_{i=1}^{n}\left(x_{i}\right)\right)=\sum_{i=1}^{n} \mu\left(x_{i}\right) \\
\mu\left(\sum_{i=1}^{n} b_{i} x_{i}\right)=\sum_{i=1}^{n} b_{i} \mu\left(x_{i}\right)
\end{gathered}
$$

Onde $x_{1}, x_{2}, \ldots x_{n}$ são variáveis aleatórias e $b_{1}, b_{2}, \ldots, b_{n}$ são constantes.

\section{A.6.1.2 A mediana}

A mediana (median), da mesma forma que a média, também procura caracterizar o centro da distribuição de frequências, mas com critério diferente. Ela é calculada com base na ordem dos valores que formam o conjunto de dados. Para variáveis aleatórias discretas, define-se mediana de um conjunto de $n$ valores ordenados, para $n$ impar, como igual ao valor $(n+1) / 2$ desse conjunto. Para $n$ par, a mediana pode ser definida como o valor médio situado entre o de ordem $(n / 2)$ e $(n / 2)+1^{[4,10]}$. O conceito ligado à mediana é o de dividir o conjunto ordenado de valores em duas partes com igual número de elementos ou com a mesma área sob uma distribuição contínua. Assim, para uma função densidade de probabilidade contínua $f(x)$, a mediana é definida como o ponto $z$ no qual ${ }^{[4]}$ :

$$
\int_{-\infty}^{z} f(x) d x=0,5
$$


A mediana é uma medida apropriada de tendência central para variáveis aleatórias que não são simetricamente distribuídas, pois não sofre a influência de valores extremos. Neste aspecto pode ser utilizada com vantagem como alternativa em relação à média ${ }^{[4,10]}$.

\section{A.6.1.3 A moda}

A moda (mode) de um conjunto de valores é definida como o valor de máxima frequência ou o ponto de maior probabilidade para o caso discreto e de maior densidade de probabilidade para o caso contínuo ${ }^{[10]}$.

Costa Neto ${ }^{[10]}$ sugere uma relação empírica para a média $E(x)$, a mediana $M d$ e a moda $M o$ :

$$
E(x)-M o=3[E(x)-M d]
$$

Hahn e Shapiro ${ }^{[4]}$ ilustram graficamente a localização relativa entre as três medidas de posição, conforme ilustra a Figura A.7.
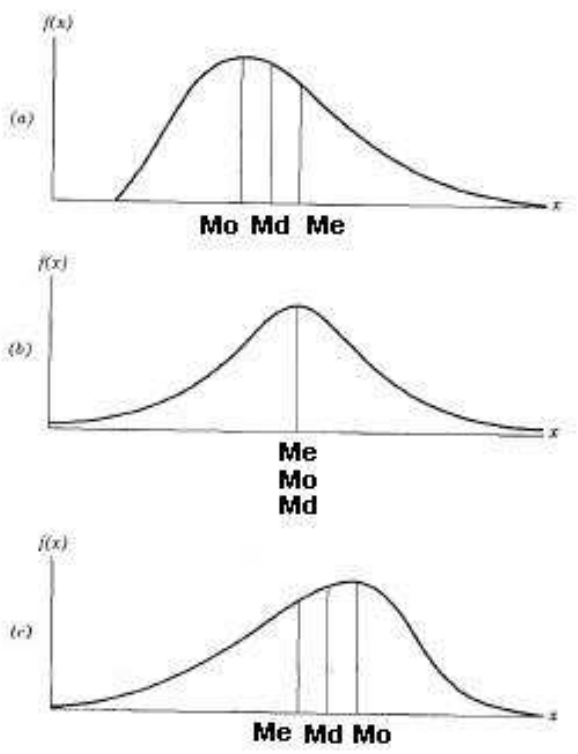

Figura A.7: Relação entre Média (Me), Mediana (Md) e Moda (Mo) para três funções densidade e probabilidade. Fonte: Hahn e Shapiro ${ }^{[4]}$.

\section{A.6.2 Medidas de dispersão}

As medidas de dispersão indicam o quanto os dados se dispersam em torno da região central e caracterizam o grau de variação de um conjunto de valores. As medidas de dispersão de interesse no cálculo estatístico são a amplitude, a variância e o coeficiente de variação. A amplitude, já definida através da Equação 
A.1, depende apenas de dois valores e, por conter pouca informação, apresenta uso limitado.

\section{A.6.2.1 A variância}

A variância (variance) de um conjunto de dados é definida como a média dos quadrados das diferenças dos valores em relação à média:

$$
s^{2}(x)=s_{x}^{2}=\frac{\sum_{i=1}^{n}\left(x_{i}-\bar{x}\right)^{2}}{n}
$$

Novamente, se observadas as Equações A.2 e A.3, a Equação A.16 pode ser reescrita:

$$
s^{2}(x)=\frac{\sum_{i=1}^{k}\left(x_{i}-\bar{x}\right)^{2} f_{i}}{n}=\sum_{i=1}^{k}\left(x_{i}-\bar{x}\right)^{2} p_{i}
$$

Para uma variável contínua, pode-se escrever:

$$
\sigma^{2}(x)=\int_{-\infty}^{\infty}\left((x-\mu(x))^{2} f(x) d x\right.
$$

Como $x$ geralmente é um número fracionário, as Equações A.16 e A.17 podem ser reescritas de forma mais conveniente, como demonstra Costa Neto ${ }^{[10]}$ :

$$
\begin{gathered}
s_{x}^{2}=\frac{\sum_{i=1}^{n} x_{i}^{2}}{n}-\bar{x}^{2} \\
s_{x}^{2}=\frac{\sum_{i=1}^{k} x_{i}^{2} f_{i}}{n}-\bar{x}^{2}
\end{gathered}
$$

Uma observação importante é que as Equações A.16 a A.20 são válidas para uma população. No caso de amostras, o denominador $n$ deve ser substituído por $(n-1)$ para que se evite problemas com tendências ${ }^{[4,10]}$. O motivo desta consideração deve-se ao menor número de graus de liberdade da amostra em relação ao da população ${ }^{8}$. As seguintes propriedades da variância são de grande importância ${ }^{[10]}$ - Apêndice, aplicáveis logicamente para valores da população e de

\footnotetext{
${ }^{8} \mathrm{O}$ conceito de grau de liberdade da amostra é abstrato, mas pode ser entendido por uma colocação relativamente intuitiva: quando a relação envolver os dados de uma população, a estatística terá $n$ graus de liberdade, pois haverá $n$ valores $x_{i}$ livres para consideração no cálculo, ou seja, todos podem variar aleatoriamente da mesma forma e a falta de um deles impedirá a determinação do parâmetro. Já a estatística $s^{2}(x)$, por usar $\bar{x}$ ao invés do parâmetro populacional $\mu$, tem um grau de liberdade a menos. Isso porque o cálculo dessa estatística pressupõe que anteriormente já se tenha calculado $\bar{x}$, para o qual já foram utilizados todos os valores da amostra e estes estariam, portanto, sendo utilizados pela segunda vez. Assim, por utilizar os dados da amostra por duas vezes consecutivas, um dos valores deve ser descartado, e haverá somente $(n-1)$ graus de liberdade.
} 
uma amostra:

$$
\sigma^{2}(c)=0
$$

Onde $c=$ constante

$$
\begin{gathered}
\sigma^{2}(c x)=c^{2} \sigma^{2}(x) \\
\sigma^{2}(x \pm y)=\sigma^{2}(x)+\sigma^{2}(y) \\
\sigma^{2}(x \pm c)=\sigma^{2}(x)
\end{gathered}
$$

\section{A.6.2.2 O desvio padrão}

O desvio padrão (standard deviation) é definido como a raiz quadrada positiva da variância. Como se expressa na mesma unidade da variável, apresenta maior interesse nas aplicações práticas.

$$
s(x)=s_{x}=\sqrt{s_{x}^{2}}
$$

para valores de uma amostra, e

$$
\sigma(x)=\sigma_{x}=\sqrt{\sigma_{x}^{2}}
$$

para valores de uma população. Uma relação interessante entre o desvio padrão e a amplitude apresenta interesse prático ${ }^{[10]}$ :

$$
\frac{R}{6}<s<\frac{R}{3}
$$

Para distribuições normais estes valores são mostrados na Figura A. $8^{[9]}$.

\section{A.6.2.3 O coeficiente de variação}

O coeficiente e variação (coefficient of variation) é definido como o quociente entre o desvio padrão e a média, frequentemente expresso em porcentagem:

$$
c v(x)=\frac{s(x)}{\bar{x}}
$$

Sua principal vantagem está em caracterizar a dispersão dos dados em relação ao seu valor médio, evitando enganos de interpretação. Assim, uma pequena dispersão absoluta pode ter influência significativa quando comparada com a ordem 


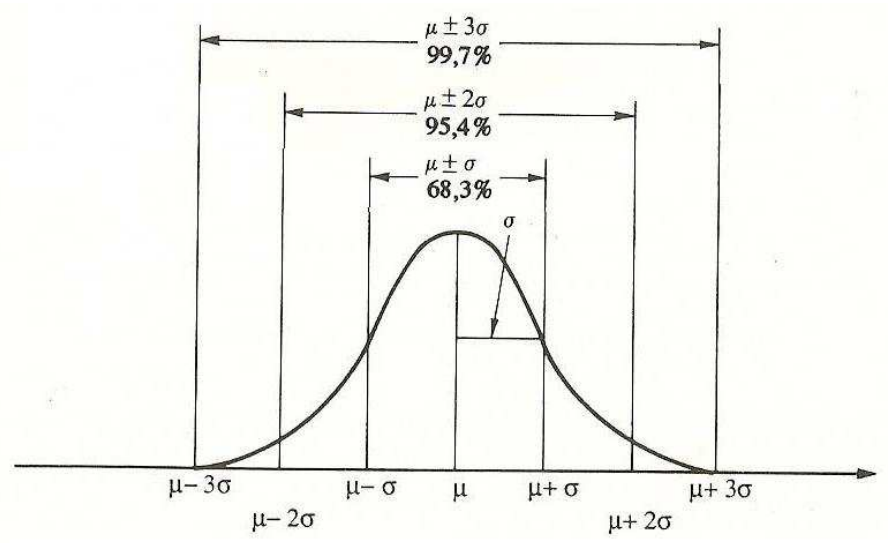

Figura A.8: Área sob a curva normal em função do desvio padrão. Fonte Kume ${ }^{[9]}$ de grandeza dos valores da variável e vice-versa ${ }^{[10]}$.

\section{A.6.3 Momentos de uma distribuição}

Define-se o momento de ordem $t$ centrado em relação a uma constante $a$ como ${ }^{[10]}$ :

$$
M_{t}^{a}=\frac{\sum_{i=1}^{n}\left(x_{i}-a\right)^{t}}{n}
$$

O momento centrado em relação à média apresenta especial interesse:

$$
m_{t}=\frac{\sum_{i=1}^{n}\left(x_{i}-\bar{x}\right)^{t}}{n}
$$

Do mesmo modo que nos casos da média e da variância, o uso das Equações A.2 e A.3 fornece:

$$
m_{t}=\frac{\sum_{i=1}^{k}\left(x_{i}-\bar{x}\right)^{t} f_{i}}{n}=\sum_{i=1}^{k}\left(x_{i}-\bar{x}\right)^{t} p_{i}
$$

No caso de variáveis contínuas:

$$
m_{t}=\int_{-\infty}^{\infty}(x-\mu)^{t} f(x) d x
$$

O estudo dos momentos apresenta grande importância na análise de tolerâncias, pois uma distribuição está completamente especificada quando todos os seus momentos forem conhecidos. Segundo Hahn e Shapiro ${ }^{[4]}$ Capítulo 2, os primeiros quatro momentos podem descrever muitas distribuições, além de fornecerem medidas descritivas úteis e aproximarem distribuições empíricas de variáveis aleatórias. 
Como os momentos $M_{t}$ estão centrados em relação à média, resulta imediatamente que:

$$
\begin{aligned}
& m_{1}=0 \\
& m_{2}=s^{2}
\end{aligned}
$$

ou seja, o segundo momento é igual à variância. Os terceiro e quarto momentos podem ser calculados a partir da Equação A.31, resultando em ${ }^{[10]}$ :

$$
\begin{gathered}
m_{3}=\frac{\sum_{i=1}^{k} x_{i}^{3} f_{i}}{n}-3 \bar{x} \frac{\sum_{i=1}^{k} x_{i}^{2} f_{i}}{n}+2 \bar{x}^{3} \\
m_{4}=\frac{\sum_{i=1}^{k} x_{i}^{4} f_{i}}{n}-4 \bar{x} \frac{\sum_{i=1}^{k} x_{i}^{3} f_{i}}{n}+2 \bar{x}^{3}+6 \bar{x}^{2} \frac{\sum_{i=1}^{k} x_{i}^{2} f_{i}}{n}-3 \bar{x}^{4}
\end{gathered}
$$

\section{A.6.4 Medidas de assimetria}

O momento de terceira ordem pode ser utilizado como medida de assimetria (skewness) de uma distribuição. Porém verifica-se que é mais conveniente o uso de uma medida adimensional relacionando-o, que é conhecida como coeficiente de assimetria (skewness coefficient):

$$
\beta_{3}=\frac{m_{3}}{s^{3}}=\frac{m_{3}}{\sqrt{m_{2}^{3}}}
$$

O coeficiente de assimetria indica a direção de uma distribuição e serve para comparar distribuições similares. Se $\beta_{3}$ é negativo, a distribuição apresenta uma cauda alongada à esquerda, conforme ilustrado na Figura A.7(c). Se $\beta_{3}$ é positivo, a situação é inversa - Figura A.7(a). Para distribuições simétricas - Figura A.7 (b), $\beta_{3}=0^{[4]}$.

\section{A.6.5 Medidas de achatamento}

O momento de quarta ordem pode ser utilizado como medida de achatamento (kurtosis) ou curtose da distribuição. A distribuição normal é utilizada como padrão de comparação da forma de uma distribuição em relação ao seu achatamento, mas esta caracterização somente tem sentido em termos práticos se a distribuição for pelo menos aproximadamente simétrica ${ }^{[10]}$. Define-se o coeficiente de curtose (kurtosis coefficient) como sendo o quociente entre o momento de quarta ordem 
e o quadrado da variância:

$$
\beta_{4}=\frac{m_{4}}{s^{4}}
$$

O coeficiente de curtose é adimensional e identifica a forma da distribuição: $\beta_{4}<3$ - distribuição platicúrtica (platikurtic);

$\beta_{4}=3$ - distribuição mesocúrtica (mesokurtic);

$\beta_{4}>3$ - distribuição leptocúrtica (leptokurtic).

A Figura A.9 ilustra as formas citadas.

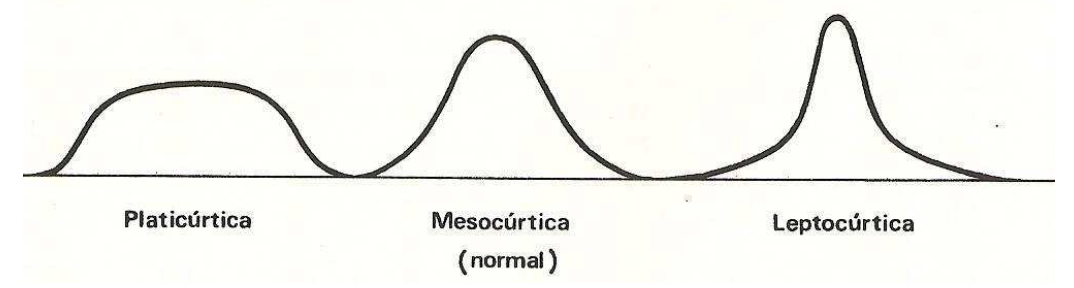

Figura A.9: Distribuições platicúrtica, mesocúrtica e leptocúrtica. Fonte: Costa Neto ${ }^{[10]}$.

\section{A.7 Índice de capacidade do processo}

As medidas descritivas da distribuição normal consideram as características intrínsecas de um processo, mas não contemplam a viabilidade deste processo e os índices de rejeição esperados, pois não referem dados da especificação de projeto do componente. O índice de capacidade do processo (process capability index) foi criado com o objetivo de indicar a adequação de um processo regido por uma distribuição normal em atender ao campo de tolerâncias de projeto e pode ser definido por diferentes relações, conforme a posição da média em relação aos limites da especificação. Para especificações bilaterais centradas, ou seja, da forma dimensão \pm tolerância, define-se ${ }^{[9,12]}$ :

$$
C p=\frac{L S E-L I E}{6 \sigma}
$$

onde $L S E, L I E$ e $\sigma$ são o limite superior da especificação, limite inferior da especificação e o desvio padrão da amostra, respectivamente. Este índice é o mais recorrente, pois as especificações bilaterais centradas são mais utilizadas. Para especificações não centradas, ou unilaterais (da forma dimensão $+L S E-z e r o$, ou dimensão zero - LIE), define-se:

$$
C p_{s}=\frac{L S E-\mu}{3 \sigma}
$$




$$
\begin{gathered}
C p_{i}=\frac{\mu-L I E}{3 \sigma} \\
C p_{k}=M I N\left(C p_{i}, C p_{s}\right)
\end{gathered}
$$

Algumas observações podem ser feitas:

1. As relações referem a média e o desvio padrão da população. Eventualmente, quando o processo é novo ou foram realizadas alterações, estas medidas podem não estar disponíveis, devendo ser substituídas pela média e desvio padrão das amostras;

2. A Figura A.10 ilustra casos para $C p=1$ e $C p=2$. Como visto na Figura A.8, quando $C p=1$ pode-se estimar que aproximadamente $0,26 \%$ da população esteja fora da especificação;

3. Quando a distribuição estiver centrada com a especificação, $C p=C p_{k}$.
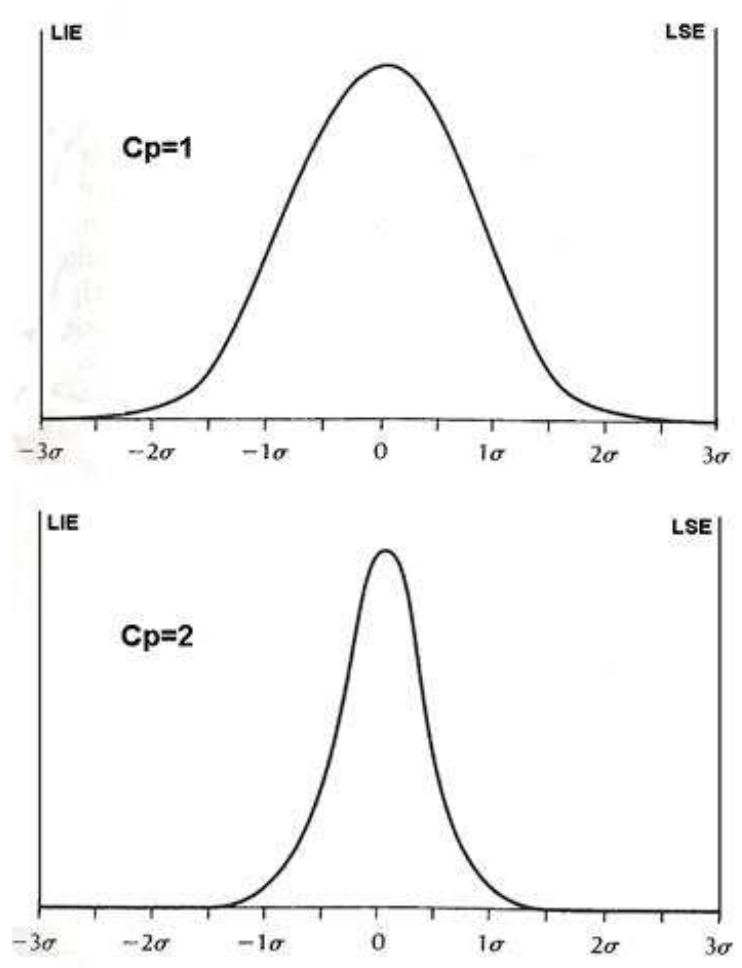

Figura A.10: Distribuições para $C p=1$ e $C p=2$. Fonte: Creveling ${ }^{[12]}$ 


\section{A.8 Tipos de distribuições de frequências}

Existem inúmeros tipos de funções que podem representar a distribuição dos dados obtidos de um processo. A seguir são descritas somente as principais distribuições de interesse para a consideração dos processos de produção conhecidos.

\section{A.8.1 Distribuição retangular ou uniforme}

A distribuição de frequências com probabilidade constante num intervalo é chamada retangular ${ }^{[1,10,13]}$. A melhor forma para definir a equação da distribuição retangular $f(x)$ é considerar sua função de distribuição acumulada $F(x)$, conforme Figura A.11:

$$
\begin{gathered}
F(x)=\frac{x}{K} \quad(0 \leq x \leq K) \\
f(x)=0 \quad \text { para } \quad x<0 \quad \text { e para } \quad x>K, \\
f(x)=\frac{d F(x)}{d x}=\frac{1}{K}
\end{gathered}
$$

Então, a definição da distribuição é:

$$
f(x)=\frac{1}{K} \quad(0 \leq x \leq K)
$$

A distribuição retangular será mencionada neste texto quando for abordada a síntese de tolerâncias.

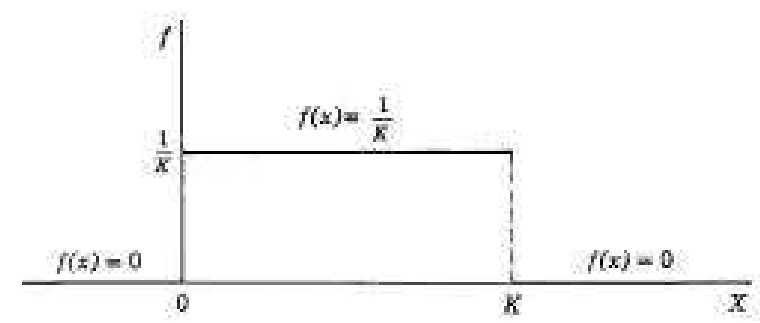

Figura A.11: Distribuição retangular. Fonte: Haugen ${ }^{[13]}$.

\section{A.8.2 Distribuição normal}

A Distribuição Normal foi descoberta pelo matemático francês De Moivre por volta de 1730, como forma limitante da distribuição binomial ${ }^{[13]}$ - Capítulo 2. Seu desenvolvimento está demonstrado na mesma referência. A distribuição normal serve como aproximação útil de várias outras distribuições de manipulação muito mais complexas, o que prova sua importância prática. Ela é considerada 
unimodal, isto é, sua moda está localizada em $x=\mu$ e apresenta dois pontos de inflexão à distância de um desvio padrão de cada lado do valor modal. A curva é simétrica em relação a $\mu$ e cai rapidamente à medida que $x-\mu$ aumenta, como ilustram as Figuras A.8, A.9 e A.10. Embora o intervalo seja infinito $(-\infty,+\infty)$, a probabilidade de um grande desvio em relação a $\mu$ torna-se muitíssimo pequena e pode ser desprezada na maioria dos casos práticos. A distribuição normal pode ser utilizada para aproximar distribuições com intervalos infinitos. Sua equação é dada pelas fórmulas:

$$
\begin{gathered}
f(x)=\frac{1}{\sqrt{2 \pi} \sigma_{x}} \exp \left[-\frac{1}{2}\left(\frac{x-\mu_{x}}{\sigma_{x}}\right)^{2}\right] \quad(-\infty,+\infty) \\
F(x)=\frac{1}{\sqrt{2 \pi} \sigma_{x}} \int_{-\infty}^{+\infty} \exp \left[-\left(\frac{x-\mu_{x}}{\sigma_{x}}\right)^{2}\right] d x
\end{gathered}
$$

Através das Equações A.47 e A.48, nota-se que a distribuição normal fica completamente caracterizada com o conhecimento de $\mu$ e $\sigma$.

\section{A.8.3 Distribuição normal padronizada}

A distribuição normal padronizada, geralmente denominada distribuição Z é uma distribuição normal particular, com média 0 e desvio padrão 1, e foi concebida para facilitar o uso da distribuição normal através do uso de valores tabelados: entrando-se com um valor $z_{0}$, a tabela fornece

$$
P\left(0<Z<z_{0}\right)
$$

que corresponde à área hachurada da Figura A.12. Desejando-se obter a área entre a média $\mu$ e um ponto $x_{0}$ qualquer, em uma distribuição normal genérica, basta calcular o valor padronizado correspondente a $x_{0}$ através da relação:

$$
z_{0}=\frac{x_{0}-\mu}{\sigma}
$$

Ao entrar-se na tabela com este valor, obter-se-á diretamente

$$
P\left(0 \leq Z \leq z_{0}\right)=P\left(\mu \leq X \leq x_{0}\right)
$$

Outras probabilidades podem ser obtidas a partir desta, com base na simetria da distribuição e por artifícios na entrada de dados. Um exemplo útil do uso da distribuição normal padronizada é o da estimativa do índice de rejeição de um processo, através da equação ${ }^{[12]}$ :

$$
Z=\frac{\mathrm{LSE} \text { ou LIE }-\mu}{\sigma}
$$


É importante observar que a utilização da distribuição normal padronizada é aplicável somente quando o número de valores de uma amostra é superior a 30 .

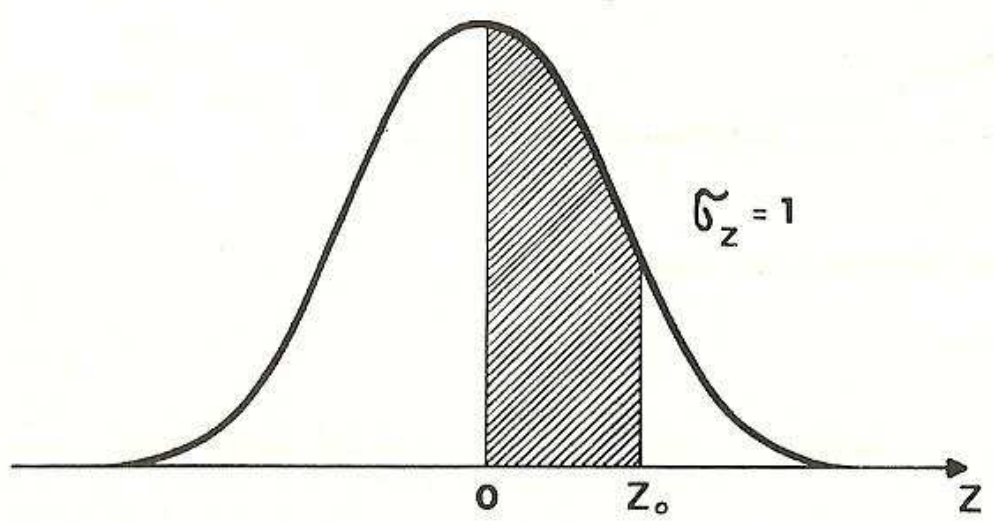

Figura A.12: Distribuição normal padronizada. Fonte: Costa Neto ${ }^{[10]}$.

\section{A.8.4 Distribuição t de student}

A distribuição t de student foi desenvolvida por W. S. Gosset, estatístico inglês, que publicou seus trabalhos sob o pseudônimo de student ${ }^{[10]}$, e é uma aproximação da distribuição normal aplicável para amostras pequenas de dados, abaixo de 30 . Sua equação é similar à da distribuição normal reduzida, porém com estatísticas da amostra:

$$
t=\frac{\bar{x}-\mu}{s(x) / \sqrt{n}}
$$

Ela distribui-se simetricamente em relação à média 0 , porém não normalmente, como ilustra a Figura A.13. Similarmente à distribuição Z, os valores para cálculo também encontram-se tabelados ${ }^{[10,12]}$.

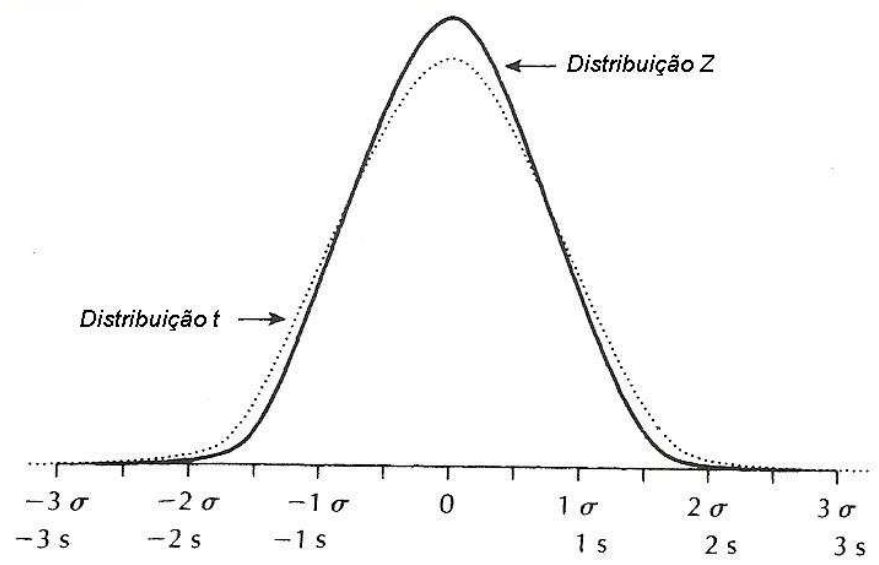

Figura A.13: Distribuição t de student. Fonte: Creveling ${ }^{[12]}$ 


\section{A.8.5 Outras distribuições}

Outras distribuições podem ser utilizadas no estudo de tolerâncias, tais como a Beta $^{[13]}$, as distribuições de Johnson e de Pearson ${ }^{[4]}$. 


\section{Apêndice B - Exemplo prático de aplicação do método de monte carlo}

O desenvolvimento do método de Monte Carlo pode ser melhor ilustrado através de um exemplo prático. Para isso será utilizado neste texto o exemplo de Spotts [14] - Capítulo 6: a análise é realizada para um conjunto formado por três componentes montados sequencialmente, ou seja, com equação fundamental:

$D=d_{1}+d_{2}+d_{3}$

A Figura B.1 ilustra as distribuições de frequências conhecidas dos processos de cada dimensão, cada uma com 5 classes de frequências. As dimensões encontramse codificadas, através da subtração de um valor e o resultado dividido por uma constante adequada para a obtenção dos valores $d_{i}$ mostrados. As frequências também estão codificadas para resultar em soma unitária. A terceira coluna de

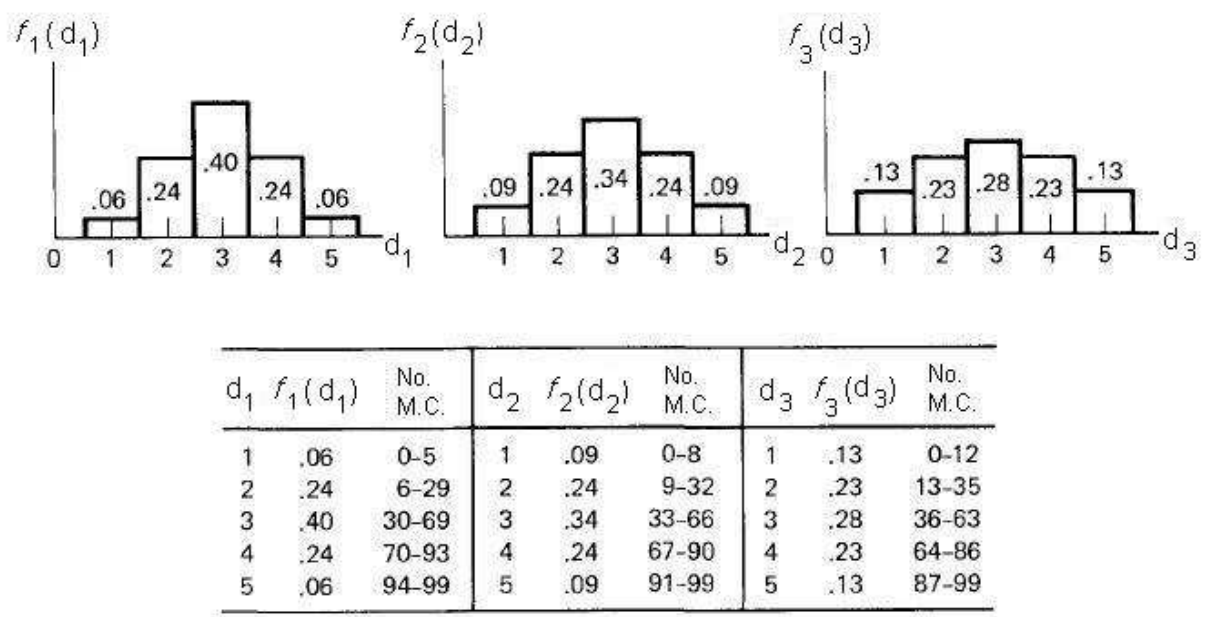

Figura B.1: Distribuições de dimensões de três componentes montados em conjunto sequencial. Fonte: Spotts ${ }^{[14]}$

cada componente foi elaborada para um espectro de 100 valores de Monte Carlo, de 0 a 99, com campos divididos proporcionalmente às frequências da segunda 
coluna. Assim para a primeira classe do primeiro componente, tem-se $100 \times 0,6$, ou seja, números aleatórios de 0 a 5 inclusive. As outras linhas deste e dos outros componentes são preenchidas da mesma forma. A geração dos números aleatórios foi realizada através de tabela de números com quatro dígitos, disponível na mesma referência. Foram aproveitados apenas os primeiros dois dígitos de cada número para a geração de números aleatórios correspondentes a 50 conjuntos, ilustrados na Figura B.2. Qualquer outra combinação poderia ser adotada para a escolha. As classes de cada linha para cada conjunto e cada componente são identificadas através da coluna de números aleatórios. Por exemplo, para a primeira linha do primeiro componente, o número aleatório 9 está entre 6 e 29, conforme Figura B.1 e, portanto, pertence à classe 2 para $d_{1}$. O mesmo procedimento é realizado para $d_{2}$ e $d_{3}$. O valor da dimensão do conjunto é então $D=d_{1}+d_{2}+d_{3}=2+4+2=8$. O processo é repetido para cada conjunto e os valores são identificados agora em cada uma das 15 classes do conjunto, mostradas na tabela (a) da Figura B.3, na forma de frequências de ocorrências. Na terceira coluna são mostrados os valores decimais proporcionais aos da coluna 2. A distribuição no item (b) da figura pode então ser desenhada, gerando o resultado final da simulação de Monte Carlo para os 50 conjuntos. Spotts mostra ainda no item (c) da Figura B.3 o resultado para um grande número de conjuntos, onde se pode notar uma distribuição mais equilibrada aproximando-se da distribuição normal e a propagação de valores para as caudas da distribuição. 


\begin{tabular}{|c|c|c|c|c|c|c|c|c|c|c|c|c|c|c|c|}
\hline \multirow[b]{2}{*}{$\begin{array}{l}\text { Con- } \\
\text { junto }\end{array}$} & \multicolumn{2}{|c|}{$\begin{array}{c}\text { 1a. } \\
\text { Distrib. }\end{array}$} & \multicolumn{2}{|c|}{$\begin{array}{c}2 \mathrm{a} . \\
\text { Distrib. }\end{array}$} & \multicolumn{2}{|c|}{$\begin{array}{c}\text { 3a. } \\
\text { Distrib. }\end{array}$} & \multirow[b]{2}{*}{$D$} & \multirow[b]{2}{*}{$\begin{array}{l}\text { Con- } \\
\text { junto }\end{array}$} & \multicolumn{2}{|c|}{$\begin{array}{c}\text { 1a. } \\
\text { Distrib. }\end{array}$} & \multicolumn{2}{|c|}{$\begin{array}{c}2 \mathrm{a} . \\
\text { Distrib. }\end{array}$} & \multicolumn{2}{|c|}{$\begin{array}{c}\text { 3a. } \\
\text { Distrib. }\end{array}$} & \\
\hline & $\begin{array}{l}\text { No. } \\
\text { Aleat. }\end{array}$ & $d_{1}$ & $\begin{array}{l}\text { No. } \\
\text { Aleat. }\end{array}$ & & $\begin{array}{l}\text { No. } \\
\text { Aleat. }\end{array}$ & & & & $\begin{array}{l}\text { No. } \\
\text { Aleat. }\end{array}$ & $d_{1}$ & $\begin{array}{l}\text { No. } \\
\text { Aleat. }\end{array}$ & & $\begin{array}{l}\text { No. } \\
\text { Aleat. }\end{array}$ & $d_{3}$ & D \\
\hline 1 & 9 & 2 & 89 & 4 & 29 & 2 & 8 & 26 & 30 & 3 & 24 & 2 & 3 & 1 & 6 \\
\hline 2 & 66 & 3 & 7 & 1 & 96 & 5 & 9 & 27 & 40 & 3 & 65 & 3 & 72 & 4 & 10 \\
\hline 3 & 88 & 4 & 83 & 4 & 78 & 4 & 12 & 28 & 1 & 1 & 92 & 5 & 17 & 2 & 8 \\
\hline 4 & 83 & 4 & 67 & 4 & 5 & 1 & 9 & 29 & 64 & 3 & 79 & 4 & 29 & 2 & 9 \\
\hline 5 & 67 & 3 & 10 & 2 & 20 & 2 & 7 & 30 & 3 & 1 & 68 & 4 & 85 & 4 & 9 \\
\hline 6 & 47 & 3 & 16 & 2 & 90 & 5 & 10 & 31 & 98 & 5 & 9 & 2 & 73 & 4 & 11 \\
\hline 7 & 84 & 4 & 68 & 4 & 31 & 2 & 10 & 32 & 86 & 4 & 10 & 2 & 14 & 2 & 8 \\
\hline 8 & 36 & 3 & 80 & 4 & 67 & 4 & 11 & 33 & 8 & 2 & 45 & 3 & 32 & 2 & 7 \\
\hline 9 & 67 & 3 & 51 & 3 & 80 & 4 & 10 & 34 & 23 & 2 & 92 & 5 & 54 & 3 & 10 \\
\hline 10 & 26 & 2 & 27 & 2 & 28 & 2 & 6 & 35 & 21 & 2 & 63 & 3 & 56 & 3 & 8 \\
\hline 11 & 13 & 2 & 86 & 4 & 16 & 2 & 8 & 36 & 33 & 3 & 15 & 2 & 7 & 1 & 6 \\
\hline 12 & 15 & 2 & 76 & 4 & 91 & 5 & 11 & 37 & 44 & 3 & 2 & 1 & 70 & 4 & 8 \\
\hline 13 & 96 & 5 & 28 & 2 & 75 & 4 & 11 & 38 & 49 & 3 & 4 & 1 & 81 & 4 & 8 \\
\hline 14 & 8 & 2 & 67 & 4 & 35 & 2 & 8 & 39 & 40 & 3 & 30 & 2 & 23 & 2 & 7 \\
\hline 15 & 0 & 1 & 42 & 3 & 23 & 2 & 6 & 40 & 43 & 3 & 19 & 2 & 81 & 4 & 9 \\
\hline 16 & 46 & 3 & 98 & 5 & 79 & 4 & 12 & 41 & 93 & 4 & 20 & 2 & 94 & 5 & 11 \\
\hline 17 & 10 & 2 & 37 & 3 & 41 & 3 & 8 & 42 & 63 & 3 & 11 & 2 & 85 & 4 & 9 \\
\hline 18 & 33 & 3 & 35 & 3 & 68 & 4 & 10 & 43 & 88 & 4 & 33 & 3 & 16 & 2 & 9 \\
\hline 19 & 36 & 3 & 96 & 5 & 14 & 2 & 10 & 44 & 43 & 3 & 47 & 3 & 55 & 3 & 9 \\
\hline 20 & 72 & 4 & 57 & 3 & 79 & 4 & 11 & 45 & 76 & 4 & 92 & 5 & 35 & 2 & 11 \\
\hline 21 & 23 & 2 & 83 & 4 & 28 & 2 & 8 & 46 & 40 & 3 & 30 & 2 & 17 & 2 & 7 \\
\hline 22 & 10 & 2 & 20 & 2 & 89 & 5 & 9 & 47 & 56 & 3 & 72 & 4 & 49 & 3 & 10 \\
\hline 23 & 5 & 1 & 40 & 3 & 5 & 1 & 5 & 48 & 71 & 4 & 10 & 2 & 20 & 2 & 8 \\
\hline 24 & 56 & 3 & 40 & 3 & 52 & 3 & 9 & 49 & 43 & 3 & 65 & 3 & 66 & 4 & 10 \\
\hline 25 & 82 & 4 & 75 & 4 & 11 & 1 & 9 & 50 & 23 & 2 & 52 & 3 & 68 & 4 & 9 \\
\hline
\end{tabular}

Figura B.2: Determinação de dimensões de 50 conjuntos de três componentes pelo Método de Monte Carlo. Fonte: Spotts ${ }^{[14]}$

\begin{tabular}{|c|c|c|}
\hline D & & (D) \\
\hline 3 & 0 & \\
\hline 4 & 0 & \\
\hline 5 & 10 & 02 \\
\hline 6 & 4 & .08 \\
\hline 7 & 4 & .08 \\
\hline 8 & 11 & .22 \\
\hline 9 & 12 & .24 \\
\hline 10 & 9 & .18 \\
\hline 11 & 7 & .14 \\
\hline 12 & 2 & .04 \\
\hline 13 & 0 & \\
\hline 14 & 0 & \\
\hline 15 & 0 & \\
\hline
\end{tabular}

(a)

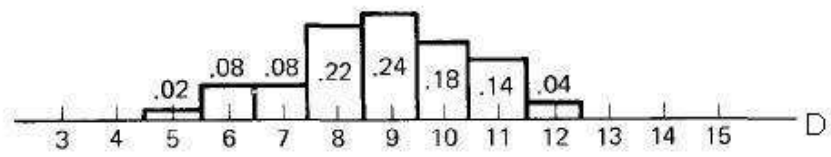

(b)

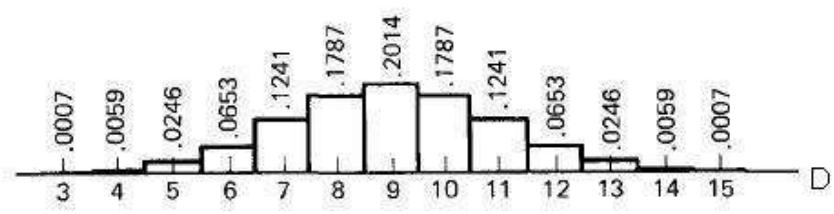

(c)

Figura B.3: Determinação da distribuição de frequências do conjunto: a) Classes de frequência da soma dos componentes; b) Distribuição das dimensões dos 50 conjuntos conforme item (a); c) Distribuição a longo prazo para o conjunto. Fonte: Spotts ${ }^{[14]}$ 


\section{Apêndice C - Representações geométrica e vetorial}

\section{C.1 Representação geométrica}

O sistema de representação de tolerâncias por coordenadas, mais simples e intuitivo, ainda é usualmente empregado. Outro tipo de representação, porém, foi desenvolvido devido a limitações observadas no uso do primeiro. A representação geométrica, que define as "Tolerâncias de Forma e Posição" (Geometric Dimensioning and Tolerancing - GD\&T), foi concebida como meio de especificar os requisitos de projeto com base em duas de suas características ${ }^{[15]}$ :

- função;

- relacionamento.

Estas duas características auxiliam na garantia de montagem entre peças. A representação geométrica não toma o lugar da representação convencional (coordenadas ortogonais), mas especifica os requisitos mais precisamente, garantindo uma interpretação inequívoca ${ }^{[75]}$; também, quando adequadamente empregada, a técnica pode assegurar uma produção mais econômica, pois considera a forma de geração cilíndrica dos processos reais de produção. Isto pode ser melhor entendido através de uma de suas representações, a tolerância posicional. A Figura C.1 ilustra a equivalência entre as representações geométrica e convencional por coordenadas, que pode ser utilizada na conversão proporcional de valores entre os dois sistemas ${ }^{[15]}$.

Nota-se, no exemplo, que a tolerância geométrica apresenta um valor maior $(0,007)$ para representar o mesmo campo de tolerância especificado por coordenadas ortogonais $(0,005)$. Ou seja, se um furo de seção quadrada fosse usinado através de um processo especial, para que apresentasse uma tolerância máxima total de 0,007 mm (diametral), ele teria de ser especificado por uma tolerância menor, igual a $0,005 \mathrm{~mm}$ para que atendesse a esta especificação. Assim, como a 
quase totalidade dos elementos de fixação e posicionamento apresentam formas de geração cilíndricas, como também seus respectivos alojamentos, o uso da representação geométrica é muito mais racional e econômica.

Outro exemplo da vantagem da representação geométrica pode ser observado

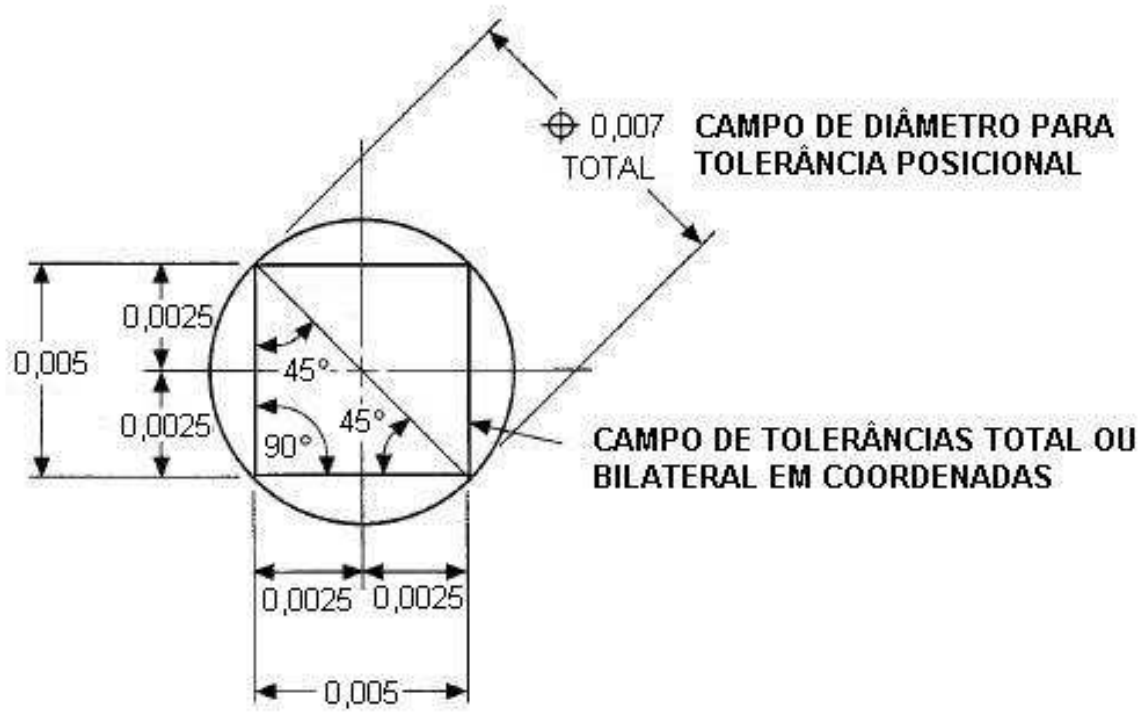

Figura C.1: Equivalência entre representação geométrica e por coordenadas ortogonais. Fonte: Foster ${ }^{[15]}$.

através da Figura C.2. Nela está ilustrada uma tolerância de forma de uma superfície, a de planeza. Observa-se que a variação total da posição através da representação convencional é de $\pm 1,0 \mathrm{~mm}$. Através da especificação da tolerância de planeza, necessária hipoteticamente para o caso, a tolerância de posição pode ser mantida no valor ilustrado, pois seu valor não é hipoteticamente crítico para o caso. Na representação por coordenadas, a tolerância total deveria ser especificada em $\pm 0,1 \mathrm{~mm}(0,2 \div 2)$ para obter-se o mesma especificação, ou mantido o valor especificado, a planeza deveria ser referida em forma de nota no desenho, fato que poderia gerar dúvida na sua interpretação. Uma das características da representação geométrica é o uso de simbologia, que apresenta as seguintes vantagens $^{[15]}$ :

- o símbolo tem um significado uniforme e notas dependem da forma de redação com risco de má interpretação;

- símbolos são compactos, rápidos de desenhar, podem ser colocados na região aplicável e são adaptáveis a aplicações em CAD;

- notas requerem muito espaço, podem estar dispersas no desenho e, frequentemente, estão separadas da região de aplicação da característica; 


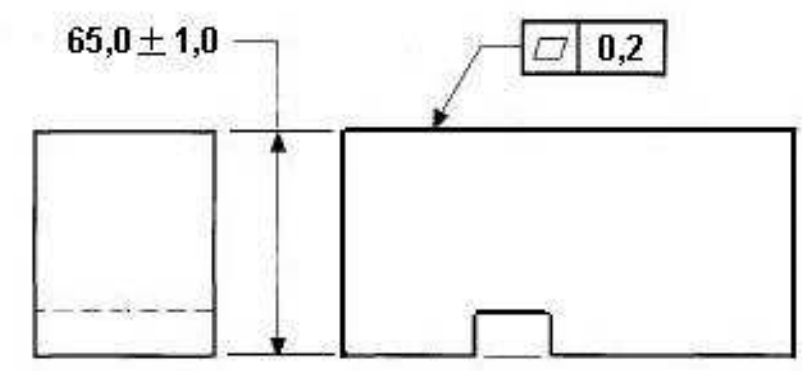

Figura C.2: Tolerância de planeza.

- simbologia é uma linguagem internacional que suplanta barreiras da língua local e notas requerem tradução caso o desenho seja aplicado em outro país;

- símbolos podem ser utilizados a partir de bancos de dados e retém maior legibilidade em várias formas de reprodução;

- símbolos de tolerâncias geométricas seguem os mesmos padrões utilizados em outros sistemas (eletrônicos, soldagem, rugosidade superficial etc.).

Os símbolos de características geométricas estão ilustrados na Figura C.3 e estão padronizados pelas normas ASME Y14.5M $\mathrm{M}^{[22]}$, ISO 1101 ${ }^{[29]}$ e NBR 6049 ${ }^{[16]}$. Sua descrição precisa é relativamente extensa e não será apresentada neste trabalho. Outras características importantes incluídas na simbologia de representação geométrica são a de máximo e mínimo material e de tolerâncias estatísticas. A de máximo material amplia proporcionalmente o valor da tolerância posicional, com o mesmo valor diferencial, da tolerância do diâmetro especificado quando este parte da condição de máximo material (diâmetro mínimo de um furo ou máximo de um eixo). Tolerâncias estatísticas podem também ser especificadas através da referida norma ASME, aumentando a flexibilidade da especificação.

O problema recorrente no uso da representação geométrica é a sua consideração no processo de análise de tolerâncias. Existe grande dificuldade na avaliação da influência das tolerâncias de forma e também da condição de máximo material em tolerâncias posicionais. Alguns métodos são propostos para a solução de problemas específicos ${ }^{[76-81]}$.

Além das referências citadas de Foster ${ }^{[15]}$ e Madsen ${ }^{[75]}$, outras com o mesmo conteúdo podem ser mencionadas: Gooldy ${ }^{[82]}$, Meadows ${ }^{[83]}$, Wilson ${ }^{[84]}$, Henzold ${ }^{[85]}$, Jensen $^{[86]}$, Krulikowski ${ }^{[87]}$ e Puncochar ${ }^{[88]}$. 


$\left.\begin{array}{lll}\text { Retitude } & \text { Planeza } \\ & \begin{array}{l}\text { Circularidade } \\ \text { Perfil de superficie qualquer }\end{array}\end{array}\right]$ FORMA

Figura C.3: Símbolos da representação geométrica de tolerâncias. Fonte: NBR 6049:1997 $7^{[16]}$

\section{C.2 Representação vetorial}

A representação de tolerâncias através de vetores é particularmente importante nas análises de tolerâncias geométricas bidimensionais e particularmente nas tridimensionais. Conforme Wirtz ${ }^{[89]}$, "seu objetivo é a definição de informações da forma e das tolerâncias da peça em uma base realmente matemática" . A Figura C.4 ilustra o princípio básico da representação vetorial em três dimensões. Pode-se notar elementos que definem cada ponto de uma peça ${ }^{[89]}$ :

1. O vetor de posição $P_{0}$ e seu campo de tolerâncias $T o l-\overline{P_{0}}$;

2. O vetor de direção $E$ e o seu campo de tolerâncias $T o l-\bar{E}$;

3. O vetor de dimensão $R$ e o seu campo de tolerâncias $T o l-\bar{R}$.

A representação vetorial é particularmente importante na integração do projeto com as áreas de manufatura e controle de qualidade, pois consegue representar a tolerância de forma precisa. As normas de representação geométrica apenas conseguem indicar um campo tolerância na qual a forma está inserida. A Figura C.5 ilustra a questão. 


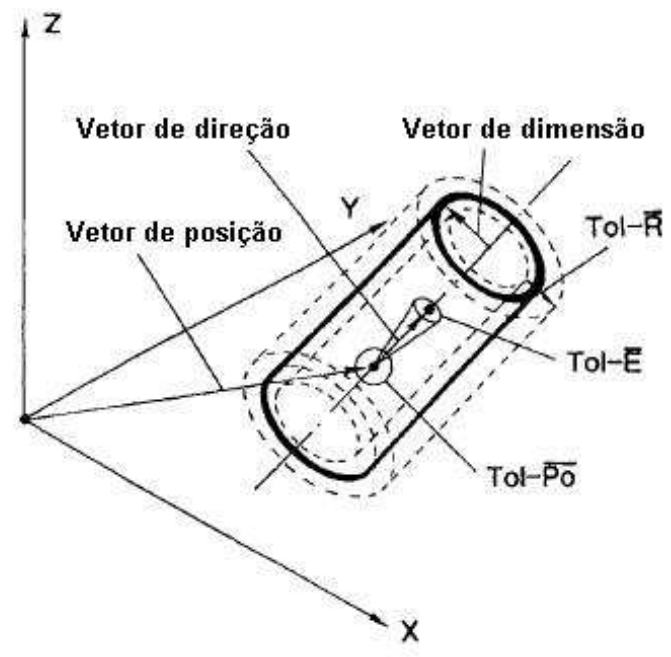

Figura C.4: Representação dos três vetores básicos e de suas tolerâncias na representação vetorial. Fonte: Wirtz ${ }^{[17]}$.

A Norma ASME Y14.5.1M:1994 ${ }^{[19]}$ apresenta a definição matemática de dimensões e tolerâncias geométricas definidas na Norma ASME Y14.5M:1994 ${ }^{[22]}$. As equações relacionam números reais, vetores tridimensionais, sistemas de coordenadas associados a sistemas de referência. Na norma, os vetores de posição são utilizados para representar pontos no espaço. Um vetor pode ser expandido em componentes escalares. Sejam $\hat{i}, \hat{j}$ e $\hat{k}$ os vetores unitários nas direções dos eixos $x, y$ e $z$, respectivamente, de um sistema de coordenadas; o vetor $\vec{V}$ pode ser expandido individualmente como:

$$
\vec{V}=a \hat{i}+b \hat{j}+c \hat{k}
$$

Este vetor pode ser representado por $\vec{V}=(a, b, c)$. A magnitude (comprimento) do vetor $\vec{V}$ é notado $|\vec{V}|$ e pode ser calculado por:

$$
|\vec{V}|=\sqrt{a^{2}+b^{2}+c^{2}}
$$

Um vetor unitário $\vec{V}$ é qualquer vetor com magnitude igual a um. O produto escalar de dois vetores $\vec{V}_{1}=\left(a_{1}, b_{1}, c_{1}\right)$ e $\vec{V}_{2}=\left(a_{2}, b_{2}, c_{2}\right)$ é notado por $\vec{V}_{1} \cdot \vec{V}_{2}$. Seu produto escalar é um número real dado por:

$$
\vec{V}_{1} \cdot \vec{V}_{2}=a_{1} \cdot a_{2}+b_{1} \cdot b_{2}+c_{1} \cdot c_{2}
$$

O produto escalar é igual ao produto dos comprimentos dos dois vetores pelo cosseno do ângulo compreendido por eles. O produto vetorial de dois vetores $\vec{V}_{1}$ e $\vec{V}_{2}$ é notado por $\vec{V}_{1} \times \vec{V}_{2}$. O produto vetorial é um vetor $\vec{V}_{3}=\left(a_{3}, b_{3}, c_{3}\right)$ com 

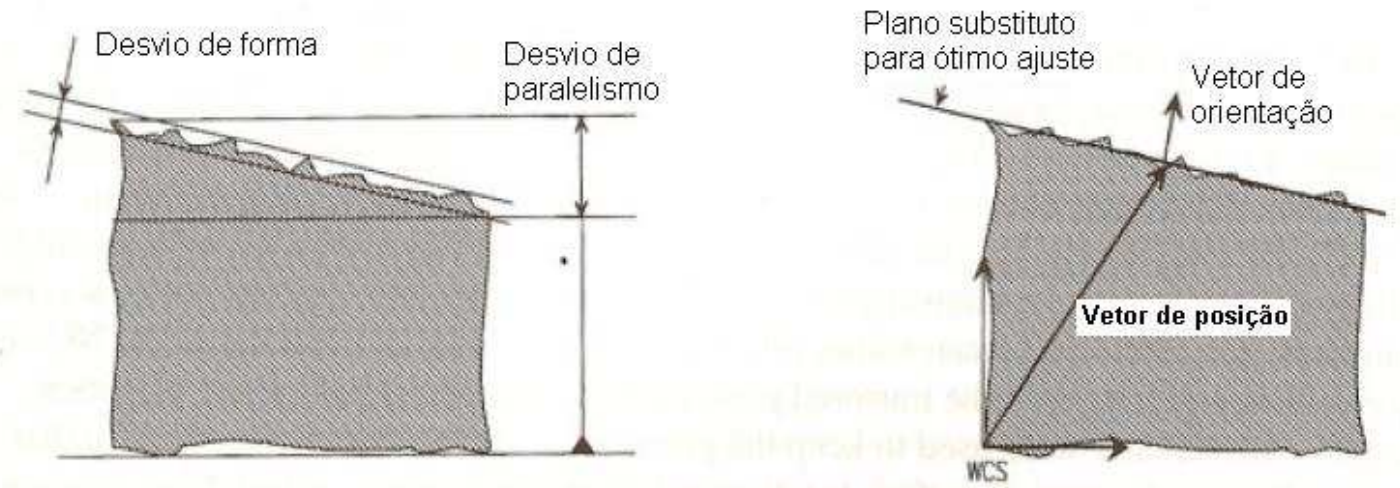

Figura C.5: Comparação da representação geométrica de tolerâncias de paralelismo e planeza especificadas por norma e caso real por representação vetorial. Fonte: Martinsen $^{[18]}$.

componentes:

$$
\begin{aligned}
& a_{3}=b_{1} c_{2}-b_{2} c_{1} \\
& b_{3}=a_{2} c_{1}-a_{1} c_{2} \\
& c_{3}=a_{1} b_{2}-a_{2} b_{1}
\end{aligned}
$$

A magnitude do produto vetorial é igual ao valor do produto dos comprimentos dos dois vetores pelo seno do ângulo compreendido entre eles.

Todas as tolerâncias geométricas são representadas por relações vetoriais. Como exemplo, será aqui apenas apresentado o caso da tolerância de retitude, no qual os elementos lineares de uma característica devem estar em uma zona de tolerância limitada por duas linhas paralelas contidas num plano de corte definindo o elemento linear.

Definição: A zona de retitude para o elemento linear da superfície é uma área entre linhas paralelas, consistindo de todos os pontos $\vec{P}$ satisfazendo a condição:

$$
|\hat{T} \times(\vec{P}-\vec{A})| \leq \frac{t}{2}
$$


e

$$
\begin{array}{r}
\hat{C}_{p} \cdot\left(\vec{P}-\vec{P}_{s}\right)=0 \\
\hat{C}_{p} \cdot\left(\vec{A}-\vec{P}_{s}\right)=0 \\
\hat{C}_{p} \cdot \hat{T}=0
\end{array}
$$

Onde:

- $\hat{T}=$ vetor direção da linha de centro da zona de retitude;

- $\vec{A}=$ vetor de posição localizando a linha de centro da zona de retitude;

- $t=$ tamanho da zona de retitude (separação entre as linhas paralelas);

- $\hat{C}_{p}=$ a normal do plano de corte definido como o produto do vetor de corte desejado e a superfície de contato normal em $\vec{P}_{s}$;

- $\vec{P}_{s}=$ um ponto na superfície, contido pelo plano de corte.

A Figura C.6 ilustra a zona de tolerância de retitude para elementos de linha de superfície de uma característica cilíndrica.

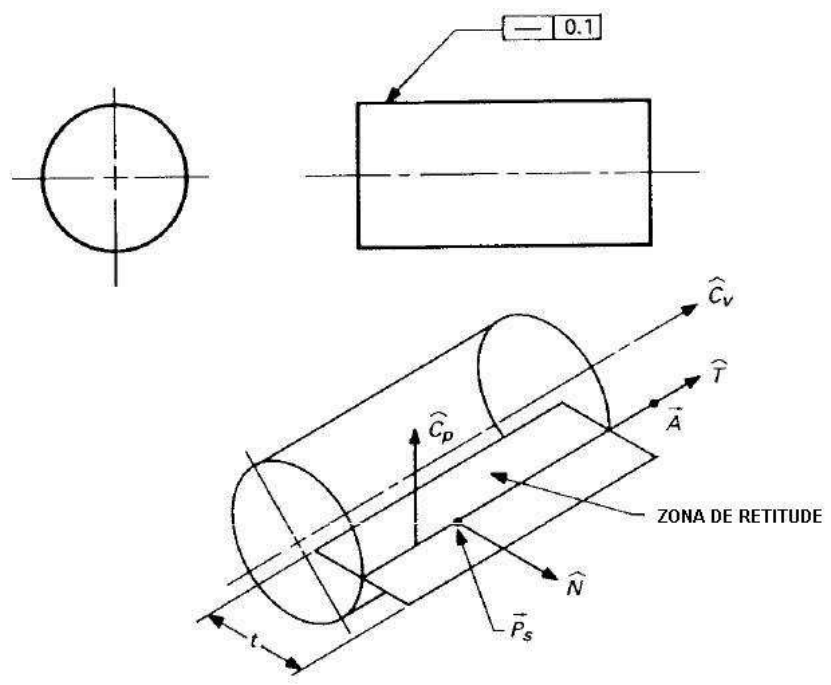

Figura C.6: Avaliação da retitude de uma superfície cilíndrica. Fonte: $\mathrm{ASME}^{[19]}$ 
Adequação: Um elemento de linha de superfície está adequado à tolerância de retitude $t_{0}$ de um plano de corte se todos os seus pontos estiverem contidos em alguma zona de tolerância de retitude conforme definição acima, com $t=t_{0}$. Isto é, existem $\vec{T}$ e $\vec{A}$ tais que com $t=t_{0}$, todos os pontos do elemento de linha de superfície estão na zona de retitude. Uma superfície está adequada à tolerância de retitude $t_{0}$ se ela se adequar simultaneamente em todos os elementos de linha de superfície correspondentes a alguma superfície de contato.

Valor real: $O$ valor real da retitude de uma superfície é a menor tolerância de retitude para a qual a superfície se adeque. 


\section{Apêndice D - Análise de modos e efeitos de falha}

A ferramenta Análise de Modos e Efeitos de Falha - FMEA Failure Mode and Effects Analysis - pode ser definida como uma série de atividades que visam ${ }^{[90]}$ :

- Reconhecer e avaliar falhas potenciais de um produto/processo e seus respectivos efeitos;

- Identificar ações que possam eliminar ou reduzir a possibilidade de ocorrência de falhas potenciais;

- Documentar o processo.

A ferramenta FMEA pode apresentar vários tipos, dependendo de sua aplicação, sendo as principais a de projeto - DFMEA - e de processo - PFMEA e deve ser elaborada por equipe multi-disciplinar.

Neste trabalho são apresentadas apenas as considerações essenciais para o entendimento básico da ferramenta, já que sua abordagem completa é complexa, envolve a utilização de outras ferramentas de qualidade e foge ao escopo do texto.

Referências específicas, inclusive normativas, podem ser consultadas ${ }^{[90-92]}$. A planilha apresentada nas próximas páginas ilustra um preenchimento simplificado do formulário para o exemplo do trabalho, onde podem ser observadas as seguintes colunas:

1. Item/Função: Descrição do item analisado e de sua função;

2. Modo de falha potencial: define a maneira na qual o item pode falhar. Esta falha pode ser total, parcial, intermitente ou não intencional ${ }^{[90]}$;

3. Efeito de falha potencial: define o efeito da falha na função, como percebido pelo cliente ou usuário; 
4. S: Severidade, é um índice numérico. Pode variar de 1, para efeitos imperceptíveis, a 10, para efeitos de alto risco de segurança sem aviso prévio. Quando houver uma percepção prévia do risco pelo cliente, o índice 9 deve ser utilizado;

5. Causa da falha potencial: indica as deficiências do projeto como consequência de cada modo de falha;

6. O: Ocorrência, é um índice que indica a probabilidade de ocorrência do modo de falha durante a vida útil do produto, podendo variar entre 1, pouco provável, a 10, certeza de ocorrência;

7. Controles de projeto: São as ações preventivas que garantem a adequação do projeto em relação aos modos de falha; podem ser de prevenção, como as de garantia para que os modos de falha não ocorram (exemplo: utilização de válvulas de alívio em sistemas pressurizados) ou de detecção, como testes de validação do produto;

8. D: Detecção, é um índice que indica o grau de certeza de que os controles de projeto detectarão os modos de falha para que não ocorram. O índice 1 indica o nível de quase certeza de detecção e o 10, de total incerteza;

9. R: Número de proridade de risco, é o produto dos índices anteriormente citados $R=S \times O \times D$ e indica o nível de prioridade para o tratamento do problema. Os índices mais elevados devem ser tratados prioritariamente;

10. Ações recomendadas: São as ações sugeridas, após análise, que devem ser tomadas para que os modos de falha não ocorram ou sejam minimizados. Modos de falha com índices de severidade 9 e 10 devem ser considerados independentemente do número de prioridade de risco;

11. Novos índices S-O-D-R: São os novos índices previstos a partir da implementação das ações recomendadas.

As ações identificadas em negrito aplicam-se ao exemplo do trabalho. 


\begin{tabular}{|c|c|c|c|c|}
\hline \multirow{4}{*}{ 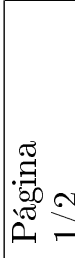 } & تصح| & $\bowtie$ & $£$ & $\stackrel{\varphi}{\infty}$ \\
\hline & A & $\infty$ & 10 & $\sim$ \\
\hline & 0 & $\neg$ & $\sim$ & $\sim$ \\
\hline & $\Omega$ & $\cong$ & 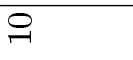 & $\sigma$ \\
\hline \multirow{10}{*}{ 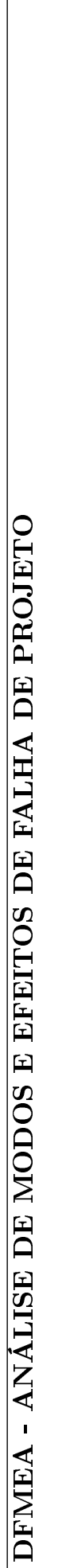 } & 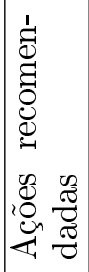 & 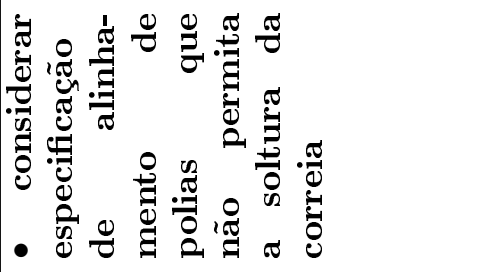 & \multicolumn{2}{|c|}{ 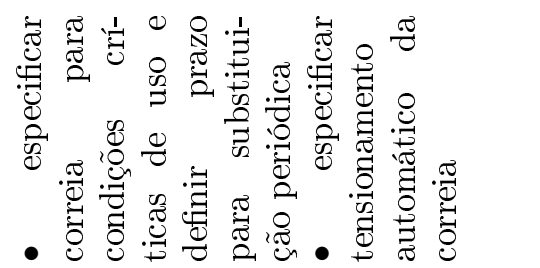 } \\
\hline & r|x & $\stackrel{8}{8}$ & $\stackrel{\mathcal{~}}{\mathscr{N}}$ & $\stackrel{\infty}{\infty}$ \\
\hline & A & $\infty$ & 10 & $\sim$ \\
\hline & 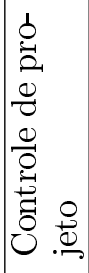 & 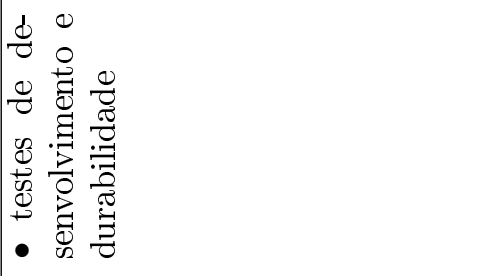 & 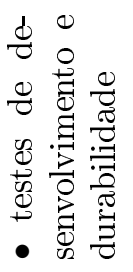 & 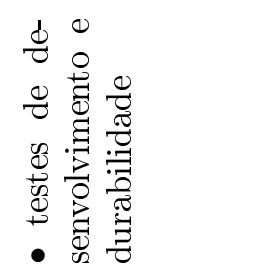 \\
\hline & 0 & 20 & 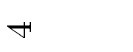 & 0 \\
\hline & 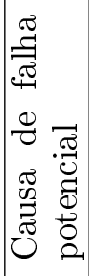 & 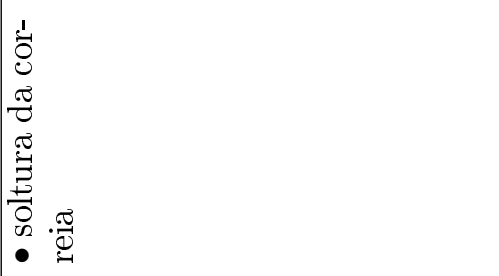 & 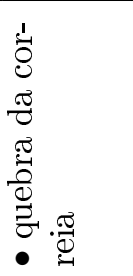 & 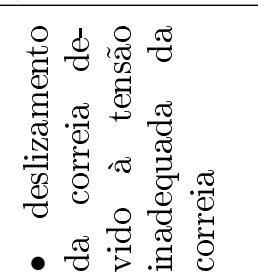 \\
\hline & $\Omega$ & $\stackrel{\varrho}{-}$ & $\stackrel{1}{\circ}$ & 0 \\
\hline & 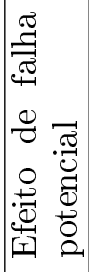 & 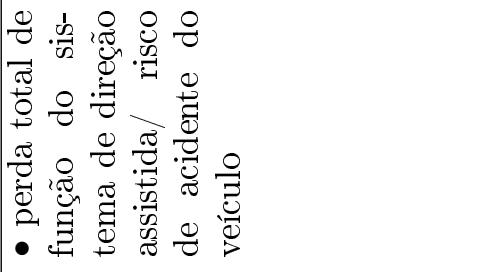 & & 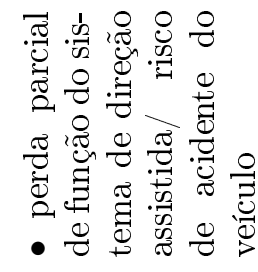 \\
\hline & 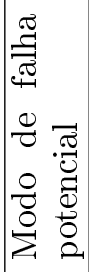 & 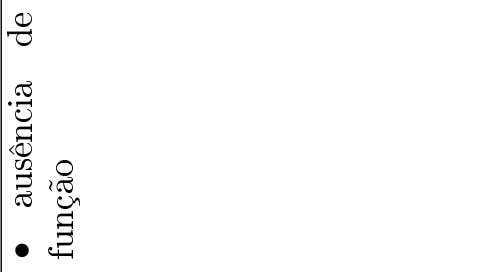 & & 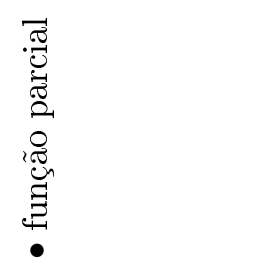 \\
\hline & 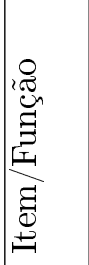 & 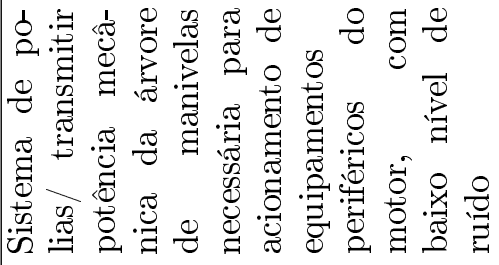 & & \\
\hline
\end{tabular}




\begin{tabular}{|c|c|c|c|c|}
\hline \multirow{4}{*}{ 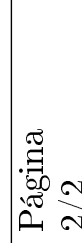 } & تصم & $\mathfrak{i}$ & 198 & లి \\
\hline & $A$ & r & $\infty$ & $\sim$ \\
\hline & 0 & $\sim$ & $\infty$ & $\sim$ \\
\hline & os & $\theta$ & 10 & $\sigma$ \\
\hline \multirow{10}{*}{ 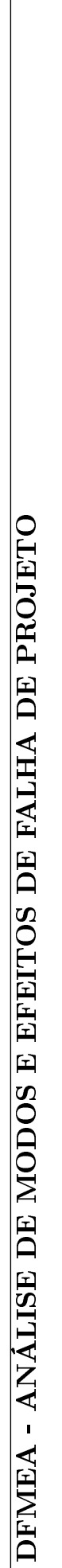 } & 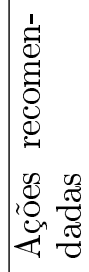 & 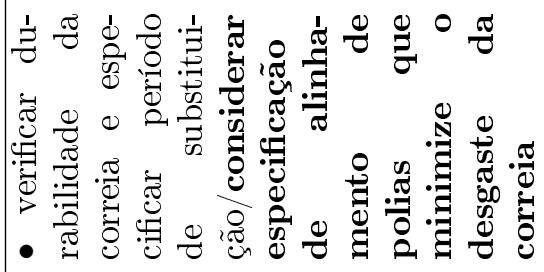 & 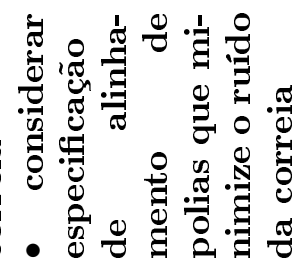 & 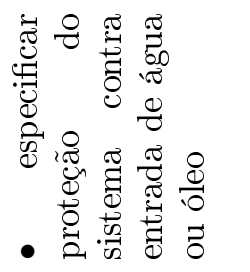 \\
\hline & تص & $\underset{\sim}{\infty}$ & $\stackrel{20}{9}$ & $\stackrel{\infty}{\stackrel{\infty}{二}}$ \\
\hline & A & 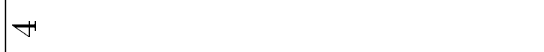 & $\infty$ & $\sim$ \\
\hline & 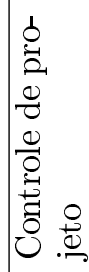 & 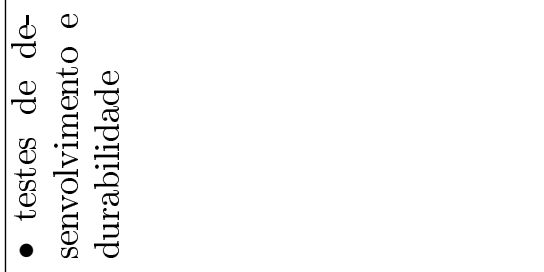 & 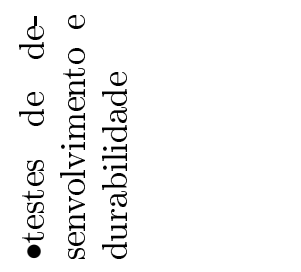 & 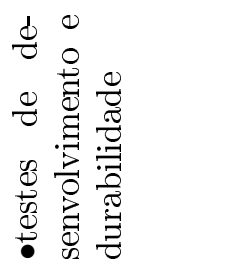 \\
\hline & 0 & 20 & 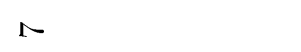 & 0 \\
\hline & 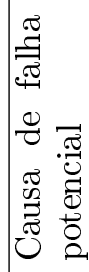 & 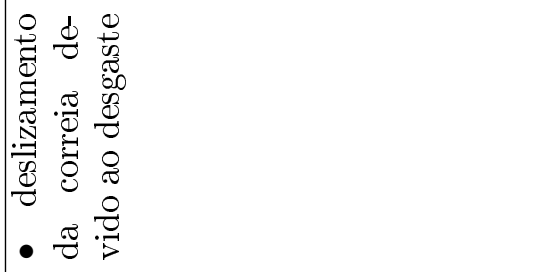 & 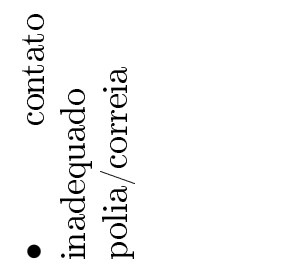 & 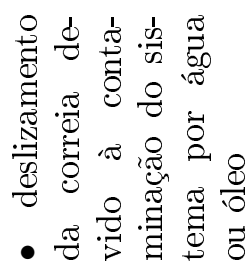 \\
\hline & ת & 0 & 20 & 0 \\
\hline & 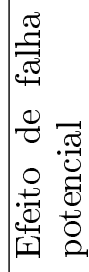 & 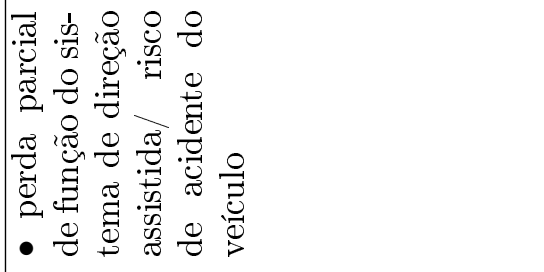 & 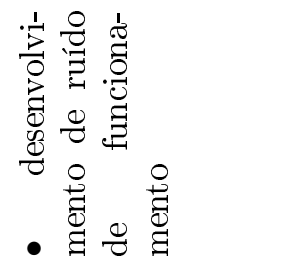 & 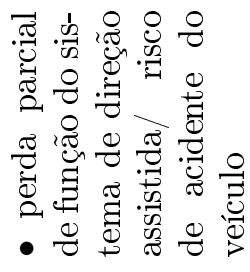 \\
\hline & 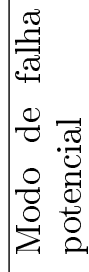 & 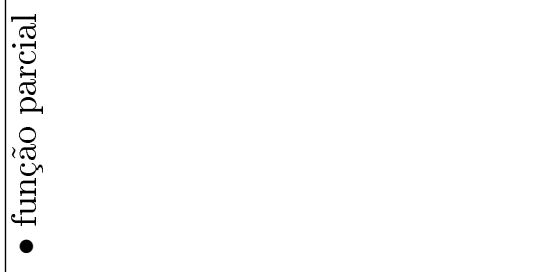 & & 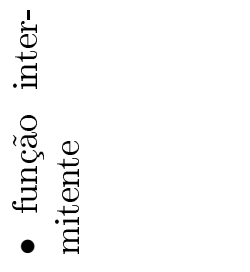 \\
\hline & 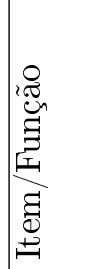 & 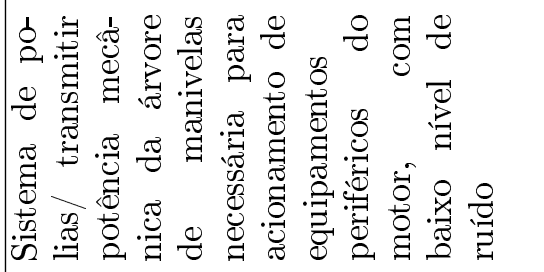 & & \\
\hline
\end{tabular}




\section{Apêndice E - Memorial de cálculo para alocação não otimizada de tolerâncias}

Os valores para cálculo de alocação de tolerâncias apresentados a seguir referem-se à classe de tolerâncias IT14 da norma ISO 286-1 ${ }^{[20]}$, nos casos aplicáveis.

\section{E.1 Alocação por tolerâncias iguais}

$$
\begin{array}{r}
T^{2}=\sum_{i=1}^{n p} t_{p i}^{2}+n d \times t_{d}^{2} \quad \text { ou }, \\
t_{d}=\sqrt{\frac{T^{2}-\sum_{i=1}^{n p} t_{p i}^{2}}{n d}}
\end{array}
$$

Para o encadeamento 2:

$$
\begin{array}{r}
T_{2}=R F_{2}=0,63 \\
t_{d}=\sqrt{\frac{(0,63)^{2}-\left((0,40)^{2}+(0,40)^{2}\right)}{4}}=0,139
\end{array}
$$

Para o encadeamento 1:

$T_{1}=R F_{1}=0,79$
$t_{d}=\sqrt{\frac{(0,79)^{2}-\left((0,03)^{2}+(0,08)^{2}\right)+(0,05)^{2}+(0,139)^{2}+(0,4)^{2}+(0,139)^{2}}{4}}=0,322$ 


\section{E.2 Alocação por fator de proporcionalidade}

$$
\begin{gathered}
T^{2}=\sum_{i=1}^{n p} t_{p i}^{2}+F_{p r o}^{2}\left[\sum_{j=1}^{n d} t_{d j}^{2}\right] \mathrm{ou}, \\
F_{p r o}=\sqrt{\frac{T^{2}-\sum_{i=1}^{n p} t_{p i}^{2}}{\sum_{j=1}^{n d} t_{d j}^{2}}} \\
t_{d j}^{\prime}=F_{p r o} t_{d j}
\end{gathered}
$$

Para o encadeamento 2:

$$
\begin{array}{r}
T_{2}=R F_{2}=0,63 \\
F_{\text {pro } 2}=\sqrt{\frac{(0,63)^{2}-\left((0,40)^{2}+(0,40)^{2}\right)}{(0,37)^{2}+(0,26)^{2}+(0,37)^{2}+(0,26)^{2}}}=0,4336 \\
t_{8}^{\prime}=0,4336 \times 0,37=0,160 \\
t_{10}^{\prime}=0,4336 \times 0,26=0,113 \\
t_{11}^{\prime}=0,4336 \times 0,37=0,160 \\
t_{13}^{\prime}=0,4336 \times 0,26=0,113
\end{array}
$$

Para o encadeamento 1:

$$
\begin{array}{r}
T_{1}=R F_{1}=0,79 \\
F_{\text {pro } 1}=\sqrt{\frac{(0,79)^{2}-\left((0,08)^{2}+(0,03)^{2}+(0,05)^{2}+(0,160)^{2}+(0,40)^{2}+(0,11)^{2}\right)}{(0,31)^{2}+(0,15)^{2}+(0,65)^{2}+(0,575)^{2}}}= \\
=0,6913 \\
t_{1}^{\prime}=0,6913 \times 0,31=0,214 \\
t_{2}^{\prime}=0,6913 \times 0,15=0,104 \\
t_{3}^{\prime}=0,6913 \times 0,65=0,449 \\
t_{6}^{\prime}=0,6913 \times 0,575=0,397
\end{array}
$$




\section{E.2.1 Alocação por fator de precisão}

$$
\begin{gathered}
T^{2}=\sum_{i=1}^{n p} t_{p i}^{2}+F_{p r e}^{2}\left[\sum_{j=1}^{n d}\left(\sqrt[3]{d_{j}}\right)^{2}\right] \mathrm{ou}, \\
F_{p r e}=\sqrt{\frac{T^{2}-\sum_{i=1}^{n p} t_{p i}^{2}}{\sum_{j=1}^{n d}\left(\sqrt[3]{d_{j}}\right)^{2}}} \\
t_{d j}^{\prime}=F_{p r e} \sqrt[3]{d_{j}}
\end{gathered}
$$

Para o encadeamento 2:

$$
\begin{array}{r}
T_{2}=R F_{2}=0,63 \\
F_{p r e 2}=\sqrt{\frac{(0,63)^{2}-\left((0,40)^{2}+(0,40)^{2}\right)}{(\sqrt[3]{55,0})^{2}+(\sqrt[3]{25,0})^{2}+(\sqrt[3]{65,0})^{2}+(\sqrt[3]{30,0})^{2}}}=0,0397 \\
t_{8}^{\prime}=0,0397 \times \sqrt[3]{55,0}=0,151 \\
t_{10}^{\prime}=0,0397 \times \sqrt[3]{25,0}=0,116 \\
t_{11}^{\prime}=0,0397 \times \sqrt[3]{65,0}=0,160 \\
t_{13}^{\prime}=0,0397 \times \sqrt[3]{30,0}=0,123
\end{array}
$$

Para o encadeamento 1:

$$
\begin{array}{r}
T_{1}=R F_{1}=0,79 \\
F_{\text {pre } 1}=\sqrt{\frac{(0,79)^{2}-\left((0,08)^{2}+(0,03)^{2}+(0,05)^{2}+(0,16)^{2}+(0,4)^{2}+(0,12)^{2}\right)}{(\sqrt[3]{35,0})^{2}+(\sqrt[3]{5,0})^{2}+(\sqrt[3]{255,0})^{2}+(\sqrt[3]{190,0})^{2}}}= \\
t_{1}^{\prime}=0,0691 \times \sqrt[3]{35,0}=0,227 \\
t_{2}^{\prime}=0,0691 \times \sqrt[3]{5,0}=0,119 \\
t_{3}^{\prime}=0,0691 \times \sqrt[3]{255,0}=0,440 \\
t_{6}^{\prime}=0,0691 \times \sqrt[3]{190,0}=0,399
\end{array}
$$




\section{E.3 Alocação por fatores de peso}

$$
\begin{gathered}
T^{2}=\sum_{i=1}^{n p} t_{p i}^{2}+F_{p e s}^{2}\left[\sum_{j=1}^{n d}\left(\frac{p_{j}}{\sum_{j=1}^{n d} p_{j}}\right)^{2} t_{d j}^{2} \mathrm{ou},\right. \\
F_{p e s}=\sqrt{\frac{T^{2}-\sum_{i=1}^{n p} t_{p i}^{2}}{\sum_{j=1}^{n d}\left(\frac{p_{j}}{\sum_{j=1}^{n d} p_{j}}\right)^{2} t_{d j}^{2}}} \\
t_{d j}^{\prime}=F_{p e s}\left(\frac{p_{j}}{\sum_{j=1}^{n d} p_{j}}\right) t_{d j}
\end{gathered}
$$

Para o encadeamento 2:

Assume-se que: $p_{8}=10, p_{10}=20, p_{11}=10, p_{13}=20 \mathrm{e}$, portanto, $\sum p_{j}=60$.

$$
\begin{array}{r}
T_{2}=R F_{2}=0,63 \\
F_{\text {pes }}=\sqrt{\frac{(0,63)^{2}-\left((0,40)^{2}+(0,40)^{2}\right)}{\left(\frac{10}{60}\right)^{2}(0,37)^{2}+\left(\frac{20}{60}\right)^{2}(0,26)^{2}+\left(\frac{10}{60}\right)^{2}(0,37)^{2}+\left(\frac{20}{60}\right)^{2}(0,26)^{2}}}= \\
=1,8435 \\
t_{8}^{\prime}=1,8435 \times(10 / 60) \times 0,37=0,114 \\
t_{10}^{\prime}=1,8435 \times(20 / 60) \times 0,26=0,160 \\
t_{11}^{\prime}=1,8435 \times(10 / 60) \times 0,37=0,114 \\
t_{13}^{\prime}=1,8435 \times(20 / 60) \times 0,26=0,160
\end{array}
$$

Para o encadeamento 1:

Assume-se que: $p_{1}=20, p_{2}=40, p_{3}=5, p_{6}=5$ e, portanto, $\sum p_{j}=70$.

$$
\begin{array}{r}
T_{1}=R F_{1}=0,79 \\
F_{\text {pes }}=\sqrt{\frac{(0,79)^{2}-\left((0,08)^{2}+(0,03)^{2}+(0,05)^{2}+(0,114)^{2}+(0,4)^{2}+(0,160)^{2}\right)}{\left(\frac{20}{70}\right)^{2}(0,31)^{2}+\left(\frac{40}{70}\right)^{2}(0,15)^{2}+\left(\frac{5}{70}\right)^{2}(0,65)^{2}+\left(\frac{5}{70}\right)^{2}(0,575)^{2}}}= \\
=4,6733 \\
t_{1}^{\prime}=4,6733 \times(20 / 70) \times 0,31=0,414 \\
t_{2}^{\prime}=4,6733 \times(40 / 70) \times 0,15=0,401 \\
t_{3}^{\prime}=4,6733 \times(5 / 70) \times 0,65=0,217 \\
t_{6}^{\prime}=4,6733 \times(5 / 70) \times 0,575=0,192
\end{array}
$$

